\title{
Fluorophosphates: Next Generation Cathode Materials for Rechargeable Batteries
}

\author{
Lalit Sharma, Shashishekar P. Adiga, Husam N. Alshareef, and Prabeer Barpanda*
}

Cost, safety, and cycle life have emerged as prime concerns to build robust batteries to cater to the global energy demand. These concerns are impacted by all battery components, but the realizable energy density of lithium-ion batteries (LIBs)is limited by the performance of cathodes. Thus, cathode materials have a significant role to play in advancing the performance and economics of secondary batteries. To realize next generation Li-ion and post Li-ion batteries, a variety of cathode insertion materials have been explored, but finding a cost effective and stable cathode material that can deliver high energy density has been a daunting task. Oxide cathode materials are ubiquitous in commercial applications, as they can deliver high capacity. In comparison, polyanionic insertion materials can offer tuneable (high) redox potential, operational safety, and structural as well as thermal stability. Indeed, a wide range of polyanionic materials like phosphates, borates, sulfates, and their complexes have been reported. In this article, alkali metal fluorophosphates class of polyanionic cathodes for secondary batteries is discussed. The various reported fluorophosphate insertion materials are discussed in terms of their electrochemical and electrocatalytic properties. The historical overview, recent progress, and remaining challenges for polyanionic fluorophosphates are presented along with suggested future research directions and potential application. steadily depleting. These realities have 10 triggered significant efforts to harness 11 renewable energy sources like hydro, 12 solar, geothermal, or tidal energy that are 13 intermittent in nature. Economic and 14 sustainable energy storage devices can be 15 coupled with renewable energy generators 16 to realize uninterrupted energy supply. In 17 this sector, rechargeable batteries form the 18 most viable energy storage devices. Today, 19 lithium-ion batteries dominate the elec- 20 tronics market due to their high volu- 21 metric and specific energy density. ${ }^{[1-5]} 22$ The manifold consumption of lithium 23 resources due to the booming multibil- 24 lion-dollar industry and limited global 25 lithium reserves have raised concerns over 26 the future supply of Li-based precursors to 27 cater to the large scale production of lith- 28 ium-ion batteries. To alleviate this issue, 29 various alternatives using earth-abundant 30 elements (e.g., monovalent $\mathrm{Na}^{+} / \mathrm{K}^{+}$and 31 multivalent $\left.\mathrm{Mg}^{2+} / \mathrm{Ca}^{2+} / \mathrm{Al}^{3+}\right)$ have been 32 proposed to replace LIBs. ${ }^{[6-10]} \quad 33$

The energy density of batteries is lim- 34 ited by the performance of cathodes. Thus, 35

\section{Introduction}

Energy has emerged as one of the prime challenges of the 21st century. The overdependence on fossil fuels and carbonaceous materials for energy needs have resulted in an increase in carbon dioxide emissions to alarming levels in the earth's atmosphere. At the same time, the fossil fuel reserves are

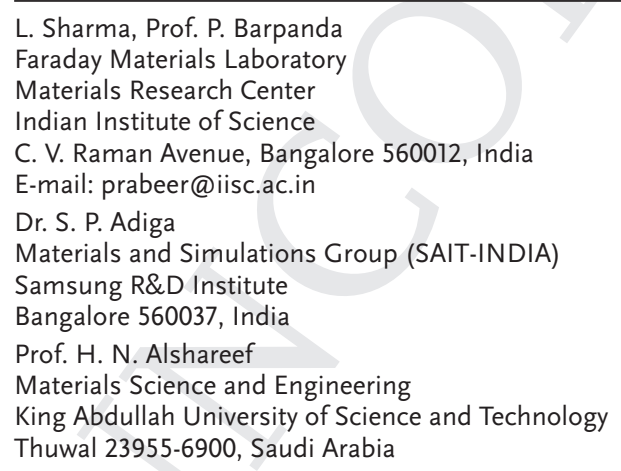

The ORCID identification number(s) for the author(s) of this article can be found under https://doi.org/10.1002/aenm.202001449.

DOI: 10.1002/aenm.202001449 over the last five decades, three major types of insertion mate- 36 rials have been examined as cathodes for secondary batteries: 37 layered transition metal oxides, Mn-based spinels, and polyanion 38 type materials (Figure 1a). 2D layered transition metal oxides 39 have been extensively studied, but issues like oxygen loss at high 40 potentials raise safety concerns and hence oxides like $\mathrm{LiCoO}_{2} \quad 41$ or $\mathrm{LiNi}_{1-x-y} \mathrm{Co}_{x} \mathrm{Mn}_{\mathrm{y}} \mathrm{O}_{2}(x<1, y<1)$ are mainly limited to small 42 portable electronics. Though oxides deliver high energy density, 43 they have lower redox potentials due to highly covalent $\mathrm{M}-\mathrm{O} \quad 44$ bonding character. ${ }^{[11]}$ This issue can be evaded by implementing 45 3D polyanionic cathode materials with tuneable (high) redox 46 potential along with structural/thermal stability leading to safe 47 battery operation. ${ }^{[12,13]}$ Plethora of insertion materials have been 48 reported with different polyanionic subunits $\left[\left(\mathrm{XO}_{4}\right)_{m}{ }^{n-}: \mathrm{X}=\mathrm{B}, \mathrm{P}, 49\right.$ $\mathrm{Si}, \mathrm{S}, \mathrm{W}, \mathrm{Mo}, \mathrm{As}, \mathrm{Ti}, \mathrm{V}] .{ }^{[14-16]}$ The high (Pauling's) electronegativity 50 of the $\mathrm{X}$ atom increases the ionic character of redox metal spe- 51 cies enhancing their redox potentials. Variety of insertion mate- 52 rials have been reported by combining different polyanionic 53 subunits (e.g., $\mathrm{PO}_{4} \mathrm{CO}_{3}$ ) or by combining polyanionic units with 54 other electronegative elements (e.g., $\mathrm{SO}_{4} \mathrm{~F}$ ) (Figure 1). One such 55 attractive class of cathodes is alkali metal fluorophosphates 56 with high redox potentials stemming from the electronegativity 57 of fluorine. Utilizing this concept, Barker et al. first reported 58 $\mathrm{LiVPO}_{4} \mathrm{~F}$ as a $4.1 \mathrm{~V}$ cathode for Li-ion batteries (around 2003), 59 
(a)
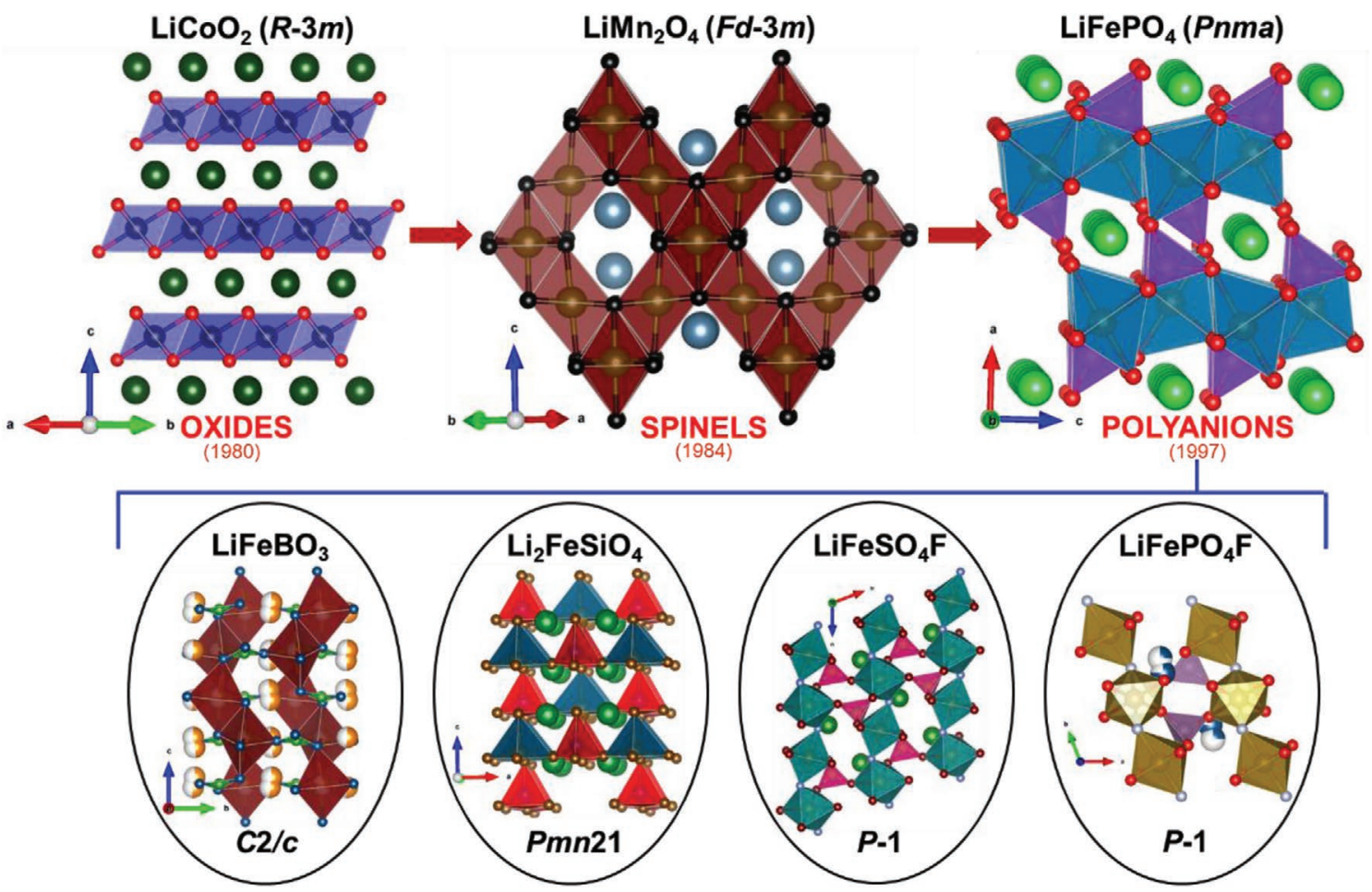

(b)

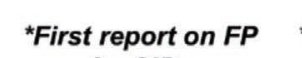
for SIBS $\mathrm{NaVPO}_{4} \mathrm{~F}$

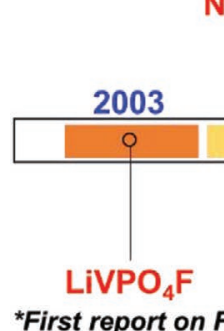

*First report on FP for LIBs
*First electrochemical report

LiTiPO ${ }_{4} \mathrm{~F}$ "First electrochemical
report $\mathrm{Na}_{2} \mathrm{CoPO}_{4} \mathrm{~F}$
*First report on FP for KIBs

$\mathrm{NaVPO}_{4} \mathrm{~F}$

Figure 1. a) Historical development of cathode materials for secondary batteries from oxides to polyanions. (Top) Three major classes of cathode materials developed in the past forty years: oxides, spinels, and polyanions. (Bottom) Polyanionic materials adopt diverse crystal structure based on the type of polyanionic chemistry and constituent transition metals. b) Timeline depicting some key developments in the field of fluorophosphate cathode materials for $\mathrm{Li}-, \mathrm{Na}-$, and $\mathrm{K}$-ion batteries.

which opened the floodgate of reports on various fluorophosphate cathodes. ${ }^{[17-22]}$ Apart from earth-abundant Fe-based multifunctional end-member, several fluorophosphates have been shown to involve multiple electron reaction. Thus, it has been possible to realize fluorophosphates as both cathode and anode candidates, which can be exploited as both cathode and anode to form symmetric batteries. Off late, fluorophosphate family have been extended to Na-ion and K-ion batteries with high voltage operation. Figure $1 \mathrm{~b}$ depicts some key milestones in the saga of fluorophosphate cathodes for lithium, sodium and potassium ion batteries. The structure and electrochemical activity of various alkali metal fluorophosphates have been summarized in Table 1.
Parallel to nonaqueous (organic electrolytes based) batteries, environmentally benign and economic batteries can be fabricated using aqueous electrolytes offering superior ionic conductivity, roundtrip efficiency and rate kinetics. ${ }^{[23]}$ Dahn et al. first reported the concept of aqueous LIBs and since then many battery insertion materials have been implemented in aqueous media. ${ }^{[24-28]}$ Additionally, exploiting the transition metal redox centers, these fluorophosphate intercalation materials can be employed as low cost electrocatalysts suitable for metal-air batteries. This review provides detailed outlook at the recent advances in exploration of fluorophosphate class of polyanionic insertion materials, which are so versatile that they can be

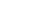

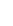

(1)

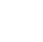
.

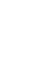
. (6)

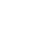

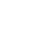
0

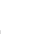

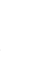
.

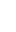
. (n) (1) . (n) . . 
Table 1. Overview of fluorophosphate based cathode materials for lithium, sodium, and potassium on batteries (C, carbon; rGO, reduced graphene 1 oxide; CTR, carbo thermal reduction; CNT, carbon nanotube; MWCNT, multiwalled carbon nanotube; SWCNT, single-walled carbon nano tube).

\begin{tabular}{lllll}
\hline Material & Synthesis route & Structure & Electrolyte used & Capacity reported (theoretical capacity) $\mathrm{mAh}^{-1} \quad \mathrm{Reference}^{-}$
\end{tabular}

$\mathrm{LiVPO}_{4} \mathrm{~F}$

Carbothermal reduction Triclinic

$1 \mathrm{M} \mathrm{LiPF}_{6}$ EC-DMC

115 (156)

155 (156)

$\mathrm{LiVPO}_{4} \mathrm{~F}$

Solid-state

Triclinic

$1 \mathrm{M} \mathrm{LiPF}_{6}$ EC-DMC

140 (156)

$\mathrm{LiVPO}_{4} \mathrm{~F}$

$\mathrm{LiVPO}_{4} \mathrm{~F} / \mathrm{N}-\mathrm{C}$

Carbothermal reduction

Triclinic

$1 \mathrm{M} \mathrm{LiPF}{ }_{6} \mathrm{EC}-\mathrm{DMC}$

152.7 (156)

$142.1(156)$

$1 \mathrm{M} \mathrm{LiPF}_{6}$ EC-DMC

Sol-gel

Triclinic

$1 \mathrm{M} \mathrm{LiPF}_{6}$ EC-DMC

$\mathrm{Li}_{3} \mathrm{PO}_{4}$ coated $\mathrm{LiVPO}_{4} \mathrm{~F}$

Sol-gel

Polyaniline coated $\mathrm{LiVPO}_{4} \mathrm{~F}$

Solution method

Triclinic

$1 \mathrm{M} \mathrm{LiPF} 6$ EC-EMC-DMC

$151.6(156)$

134 (156)

Sol-gel

Triclinic

$1 \mathrm{M} \mathrm{LiPF}_{6}$ EC-DMC

149.3 (156)

Modified CTR

Triclinic

$1 \mathrm{M} \mathrm{LiPF}{ }_{6}$ EC-DMC

$\mathrm{LiV}_{0.96} \mathrm{Mn}_{0.04} \mathrm{PO}_{4} \mathrm{~F}$

Ti doped $\mathrm{LiVPO}_{4} \mathrm{~F}$

$\mathrm{LiVPO}_{4} \mathrm{~F} @ \mathrm{C}$

$\mathrm{Li}_{5} \mathrm{~V}\left(\mathrm{PO}_{4}\right)_{2} \mathrm{~F}_{2} / \mathrm{C}$

Carbothermal reduction

Triclinic

$1 \mathrm{M} \mathrm{LiPF}_{6}$ EC-DMC

143.5 (156)

139 (156)

128 (156)

147.9 (156)

88 (170)

70 (85)

[17]

[59]

$\mathrm{Li}_{5} \mathrm{~V}\left(\mathrm{PO}_{4}\right)_{2} \mathrm{~F}_{2} / \mathrm{C}$ nanocomposite

Sol-gel + solid state

Triclinic

$1 \mathrm{M} \mathrm{LiPF}{ }_{6}$ EC-DMC

[61]

[68]

[69]

[70]

[73]

[76]

[78]

15

Dimensional reduction Monoclinic $1 \mathrm{M} \mathrm{LiPF}_{6}$ EC-DMC

Optimized solid state

$1 \mathrm{M} \mathrm{LiPF}_{6}$ EC-DMC

128.38 (152)

145 (152)

131 (152)

119 (152)

146 (152)

125 (152)

150 (159)

157 (159)

$\mathrm{LiTiPO}_{4} \mathrm{~F} / \mathrm{C}$

$\mathrm{Li}_{2} \mathrm{CoPO}_{4} \mathrm{~F}$

Phosphorous acid route

Triclinic

$1 \mathrm{M} \mathrm{LiPF}{ }_{6}$ EC-DMC

[79] 16

[82] 17

[84] 18

[90] 19

[92] $\quad 20$

92] 21

95] 22

[96] 23

[97] 24

98] 25

$\mathrm{LiFePO}_{4} \mathrm{~F}$

Fluorolytic sol-gel

Triclinic

$1 \mathrm{M} \mathrm{LiPF}_{6}$ EC-PC-DMC

[99] 27

Ionothermal Triclinic $\quad 1 \mathrm{M} \mathrm{LiPF}_{6} \mathrm{EC}-\mathrm{DMC}$

lonothermal

Triclinic

$1 \mathrm{M} \mathrm{LiPF}{ }_{6}$ EC-PC-DMC

$109(143.47)$

[100] 28

$\mathrm{Li}_{2} \mathrm{CoPO}_{4} \mathrm{~F} / \mathrm{C}$

Sol-gel

Ortho-

$1 \mathrm{M} \mathrm{LiPF} 6$ EMS-DMS

$132(143.47)$

[95] $\quad 29$

[103] 30

[113] 31

Ortho- $1 \mathrm{M} \mathrm{LiPF} 6$ EC-DMC or EMS/DMS

rhombic

$\mathrm{Li}_{2} \mathrm{CoPO}_{4} \mathrm{~F} / \mathrm{C}$

$\mathrm{Li}_{2} \mathrm{CoPO}_{4} \mathrm{~F} / \mathrm{C}$

Solvothermal

Ortho-

rhombic

Two-step reaction

Ortho-

rhombic

$\mathrm{ZrO}_{2}$ coated $\mathrm{Li}_{2} \mathrm{CoPO}_{4} \mathrm{~F}$

Conventional solution

Ortho-

method

rhombic

Nano $\mathrm{SiO}_{2} @ \mathrm{Li}_{2} \mathrm{CoPO}_{4} \mathrm{~F}$

Hydrothermal method

Ortho-

rhombic

$\mathrm{Li}_{2} \mathrm{Ni}_{0.98} \mathrm{Co}_{0.02} \mathrm{PO}_{4} \mathrm{~F}$

$\mathrm{NaVPO}_{4} \mathrm{~F} / \mathrm{C}$

$\mathrm{NaVPO}_{4} \mathrm{~F}$

$\mathrm{NaVPO}_{4} \mathrm{~F}$

$\mathrm{NaVPO}_{4} \mathrm{~F} / \mathrm{C}$

$\mathrm{NaVPO}_{4} \mathrm{~F} / \mathrm{C}$

$\mathrm{NaVPO}_{4} \mathrm{~F} / \mathrm{C}$

$\mathrm{NaVPO}_{4} \mathrm{~F} / \mathrm{C}$

$\mathrm{NaVPO}_{4} \mathrm{~F} / \mathrm{C}$

$\mathrm{Na}_{3} \mathrm{~V}_{2}\left(\mathrm{PO}_{4}\right)_{2} \mathrm{~F}_{3}$

$\mathrm{Na}_{3} \mathrm{~V}_{2}\left(\mathrm{PO}_{4}\right)_{2} \mathrm{~F}_{3}$

$\mathrm{Na}_{3} \mathrm{~V}_{2}\left(\mathrm{PO}_{4}\right)_{2} \mathrm{~F}_{3}$

\begin{tabular}{|c|c|c|}
\hline Solid-state & Monoclinic & $1 \mathrm{M} \mathrm{NaClO}{ }_{4}$ EC-DMC \\
\hline Solid-state & Tetragonal & $1 \mathrm{M} \mathrm{NaClO}_{4}$ EC-DMC \\
\hline Soft-template method & Monoclinic & $1 \mathrm{M} \mathrm{NaClO}{ }_{4}$ EC-PC \\
\hline Hydrothermal method & Tetragonal & $1 \mathrm{M} \mathrm{NaClO}{ }_{4}$ EC-DEC \\
\hline Electro-spinning & Monoclinic & $1 \mathrm{M} \mathrm{NaClO}{ }_{4}$ PC-FEC \\
\hline Sol-gel & & $1 \mathrm{M} \mathrm{NaClO}{ }_{4}$ EC-DEC-FEC \\
\hline Molten state blending & Monoclinic & $1 \mathrm{M} \mathrm{NaClO}{ }_{4}$ EC-DEC-FEC \\
\hline Solution method & Monoclinic & $1 \mathrm{M} \mathrm{NaClO}{ }_{4} \mathrm{PC}-\mathrm{FEC}$ \\
\hline Solid-state & Tetragonal & $1 \mathrm{M} \mathrm{LiPF}_{6}$ EC-DMC \\
\hline Solid-state & Tetragonal & $1 \mathrm{M} \mathrm{NaClO}_{4} \mathrm{PC}$ \\
\hline arbothermal & Tetragonal & $1 \mathrm{M} \mathrm{NaClO}_{4} \mathrm{PC}$ \\
\hline
\end{tabular}

143 (143.47)

$1 \mathrm{M} \mathrm{LiPF} 6$ DMC-FEC

$1 \mathrm{M} \mathrm{LiPF} 6$ DMC-FEC

$120(143.47)$

36

116] $\quad 37$

$127(143.47)$

1 м LiPF 6 EC-DMC

$112.4(143.47)$

41

$1 \mathrm{M} \mathrm{LiPF}{ }_{6}$ EC-DMC

[119] 42

$\approx 6 \mu \mathrm{Ah}(143.6)$

[126]

97.8 (142.6)

78 (142.6)

$133(142.6)$

$121(142.6)$

$126.3(142.6)$

$106(142.6)$

135 (142.6)

111 (142.6)

120 (128.2)

108 (128.2)

111.6 (128.2)

$\begin{array}{ll} & 45 \\ {[20]} & 46 \\ {[52]} & 47 \\ {[132]} & 48 \\ {[133]} & 49 \\ {[134]} & 50 \\ {[135]} & 51 \\ {[136]} & 53 \\ {[137]} & 54 \\ {[22]} & 55 \\ {[146]} & 56 \\ {[147]} & 57 \\ & 59\end{array}$


Table 1. Continued.

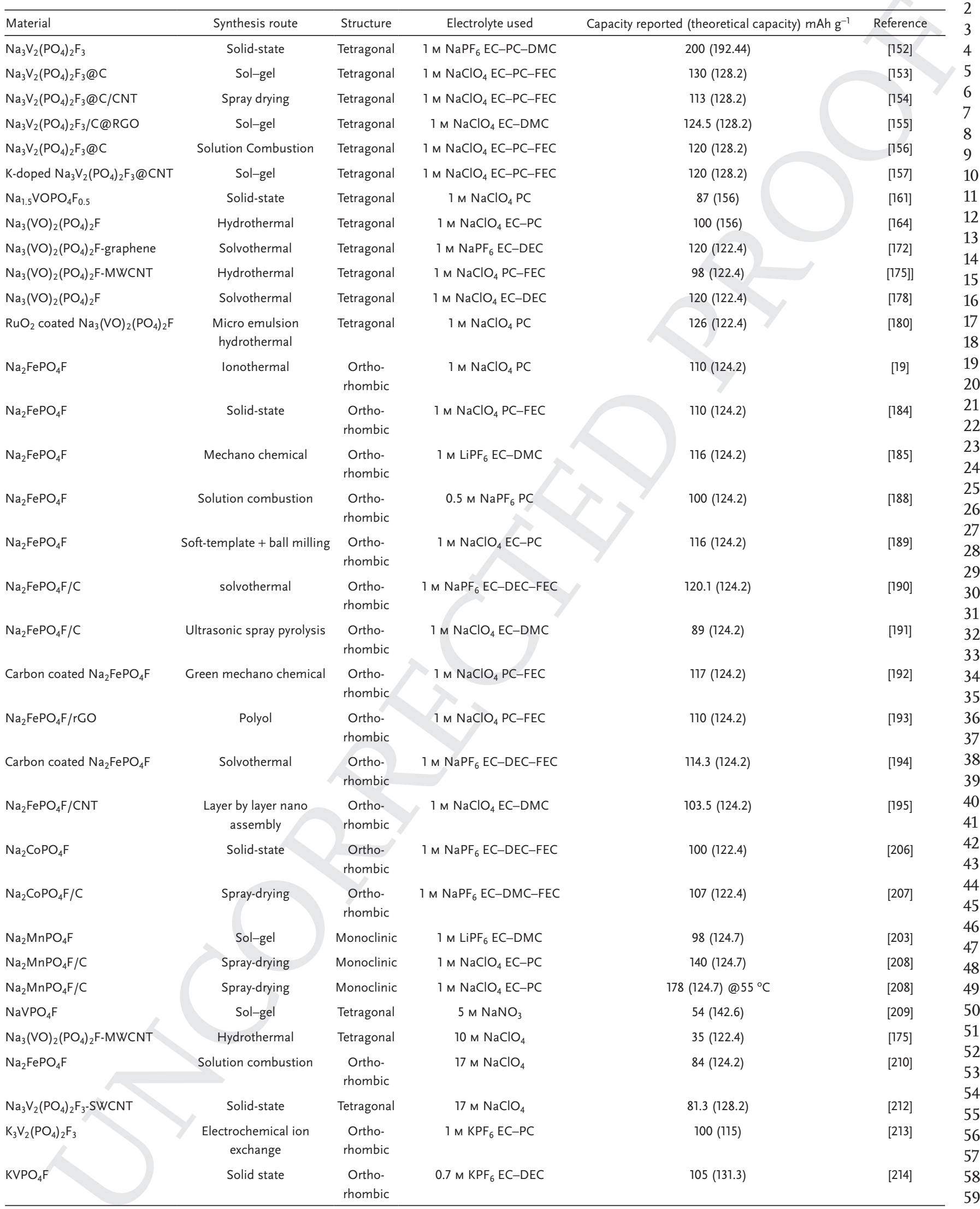


used in (non)aqueous batteries as well as bifunctional electrocatalysts. The synthetic, structural, transport, electrochemical, electrocatalytic, and mechanistic properties are summarized for various alkali metal fluorophosphates.

\section{A Brief History of Cathode Materials}

The concept of battery dates back to 1748 when Benjamin Franklin coined the termed "battery." Alessandro Volta made the first electrochemical cell in 1800. Since then, this field has witnessed a drastic development in terms of chemistry and technologies. Ni-Cd and $\mathrm{Ni}-\mathrm{MH}$ batteries were dominating in the early 19th century before lead-acid batteries were revived significantly in the mid-1970s. While some chemistry (e.g., Pb and $\mathrm{Cd}$ ) were not benign in nature, all these batteries suffered from poor gravimetric/volumetric energy density. Catering the ever-growing energy demand of the 21st century world called for superior electrochemical storage technology with high energy density. The vision was realized in 1991 with the historic commercialization of lithium-ion batteries by SONY, which remains a key milestone in modern technological revolution. It triggered an exponential rise in research and development of various Li-ion and post Li-ion battery chemistry.

Ever since secondary batteries based on lithium and sodium chemistry have come into existence, research on finding superior cathode materials has been growing, especially in LIBs using graphite as anode. In such batteries, the specific capacity and energy density of the cell is limited by the cathode performance. The era of LIBs started with oxide cathodes, i.e., $\mathrm{LiCoO}_{2}$ which was first reported by Goodeneough in 1980.[29] For almost 20 years, this material was used as cathode in commercialized LIBs. The properties of the oxide were later improved by doping of metal ions leading to the inception and successful commercialization of $\mathrm{LiNi}_{0.80} \mathrm{Co}_{0.15} \mathrm{Al}_{0.05} \mathrm{O}_{2}$ (NCA) and $\mathrm{LiNi}_{1 / 3} \mathrm{Mn}_{1 / 3} \mathrm{Co}_{1 / 3} \mathrm{O}_{2}$ (NMC) cathodes. ${ }^{[30,31]}$ Spinels like $\mathrm{LiMn}_{2} \mathrm{O}_{4}$ were also found to have high reversible capacities at high operating potential. ${ }^{[32,33]}$ However, the oxide-based materials suffer from thermal runaway at high potentials hence raising some safety issues.

Since the discovery of $\mathrm{LiFePO}_{4}$ in $1997,{ }^{[14]}$ design of polyanionic materials based on transition metal-ion having 3D crystal structures have been a subject of intense research. Polyanion-based materials exhibit many advantages over oxide-based materials like robust crystal structure, high redox potential, and structural versatility (Figure 2). Since then, variety of materials based on different polyanionic groups have been discovered. Delmas reported the electrochemical activity in NASICON based $\mathrm{LiTi}_{2}\left(\mathrm{PO}_{4}\right)_{3}$ and $\mathrm{NaTi}_{2}\left(\mathrm{PO}_{4}\right)_{3}$ in 1987-1988..$^{[34-36]}$ Insertion of $\mathrm{Li}$ in $\mathrm{Fe}_{2}\left(\mathrm{SO}_{4}\right)_{3}$ was reported by Manthiram in 1989. ${ }^{[12]}$ Armand, in 1999, demonstrated improved electrochemical performance in LiFePO ${ }_{4}$ by carbon coating. ${ }^{[37,38]}$ Since then, variety of synthesis techniques have been developed to optimize the morphology, grain size and resultant properties of cathode materials. ${ }^{[39-44]}$ In 2001, lithium metal borates, $\mathrm{LiMBO}_{3}(\mathrm{M}=\mathrm{Fe}, \mathrm{Mn}, \mathrm{Co})$ were unveiled as potential alternative to $\mathrm{LiFePO}_{4}$ due to their low molecular mass. ${ }^{[4]} \mathrm{Li}$ (de)intercalation properties of $\mathrm{Li}_{2} \mathrm{FeSiO}_{4}$ silicate was first reported by Armand and co-workers. ${ }^{[46,47]}$ Pursuing $\left(\mathrm{PO}_{4}\right)$-chemistry, pyrophosphate-based materials was

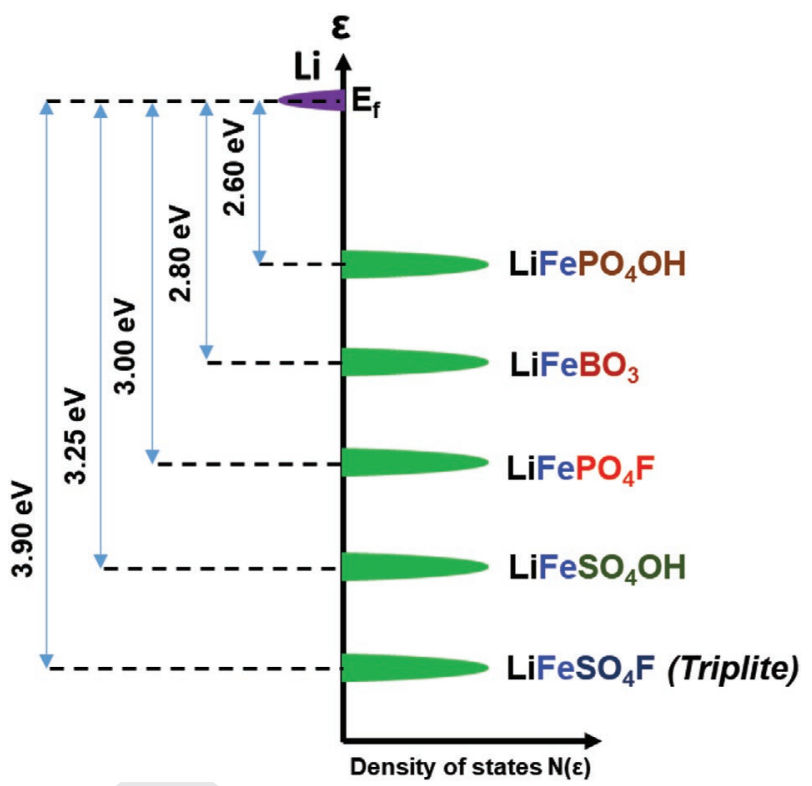

1 2 3

Figure 2. Change in the $\mathrm{Mn}^{+1} / \mathrm{Mn}$ redox potential for different poly- 22 anionic systems as a function of electronegativity of the central atom of 23 polyanionic groups. More electronegative polyanions deliver higher redox 24 potential.

also explored for their intercalation properties. ${ }^{[48-51]}$ Barker pro- 27 posed Na-intercalation in $\mathrm{NaVPO}_{4} \mathrm{~F}$ in 2003. ${ }^{[52]}$ Following this 28 report, many vanadium-based fluorophosphates were reported 29 for secondary batteries. ${ }^{[53-57]}$ It also led to the development of 30 layered- $\mathrm{Na}_{2} \mathrm{FePO}_{4} \mathrm{~F}$, which was first reported in 2007 by Nazar's 31 group. ${ }^{[18]}$ Notably, the crystal structures of the materials are 32 different depending on the nature of the polyanionic groups 33 involved. Even after extensive research over three decades, the 34 field still stays vast open for the discovery and development of 35 new polyanionic insertion materials.

This review will focus on a particular class of polyanionic materials as cathodes for secondary batteries: fluorophosphates $\left(\mathrm{AMPO}_{4} \mathrm{~F}\right)$. This subclass of polyanionic compounds exhibits a huge potential in becoming an effective cathode material for secondary batteries, in particular, sodium-ion batteries (SIBS). The review covers fluorophosphates with various transition metals ( $\mathrm{M}=\mathrm{V}, \mathrm{Fe}, \mathrm{Co}, \mathrm{Mn}, \mathrm{Ti}, \mathrm{Ni})$. This know-how can be further extended to hydroxyphosphates $\left(\mathrm{AMPO}_{4} \mathrm{OH}\right)$ taking into account the effect of anionic electronegativity $\left(\mathrm{F}^{-} \mathrm{vs} \mathrm{OH}^{-}\right)$on the redox potential. Performance of these fluorophosphate poly- 46 anionic insertion materials is summarized in both aqueous and 47 organic electrolytes. The commercial perspective of these mate- 48 rials along with some electrocatalytic studies is also discussed.

\section{Fluorophosphates}

\subsection{Fluorophosphates for Lithium-Ion Batteries}

\subsubsection{Vanadium-Based Fluorophosphates}

\section{6}

\section{7} 38 39 40 41 42 43 44

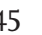

\section{6} 48

Fluorophosphates first came into existence when Barker et al. 58 introduced $\mathrm{LiVPO}_{4} \mathrm{~F}(\mathrm{LVPF})$ as a cathode material in 2003. ${ }^{[17]}$ It 59 

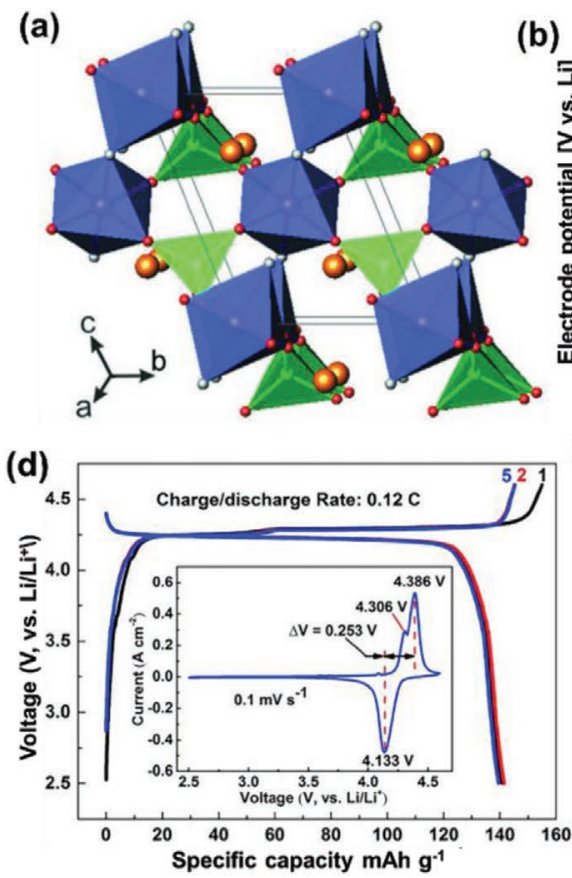

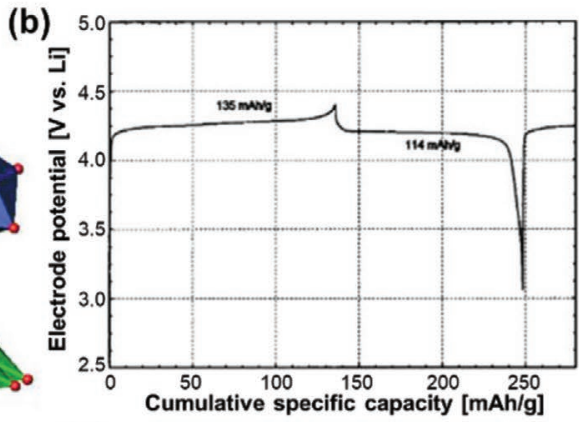

(e)

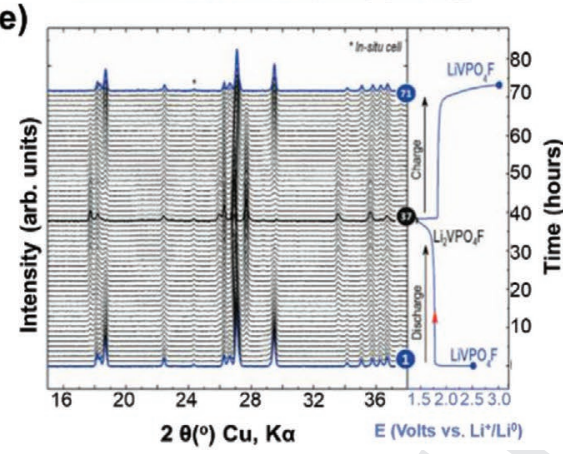

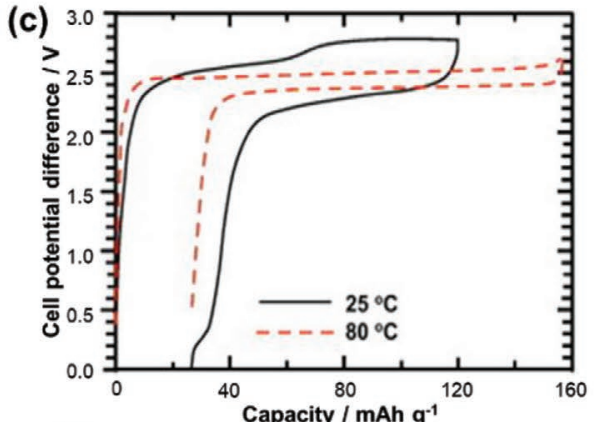

(f)

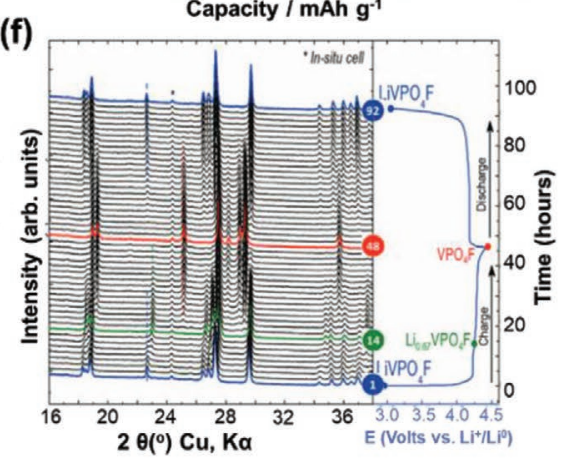

Figure 3. a) Crystal structure of tavorite $\mathrm{LiVPO}_{4} \mathrm{~F}$ (LVPF) built from $\mathrm{VO}_{4} \mathrm{~F}_{2}$ octahedra (blue) and $\mathrm{PO}_{4}$ tetrahedra (green). b) The first electrochemical report of LVPF cycled in the potential range of 3-4.4 V giving a discharge capacity of $114 \mathrm{mAh} \mathrm{g}^{-1}$. c) Cycling of LVPF symmetric cell using ionic liquid electrolyte at room temperature and $80^{\circ} \mathrm{C}$. d) Improved cyclability of LVPF on potassium doping. e, f) In situ XRD plots (2D) recorded during cycling in low-voltage and high-voltage regions respectively. a) Reproduced with permission. ${ }^{[7]}$ Copyright 2015, IUCr. b) Reproduced with permission. ${ }^{17]}$ Copyright 2003, The Electrochemical Society. c) Reproduced with permission. ${ }^{[66]}$ Copyright 2011, Elsevier. d) Reproduced with permission. ${ }^{[86]}$ Copyright 2018, Elsevier. e,f) Reproduced with permission. ${ }^{[87]}$ Copyright 2012, The Electrochemical Society.

was synthesized by a two-step carbothermal reduction method. Isostructural to $\mathrm{LiFePO}_{4} \mathrm{OH}$, it crystallizes in a triclinic structure with $P$-1 space group (s.g.) as illustrated in Figure 3a. The structure consists of $\left[\mathrm{VO}_{4} \mathrm{~F}_{2}\right]$ octahedra linked together by F-atoms present at trans position forming chains along $c$-axis. These chains are interconnected by $\mathrm{PO}_{4}$-groups giving rise to 3D framework. The constituent Li-ions are accommodated in two distinct sites: one being a penta-coordinated site $\left(\mathrm{LiO}_{5}\right)$ with occupancy of $18 \%$ and the second is an octahedral site $\left(\mathrm{LiO}_{6}\right)$ with $82 \%$ occupancy ${ }^{[58]}$ Later, Ateba et al. carried out careful structural analysis combining X-ray and neutron diffraction patterns and proposed single site occupancy for Li. ${ }^{[59]}$ Different types of tunnels were observed in the structure resulting from the connection of different octahedra chains $\left[\mathrm{VO}_{4} \mathrm{~F}_{2}\right]$ and $\mathrm{PO}_{4}$ tetrahedra units with homogeneous $\mathrm{V}-\mathrm{F}$ bond distances along the chains. Defects in this crystal structure were observed by Masquelier's group by means of ${ }^{7} \mathrm{Li}$ spin-echo nuclear magnetic resonance measurements. ${ }^{[60]}$ Barker group first tested the electrochemical properties of LVPF in lithium-based cell where they obtained a capacity of $114 \mathrm{mAh} \mathrm{g}^{-1}$ when cycled between 3 and $4.4 \mathrm{~V}$ at $\mathrm{C} / 5$ rate with a discharge plateau at $4.2 \mathrm{~V}$ (Figure $3 \mathrm{~b}$ ).

Although they initially focused on one electron $\mathrm{V}^{4+} / \mathrm{V}^{3+}$ redox activity, they later reported the presence of multivalent reactions in LVPF. ${ }^{[56]} \mathrm{A}$ capacity of $140 \mathrm{mAh} \mathrm{g}^{-1}$ was obtained with two redox plateaus at $1.8 \mathrm{~V}\left(\mathrm{~V}^{3+/ 2+}\right)$ and $4.2 \mathrm{~V}\left(\mathrm{~V}^{4+/ 3+}\right)$ having two-phase reaction. Doping of metals (e.g., Al-doping) is well-known to facilitate structural stability and hence the electrochemical performance. Barker group tried to partially substitute $\mathrm{Al}^{3+}$ into $\mathrm{V}^{3+}$ site. ${ }^{[61]}$ Aluminium was chosen because i) its ionic radius is close to that of vanadium and ii) $\mathrm{LiAlPO}_{4} \mathrm{~F}$ is isostructural to LVPF. Presence of Al decreased the polarization and enhanced the $\mathrm{V}^{4+} /^{3+}$ redox potential from 4.19 to $4.28 \mathrm{~V}$ with improved cyclability. Al-doping helps in mitigating the issue of enhanced charge-transfer resistance at the interface of cathode and electrolyte by suppressing the formation of surface layer on cathode. It results in low polarization and increased redox potential in the electrochemical performance of Al-doped cathode materials, which has also been explained by theoretical studies. ${ }^{[62-65]}$ With the material showing one electron transfer during both oxidation $(4.2 \mathrm{~V})$ and reduction $(1.8 \mathrm{~V})$ processes, a symmetric $(-) \mathrm{LiVPO}_{4} \mathrm{~F} \| \mathrm{LiVPO}_{4} \mathrm{~F}(+)$ cell was assembled. ${ }^{[56]}$ This is the first example of a symmetric cell working with same anode and cathode material. In the potential window of $2.4 \mathrm{~V}$, this symmetric cell delivered a reversible capacity of $130 \mathrm{mAh} \mathrm{g}^{-1}$ albeit with poor cyclability. Following, Okada group employed $1 \mathrm{M} \mathrm{LiBF}_{4} / \mathrm{EMIBF}_{4}$ ionic liquid electrolyte to obtain a stable and reversible symmetric cell. ${ }^{[66]}$ Even at $80{ }^{\circ} \mathrm{C}$, a discharge capacity of $120 \mathrm{mAh} \mathrm{g}^{-1}$ was obtained at a current density of $1 \mathrm{~mA} \mathrm{~cm}{ }^{-2}$ as shown in Figure 3c. LVPF || graphite full cell have been demonstrated with longrange cyclability at $\mathrm{C} / 2$ rate, giving a capacity of more than $120 \mathrm{mAh} \mathrm{g}^{-1}$ after 200 cycles. $^{[61]}$ From accelerating rate calorimetry tests on delithiated LVPF sample, it is proposed that the thermal stability of the $\mathrm{VPO}_{4} \mathrm{~F}-\mathrm{LiVPO}_{4} \mathrm{~F}$ is comparable to $\mathrm{LiFePO}_{4}-\mathrm{FePO}_{4}$ system. . $^{[6]}$

The low electronic conductivity of the material limits its application in high-power density batteries. This can be improved by surface coating and cation doping. Coating materials like
1 2 3 4 5 6 7 8 9 
graphene, $\mathrm{Li}_{3} \mathrm{PO}_{4}, \mathrm{MoS}_{2}$, and polyaniline have been reported to improve the electronic and ionic conductivity. ${ }^{[68-76]}$ Ion doping can change the electronic cloud structure while carbon coating can reduce the band gap and hence increase the electronic conductivity. ${ }^{[61,77-83]}$ Core-shell carbon coated LVPF was prepared using sol-gel technique and a capacity of $147.9 \mathrm{mAh} \mathrm{g}^{-1}$ was obtained at $0.1 \mathrm{C}$ with excellent rate capability and good cycling performance. ${ }^{[84]} \mathrm{CNT}$ decorated $\mathrm{LiVPO}_{4} \mathrm{~F} / \mathrm{C}$ were synthesized using sol-gel synthesis route and a high reversible capacity of 121.1 $\mathrm{mAh} \mathrm{g}^{-1}$ at $10 \mathrm{C}$ rate was obtained. ${ }^{[55]}$ Potassium doping into vanadium sites suppressed the formation of $\mathrm{Li}_{3} \mathrm{~V}_{2}\left(\mathrm{PO}_{4}\right)_{3}$ impurity and also reduced agglomerization leading to homogeneous distribution of particle size. ${ }^{[6]}$ The K-doped samples showed lower polarization, reduced charge transfer resistance and improved $\mathrm{Li}^{+}$diffusion coefficient when compared to the pristine LVPF as shown in Figure 3d.

Ateba et al. conducted an in-depth structural investigation by employing in situ XRD analysis. ${ }^{[87]}$ The low voltage region corresponding to $\mathrm{V}^{3+/ 2+}$ redox exhibits a biphasic mechanism while extraction of $\mathrm{Li}$ in the high voltage region $\left(\mathrm{V}^{4+/ 3+}\right.$ redox) involves two plateaus at 4.24 and $4.28 \mathrm{~V}$. The in situ XRD was recorded between 2.5 and $1.45 \mathrm{~V}$ during cycling and a gradual disappearance of peaks was observed with the gradual appearance of $\mathrm{Li}_{2} \mathrm{VPO}_{4} \mathrm{~F}$ phase having $\mathrm{C} 2 / \mathrm{c}$ space group (Figure $3 \mathrm{e}$ ). In the high voltage region, an inflection point corresponding to the composition of $\mathrm{Li}_{0.67} \mathrm{VPO}_{4} \mathrm{~F}$ was observed as shown in Figure $3 \mathrm{f}$. This phase can be indexed to a single phase during in situ XRD study. However, from $\mathrm{LiVPO}_{4} \mathrm{~F}$ to $\mathrm{Li}_{0.67} \mathrm{VPO}_{4} \mathrm{~F}$, a two-phase mechanism was noticed and similar process was observed between $\mathrm{Li}_{0.67} \mathrm{VPF}$ to $\mathrm{VPO}_{4} \mathrm{~F}$ endphase. Surprisingly, this was not observed during discharge with a single two-phase reaction occurring between $\mathrm{VPO}_{4} \mathrm{~F}$ and LVPF. This structural change was observed to be reversible. Evolving factor analysis (EFA) of X-ray absorption near-edge spectroscopy (XANES) showed the presence of three reversible phases during cycling: $\mathrm{LiVPO}_{4} \mathrm{~F}, \mathrm{Li}_{x} \mathrm{VPO}_{4} \mathrm{~F}(x=0.80-0.25)$ and $\mathrm{VPO}_{4} \mathrm{~F}$. No single phase $\mathrm{Li}_{0.67} \mathrm{VPF}$ was detected. ${ }^{[88]}$ Ellis et al. isolated two end members, namely, $\mathrm{VPO}_{4} \mathrm{~F}$ and $\mathrm{Li}_{2} \mathrm{VPO}_{4} \mathrm{~F}$, obtained during cycling of LVPF. Both these end members crystallized in a monoclinic structure with $\mathrm{C} 2 / \mathrm{c}$ symmetry. There is a volumetric change of $15.9 \%$ during the two-electron transfer process. ${ }^{6,7} \mathrm{Li}$ NMR studies identified two different crystallographic sites of $\mathrm{Li}$ in $\mathrm{Li}_{2} \mathrm{VPO}_{4} \mathrm{~F}$, which exchange at slightly above the room temperature. Vanadyl oxyphosphate, $\mathrm{LiVPO}_{4} \mathrm{O}$ that closely relates to LVPF, has also been studied by Croguennec group. It can also exploit two redox couples $\mathrm{V}^{5+/ 4+}$ at $3.95 \mathrm{~V}$ and $\mathrm{V}^{4+/ 3+}$ at $2.3 \mathrm{~V}$ (vs Li/ $/ \mathrm{Li}^{+}$). In the high-voltage region, the material delivered an initial capacity of $78 \mathrm{mAh} \mathrm{g}^{-1}$, which gradually increases to $135 \mathrm{mAh} \mathrm{g}^{-1}$ in 30 cycles with steady decrease in polarization. ${ }^{[89]}$ In the low-voltage region, three plateaus at $2.45,2.21$, and $2.04 \mathrm{~V}\left(\mathrm{vs} \mathrm{Li} / \mathrm{Li}^{+}\right.$) were observed. The structural variation during cycling was studied by in situ XRD measurements.

A new type of vanadium based fluorophosphate, $\mathrm{Li}_{5} \mathrm{~V}\left(\mathrm{PO}_{4}\right)_{2} \mathrm{~F}_{2}$, was introduced by Nazar group in 2006. ${ }^{[90]}$ This material was synthesized by reaction of $\alpha-\mathrm{Li}_{3} \mathrm{~V}_{2}\left(\mathrm{PO}_{4}\right)_{3}$ in $\mathrm{LiF}$ flux and consists of anisotropic 2D structure. Since it was synthesized starting from a 3D $\alpha-\mathrm{Li}_{3} \mathrm{~V}_{2}\left(\mathrm{PO}_{4}\right)_{3}$, it was an interesting example of "dimensional reduction," a term first coined by Long et al. (Figure 4a). ${ }^{[91]}$
It crystallizes in a monoclinic structure with $P 2_{1} / c$ space group. 1 The $\mathrm{V}-\mathrm{O}(\mathrm{F})$ octahedra are isolated from each other but they are 2 interconnected by corner-sharing $\mathrm{PO}_{4}$-tetrahedra groups. The $2 \mathrm{D} 3$ sheets of $\mathrm{VO}_{4} \mathrm{~F}_{2}-\mathrm{PO}_{4}$ sandwich the $2 \mathrm{D}$ layers of lithium ions. The 4 material has a theoretical capacity of $170 \mathrm{mAh} \mathrm{g}^{-1}$ involving two 5 electron transfer via $\mathrm{V}^{4+/ 3+}$ and $\mathrm{V}^{5+/ 4+}$ redox activity. At a current 6 rate of $\mathrm{C} / 10$, it delivered a capacity of $88 \mathrm{mAh} \mathrm{g}^{-1}$ when cycled 7 between 3 and $4.5 \mathrm{~V}$. A distinct $\mathrm{V}^{4+/ 3+}$ redox activity was observed 8 at $4.15 \mathrm{~V}$. Upon cycling till $5.0 \mathrm{~V}$, a second plateau at $4.7 \mathrm{~V}$ was 9 observed stemming from $\mathrm{V}^{5+/ 4+}$ redox activity. Employing ${ }^{6} \mathrm{Li} 10$ NMR study, six crystallographic sites for lithium were deter- 11 mined (Figure 4b). ${ }^{[92]}$ 2D exchange spectroscopy (EXSY) study 12 showed that Li-ions exchange along the $a$-axis but not through 13 (100) plane. They also reported the Li-stuffed structure is not 14 conducive for rapid Li-exchange because of high degree ordering 15 of the $\mathrm{Li}$ sites and lack of vacancies. $\mathrm{Li}_{4} \mathrm{~V}\left(\mathrm{PO}_{4}\right)_{2} \mathrm{~F}_{2} /$ carbon nano- 16 composite was prepared by solid-state route via chemical oxida- 17 tion of $\mathrm{Li}_{5} \mathrm{~V}\left(\mathrm{PO}_{4}\right)_{2} \mathrm{~F}_{2} \cdot{ }^{\left[{ }^{93}\right]}$ Upon delithiation, the ionic mobility was 18 enhanced due to creation of vacancies in the structure. ${ }^{6,7} \mathrm{Li}$ NMR 19 coupled with 2D EXSY studies were used to characterize the 20 structure. These vanadium-based materials, specially $\mathrm{LiVPO}_{4} \mathrm{~F}, 21$ exhibits high reversible capacity, good rate capability and excel- 22 lent cycling stability. Nonetheless, they never tasted commer- 23 cial success and real-life products owing to the cost and toxicity 24 issues generally associated with vanadium-based compounds. 25

27

3.1.2. Fluorophosphates with General Formula $\mathrm{LiMPO}_{4} \mathrm{~F}(\mathrm{M}=\mathrm{Fe}, \mathrm{Ti}) \quad 28$

Following the discovery of $\mathrm{LiVPO}_{4} \mathrm{~F}$, Barker tried to synthe- 30 size $\mathrm{LiMPO}_{4} \mathrm{~F}$ (M = Fe, Co, Cr, Ti) analogs. ${ }^{[94]} \mathrm{He}$ claimed all 31 these fluorophosphates to be isostructural and crystallizing in 32 triclinic tavorite structure (space group $P$-1). One such analogue 33 $\mathrm{LiFePO}_{4} \mathrm{~F}$ (LFPF) stands out owing to earth-abundant Fe com- 34 position. However, its synthesis, detailed structure and poten- 35 tial electrochemical activity was not reported. In 2010, Tarascon 36 group first synthesized this material employing both (dry) 37 solid-state and (wet) ionothermal synthesis routes. ${ }^{[95]} \mathrm{LFPF}$ is 38 isostructural to $\mathrm{LiVPO}_{4} \mathrm{~F}$ and $\mathrm{LiFePO}_{4} \mathrm{OH}$, and crystallize in a 39 triclinic framework built from $\mathrm{FeO}_{4} \mathrm{~F}_{2}$ octahedra interlinked 40 by F-atoms to form parallel chains. These parallel chains are 41 cross-linked by $\mathrm{PO}_{4}$-tetrahedra giving rise to a 3D framework. 42 They observed a staircase like profile during discharge while 43 it was missing during charge. In the same year, Nazar group 44 also came up with solid-state synthesis of LFPF but using dif- 45 ferent precursors. ${ }^{[96]}$ However, with uniform carbon coating 46 they were able to (de)intercalate $0.96 \mathrm{Li}^{+}$from the material at 47 3.0 V. No staircase like profile was observed in their case, rather 48 a sloppy behavior was observed till $0.4 \mathrm{Li}^{+}$intercalation followed 49 by appearance of a two phase plateau (Figure $5 \mathrm{a}$ ). Facile phase 50 transition was confirmed by XRD study. Moreover, it showed 51 excellent performance at a high temperature of $55{ }^{\circ} \mathrm{C}$. Chen 52 et al. reported an initial discharge capacity of $128 \mathrm{mAh} \mathrm{g}^{-1}$ at 53 $1 \mathrm{C}$ current rate retaining $71 \%$ of initial capacity at the end of 54 100 cycles (Figure 5b). ${ }^{[97]}$ From impedance spectral analysis, 55 Prabu et al. reported ionic conductivity of $0.6 \times 10^{-7} \mathrm{~S} \mathrm{~cm}^{-1} 56$ at $27{ }^{\circ} \mathrm{C}$ that increased to $5.4 \times 10^{-7} \mathrm{~S} \mathrm{~cm}^{-1}$ at $50{ }^{\circ} \mathrm{C}$. ${ }^{[98]}$ Asl 57 reported a phosphorous acid based route for synthesis of 58 LFPF. ${ }^{[9]}$ Recently microwave-assisted fluorolytic sol-gel route 59 

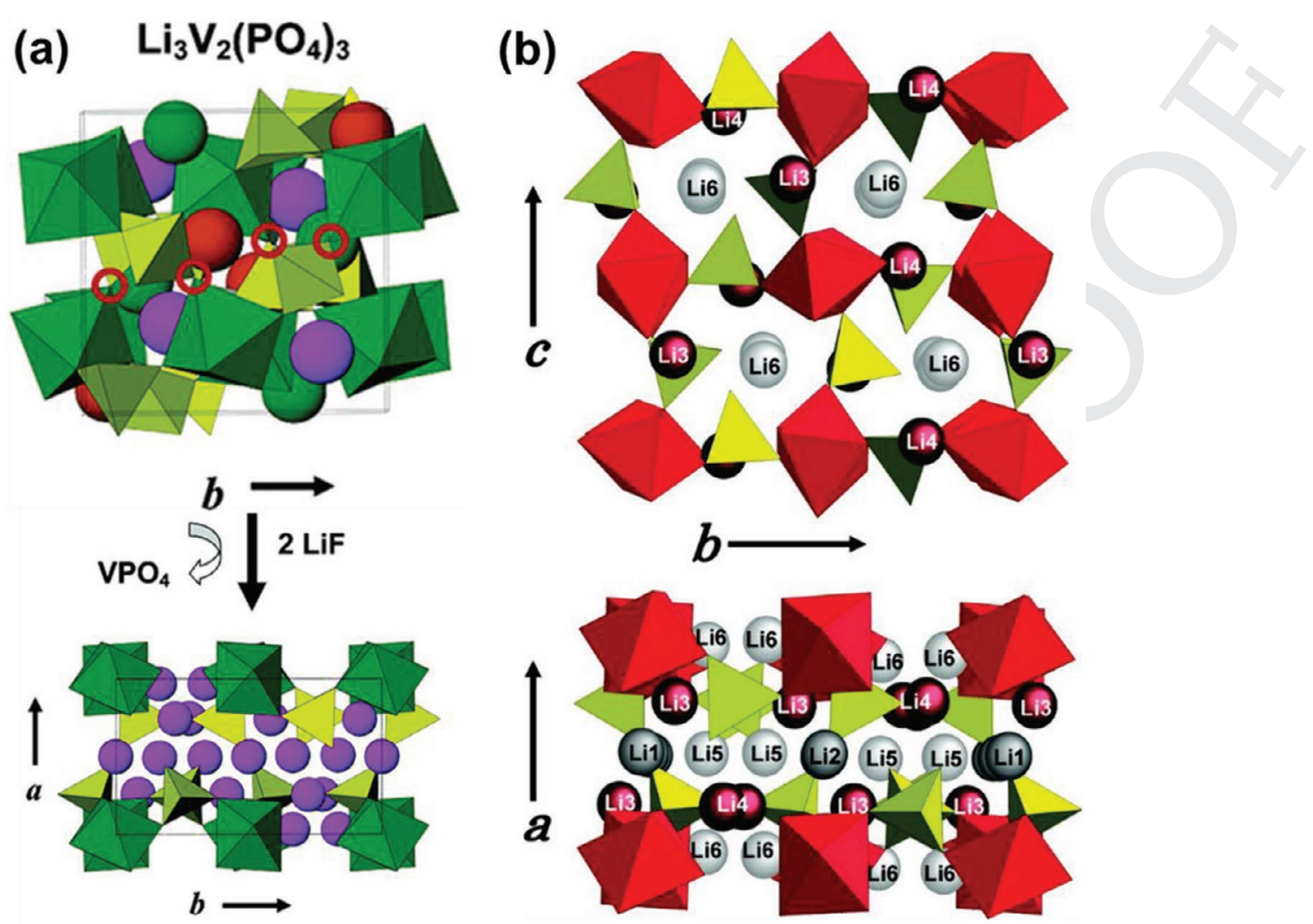

1

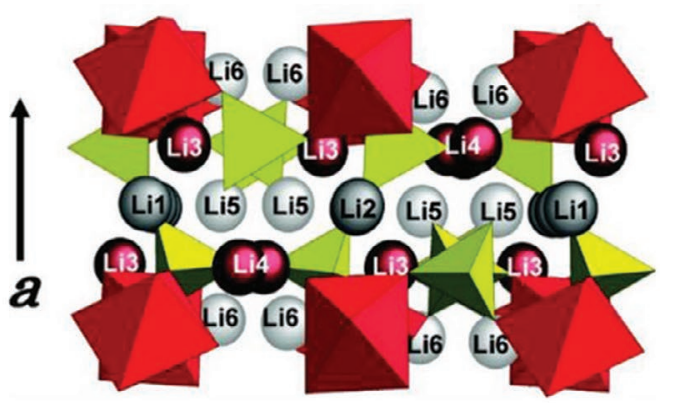

\section{$\mathrm{Li}_{5} \mathrm{~V}\left(\mathrm{PO}_{4}\right)_{2} \mathrm{~F}_{2}$}

Figure 4. a) Illustration of dimensional reduction process from $3 \mathrm{D} \alpha-\mathrm{Li}_{3} \mathrm{~V}_{2}\left(\mathrm{PO}_{4}\right)_{3}$ to $2 \mathrm{D} \mathrm{Li}_{5} \mathrm{~V}\left(\mathrm{PO}_{4}\right)_{2} \mathrm{~F}_{2}$ structure. b) Crystal structure showing six sites of lithium in the (100) plane and along $a$-axis. a) Reproduced with permission. ${ }^{[90]}$ Copyright 2006, American Chemical Society. b) Reproduced with permission. ${ }^{[92]}$ Copyright 2008, American Chemical Society.

was also reported to yield submicrometric LFPF particles. ${ }^{[100]}$ Solid-solution series between $\mathrm{LiFePO}_{4} \mathrm{~F}-\mathrm{LiVPO}_{4} \mathrm{O}$ homeotypic structures $\mathrm{LiFe}_{1-x} \mathrm{~V}_{x} \mathrm{PO}_{4} \mathrm{~F}_{1-\delta} \mathrm{O}_{\delta}(0 \leq x \leq 1 ; 0 \leq \delta \leq 0.36)$ and $\mathrm{LiFePO}_{4} \mathrm{~F}-\mathrm{LiVPO}_{4} \mathrm{~F}$ solid solutions $\mathrm{LiFe}_{1-x} \mathrm{~V}_{x} \mathrm{PO}_{4} \mathrm{~F}(x=0,0.1$, $0.3,0.5,0.7,0.9,1)$ have been attempted..$^{[101,102]}$

Tavorite mineral type $\mathrm{LiTiPO}_{4} \mathrm{~F}$ (LTPF) was first reported by Tarascon group in 2010 by adopting both high-temperature solid-state synthesis (at $700{ }^{\circ} \mathrm{C}$ ) as well as low-temperature ionothermal synthesis (at $260{ }^{\circ} \mathrm{C}$ ).${ }^{[95]}$ Isostructural to LFPF, it stabilizes into a triclinic structure with $P$-1 space group having slightly distorted $\mathrm{TiO}_{4} \mathrm{~F}_{2}$ octahedra. These octahedra are linked together by F-atoms present at trans-position to form 1D chains. Adopting ionothermal synthesis route led to finer particle morphology when compared to solid-state (ceramic) synthesis,
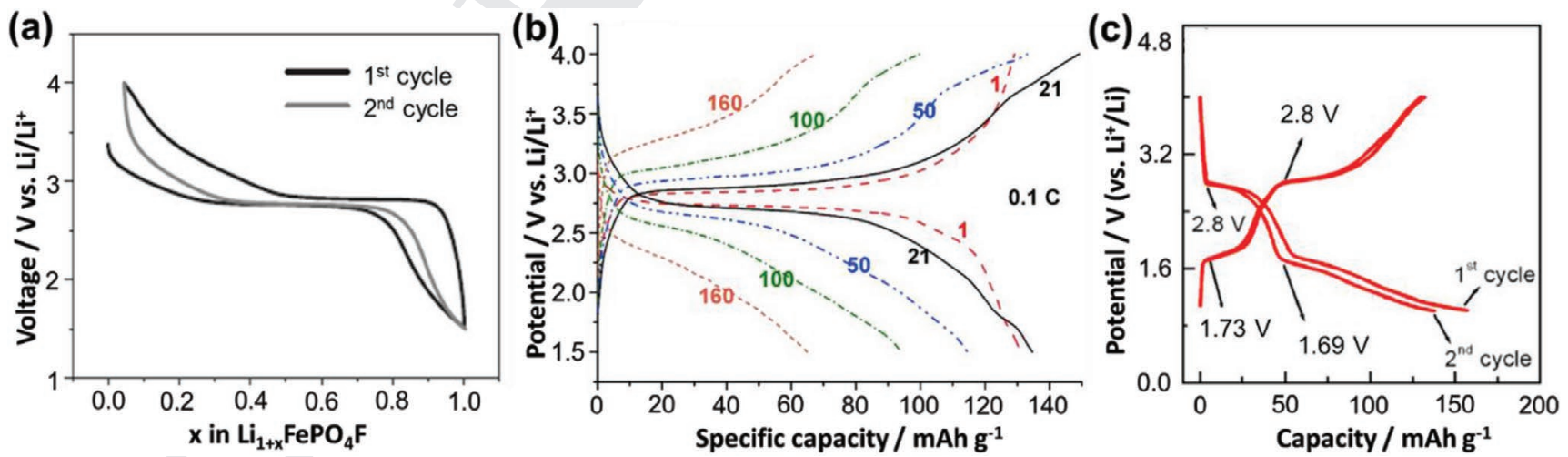

Figure 5. a) Electrochemical (dis)charge profile of tavorite $\mathrm{LiFePO}_{4} \mathrm{~F}$ at $\mathrm{C} / 10$ current rate at room temperature. b) Electrochemical (dis)charge profile of $\mathrm{LiFePO}_{4} \mathrm{~F}$ at various current rates. c) Electrochemical (dis)charge profile of $\mathrm{LiTiPO}_{4} \mathrm{~F} / \mathrm{C}$ when cycled between 1.0 and $4.0 \mathrm{~V}$ (vs $\mathrm{Li} / \mathrm{Li}^{+}$) at C/15 rate. a) Reproduced with permission. ${ }^{[96]}$ Copyright 2010, The Electrochemical Society. b) Reproduced with permission. ${ }^{[97]}$ Copyright 2014, Elsevier. c) Reproduced with permission. ${ }^{[103]}$ Copyright 2016, Wiley-VCH. 
thereby delivering a reversible capacity of $150 \mathrm{mAh} \mathrm{g}^{-1}$. The electrochemistry of the material revealed a staircase like voltage profile with reversible plateaus centered at 2.9 and $1.7 \mathrm{~V}$ (vs $\mathrm{Li}^{+} / \mathrm{Li}$ ) owing to multiple redox processes involving Ti during cycling. Rangaswamy et al. revisited the ionothermal synthesis to form carbon-coated LTPF compound by employing $\mathrm{C} 2-\mathrm{OH}$ DCA ionic liquid. ${ }^{[103]}$ From cyclic voltammetry, they confirmed the presence of $\mathrm{Ti}^{3+} / \mathrm{Ti}^{2+}$ and $\mathrm{Ti}^{4+} / \mathrm{Ti}^{3+}$ redox couples in the voltage range of $1-4 \mathrm{~V}\left(\mathrm{vs} \mathrm{Li}^{+} / \mathrm{Li}\right)$. A first discharge capacity of $157 \mathrm{mAh} \mathrm{g}^{-1}$ was obtained at C/15 rate with excellent cyclability till 200 cycles (Figure 5c). They also fabricated a full-cell with graphite as an anode delivering the first discharge capacity of $149 \mathrm{mAh} \mathrm{g}^{-1}$ and retaining $87 \%$ of the initial value at the end of 200th cycle. Effect of temperature on the half-cell properties was also studied and good cyclic behavior was observed at both low temperature $\left(10^{\circ} \mathrm{C}\right)$ and high temperature $\left(55^{\circ} \mathrm{C}\right)$. Material stability during cycling was also confirmed by ex situ XRD. They further studied LTPF in aqueous electrolyte and reported it as an anode for aqueous LIBs in $2 \mathrm{M} \mathrm{Li}_{2} \mathrm{SO}_{4}$ aqueous electrolyte. ${ }^{[104]}$ A new synthesis route namely reaction under autogenic pressure at elevated temperature (RAPET) was adopted. Li-rich $\mathrm{Li}\left[\mathrm{Li}_{0.2} \mathrm{Co}_{0.3} \mathrm{Mn}_{0.5}\right] \mathrm{O}_{2}$ was used as a cathode for full-cell electrochemical studies. With the help of CV, the potential window was carefully optimized to +1.2 to $-1.0 \mathrm{~V}$. A reversible discharge capacity of $82 \mathrm{mAh} \mathrm{g}^{-1}$ was obtained at C/5 current rate corresponding to $0.52 \mathrm{Li}^{+}$intercalating within anode and cathode. Singh et al. came up with another synthesis route for LTPF using direct chemical solution deposition process without any post heat treatment. It led to the development of flower like morphology. ${ }^{[105]} \mathrm{A}$ stable discharge capacity of $150 \mathrm{mAh} \mathrm{g}^{-1}$ at a rate of $\mathrm{C} / 10$ for the initial 10 cycles was obtained. Generally, tavorites form open frameworks capable of efficient $\mathrm{Li}^{+}$ (de)intercalation. Thereby, tavorite structured LFPF and LTPF were found to be electrochemically active electrode materials involving stair-case type voltage profiles with excellent reversibility. Based on earth-abundant Fe and Ti chemistry, they can form economic electrodes for batteries. Nonetheless, operation at intermediate voltage $(<3 \mathrm{~V}$ for LFPF and $\approx 1.1 \mathrm{~V}$ for LTPF vs $\left.\mathrm{Li}^{+} / \mathrm{Li}\right)$ restricts their energy density and therefore hindering in possible practical application.

\subsubsection{Fluorophosphates with General Formula $\mathrm{Li}_{2} \mathrm{MPO}_{4} \mathrm{~F}(\mathrm{M}=\mathrm{Fe}$, Co, $\mathrm{Mn}, \mathrm{Ni}$ )}

These materials have attracted wide interest due to the possibility of (de)intercalating more than one lithium-ion per transition metal resulting in high energy density. Depending on the type of transition metal and synthesis approach, these materials can adopt diverse crystal structure. Phase-pure $\mathrm{Li}_{2} \mathrm{FePO}_{4} \mathrm{~F}$ (L2FPF) was first obtained by Nazar group (in 2010) by chemical reduction of tavorite $\mathrm{LiFePO}_{4} \mathrm{~F} .{ }^{[96]}$ It was found to adopt an isostructural triclinic P-1 type structure with $8 \%$ increase in the unit cell volume. The reduction of $\mathrm{Fe}^{3+}$ to $\mathrm{Fe}^{2+}$ was confirmed by Mössbauer spectroscopy. The structure was solved by combining both X-ray and neutron diffraction patterns. ${ }^{[106]}$ Overall, the corner-shared framework of $\mathrm{FePO}_{4} \mathrm{~F}$ remained intact upon chemical reduction. Three crystallographically unique sites were identified for constituent Li species (Figure 6a). The Li1 is positioned close to the centroid of the split $\mathrm{Li}$ position in 1 $\mathrm{LiFePO}_{4} \mathrm{~F}$. However, due to larger size of $\mathrm{Fe}^{2+}$, the site of Li1 2 is smaller than that in $\mathrm{LiFePO}_{4} \mathrm{~F}$. The other two sites $\mathrm{Li} 2$ and 3 Li3 are equally occupied by 0.5 lithium. Li2 is situated between 4 chains of $\mathrm{Fe}$ octahedra that are coordinated by two fluorine 5 and four oxygen ligands. The Li3 site is octahedrally coordi- 6 nated by one fluorine and five oxygen ligands. Moreover, they 7 observed that L2FPF obtained from reduction of $\mathrm{LiFePO}_{4} \mathrm{~F}$ dif- 8 fers from the one obtained by ion exchange of orthorhombic 9 $\mathrm{Na}_{2} \mathrm{FePO}_{4} \mathrm{~F} \cdot{ }^{[18]}$ L2FPF obtained by ion exchange in $\mathrm{Na}_{2} \mathrm{FePO}_{4} \mathrm{~F} \quad 10$ resulted in a layered $2 \mathrm{D}$ orthorhombic structure. It delivered 11 a discharge capacity of $110 \mathrm{mAh} \mathrm{g}^{-1}$ at $3.3 \mathrm{~V}$. Antipov group 12 synthesized mixed $\mathrm{NaLiFePO}_{4} \mathrm{~F}$ followed by electrochemical 13 replacement of $\mathrm{Na}$ by $\mathrm{Li}$ to obtain $\mathrm{Li}_{2} \mathrm{FePO}_{4} \mathrm{~F}$ end-product. ${ }^{[107]} 14$ The electrochemistry showed similar behavior to that of layered 15 $\mathrm{Li}_{2} \mathrm{FePO}_{4} \mathrm{~F}$ having a solid-state regime at $3.4 \mathrm{~V}\left(\mathrm{vs} \mathrm{Li}^{+} / \mathrm{Li}\right)$. The 16 presence of antisite disorder was also studied. [108] The oxygen 17 atoms linked to $\mathrm{Li}$ and $\mathrm{P}$ atoms result in bond misbalance 18 when $\mathrm{Li}$ is extracted out of the system during charging. This 19 misbalance is restored by Fe migration toward Li sites leading 20 to $\mathrm{Li} / \mathrm{Fe}$ antisite disorder.

The cobalt analog, $\mathrm{Li}_{2} \mathrm{CoPO}_{4} \mathrm{~F}$ (L2CPF) was first reported 22 by Okada group in 2005.[109] Employing powder (X-ray and 23 neutron) diffraction patterns, L2CPF was found to assume an 24 orthorhombic structure with Pnma space group. It consists 25 of edge sharing $\mathrm{CoO}_{4} \mathrm{~F}_{2}$ octahedra resulting in the formation 26 of rutile like chains that are interconnected by $\mathrm{PO}_{4}$ tetrahedra 27 groups to give rise to a 3D structure. Being categorized as $>4 \mathrm{~V} 28$ cathode material, the cycling was carried out in $1 \mathrm{M} \mathrm{LiPF}_{6}$ in 29 ethyl methyl sulfone (EMS) electrolyte. L2CPF was reported as 30 $5 \mathrm{~V}$ cathode material with no structural changes during cycling. 31 However, an irreversible capacity loss was observed after first 32 cycle due to decomposition of electrolyte at higher voltages. 33 They also studied the solubility of material in electrolyte and 34 thermal stability of the material. The crystal structure was fur- 35 ther solved using precession electron diffraction (PED) pattern 36 and transmission electron microscopy (TEM). ${ }^{[110,111]}$ Using PED, 37 Fourier maps were built to identify the exact location of Li- 38 atoms. Khasanova et al. tried to identify the structural changes 39 happening in the material during cycling. ${ }^{[12]}$ They found three 40 crystallographic sites of lithium in the structure. Two of them 41 (L1 and L2) were present in penta-coordinated sites $\left(\mathrm{LiO}_{5}\right)$ while 42 the third one (L3) was present in an octahedral environment 43 $\left(\mathrm{LiO}_{6}\right)$. From BVS calculations, L3 site was found to be tightly 44 bonded and hence less mobile. Upon cycling in the potential 45 window of $3.0-5.1 \mathrm{~V}$ (vs Li ${ }^{+} / \mathrm{Li}$ ), irreversible structural changes 46 were observed above $4.8 \mathrm{~V}$ during first charge with volumetric 47 expansion of $>3.5 \%$ (Figure $6 \mathrm{~b}$ ). They proposed the structural 48 transformation happening due to mutual rotation of $\mathrm{CoO}_{4} \mathrm{~F}_{2} 49$ octahedra and $\mathrm{PO}_{4}$-tetrahedra. However, this transformation was 50 found to assist the subsequent Li-(de)intercalation in the struc- 51 ture, which was further confirmed using cyclic voltammetry. ${ }^{[113]} 52$ While one anodic peak was obtained upon charging till $5.0 \mathrm{~V}, 53$ two distinct anodic peaks were observed upon charging till 54 $5.5 \mathrm{~V}$. The presence of two peaks implies extraction of Li from 55 two energetically distinct sites. However, these peaks merged 56 in subsequent cycles hinting at structural relaxation hap- 57 pening during initial cycle. A reversible capacity of $109 \mathrm{mAh} \mathrm{g}^{-1} 58$ was observed when cycled between 2.0 and $5.5 \mathrm{~V}$ versus 59 

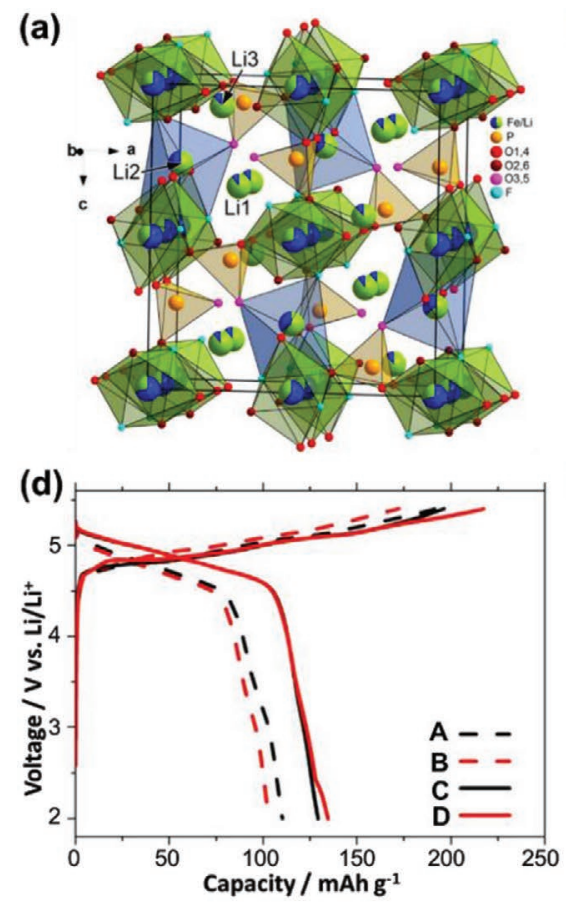

(b)

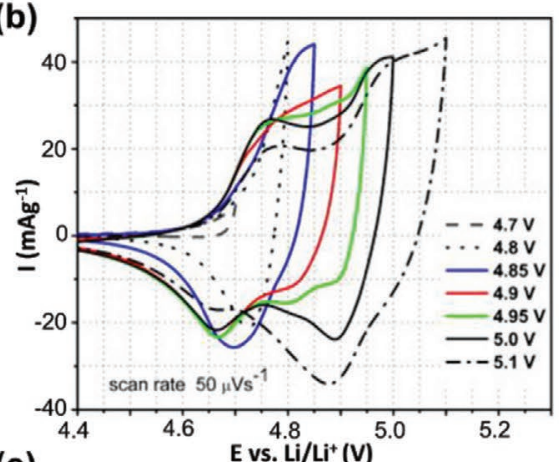

(e)

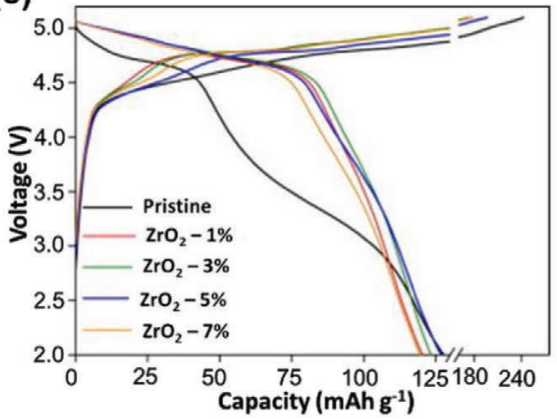

(c)

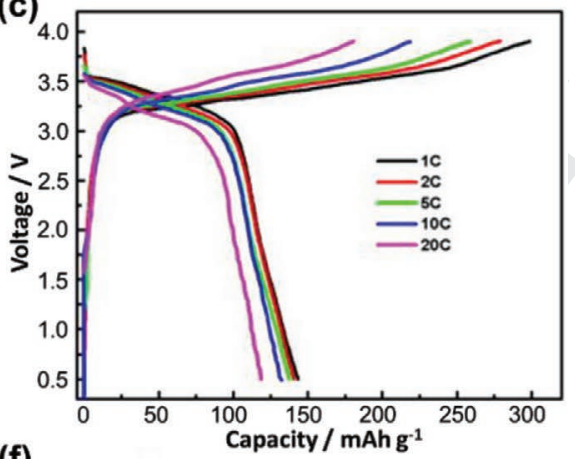

(f)

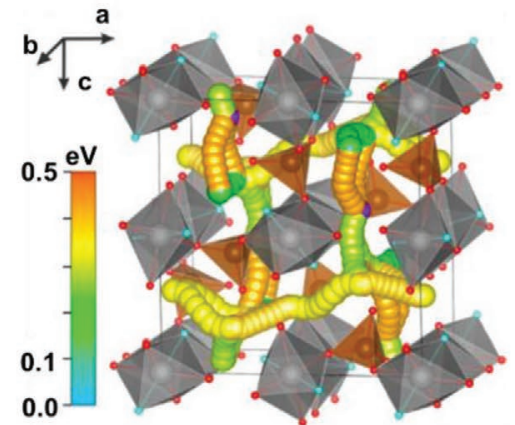

1

2

3

4

5

6

7

8

9

10

11

12

13

14

15

16

17

18

19

20

21

22

23

24

25

26

27

28

29

30

31

32

33

34

35

36

37

38

39

40

41

42

43

44

45

46

47

48

49

50

51

52

53

54

55

56

57

58

59 

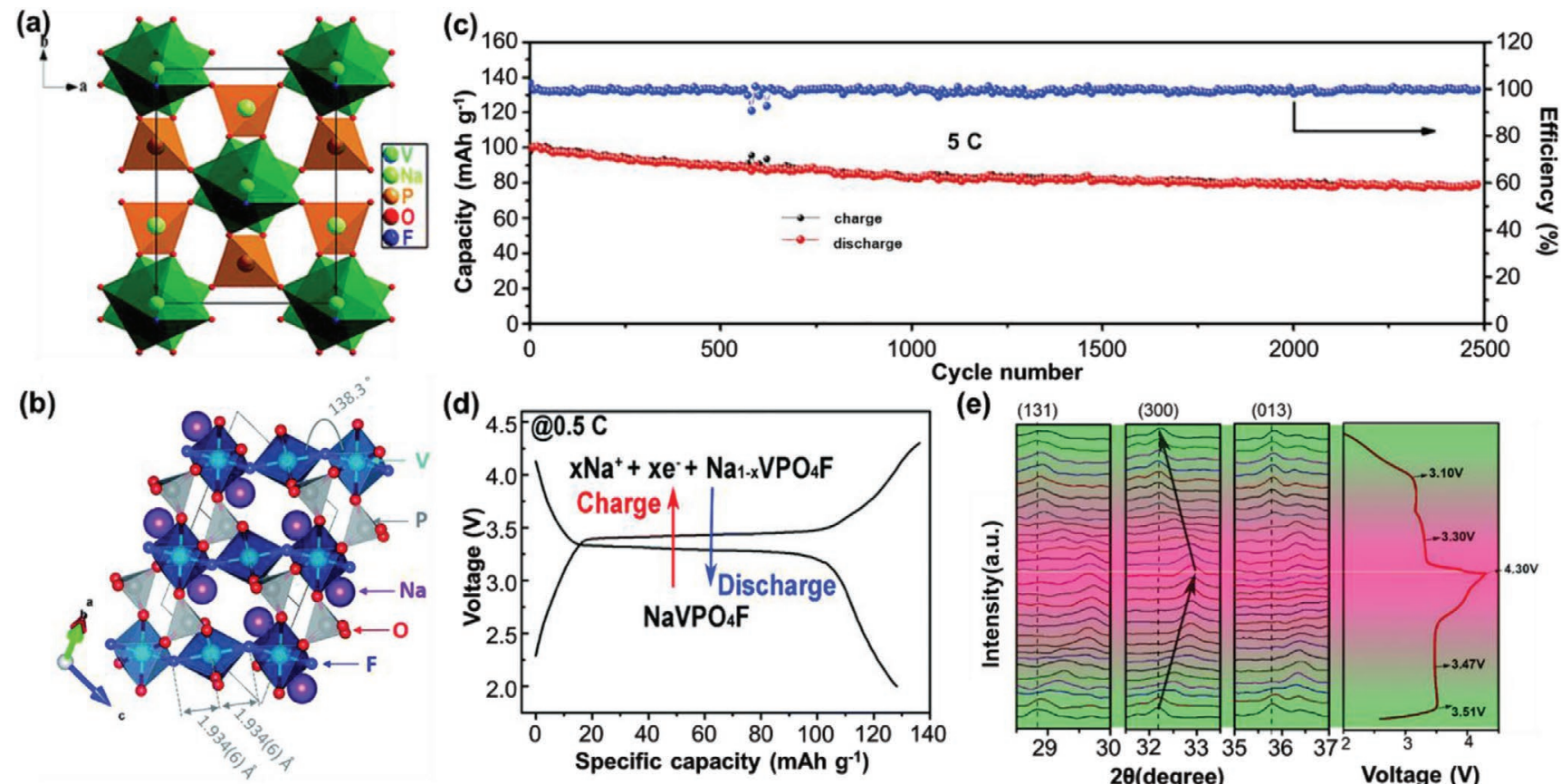

(d)

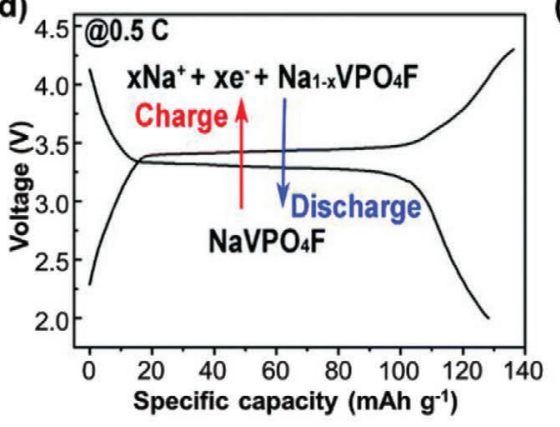

(e) (131)

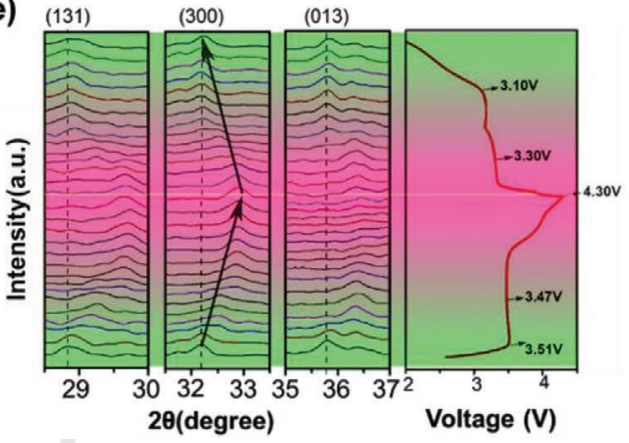

Figure 7. a) Crystal structure of monoclinic $\mathrm{NaVPO}_{4} \mathrm{~F}$. b) Crystal structure of triclinic tavorite $\mathrm{NaVPO}_{4} \mathrm{~F}$. c) Long-term cyclability of $\mathrm{NaVPO}_{4} \mathrm{~F}$ up to 250024 cycles at $5 \mathrm{C}$ rate showing $70 \%$ of capacity retention at the end. d) (Dis)charge profile of monoclinic $\mathrm{NaVPO}_{4} \mathrm{~F}$ at $0.5 \mathrm{C}$ rate when cycled between 2.025 and $4.3 \mathrm{~V}$. e) In siu XRD pattern of $\mathrm{NaVPO}_{4} \mathrm{~F}$ during (dis)charge. a,d,e) Reproduced with permission. ${ }^{[136]}$ Copyright 2018, Royal Society of Chemistry. 26 b) Reproduced with permission. ${ }^{[130]}$ Copyright 2017, Royal Society of Chemistry. c) Reproduced with permission. ${ }^{[135]}$ Copyright 2018, Elsevier. 27

et al. reported $\mathrm{ZrO}_{2}$ coated L2CPF exhibiting superior performance (Figure 6e). ${ }^{[18]}$ This also enhanced the active surface area favoring effective utilization of the capacity. Chang et al. were able to improve the performance by targeted nano- $\mathrm{SiO}_{2}$ coating on the surface of L2CPF. ${ }^{[119]}$ Antipov group elucidated the Li-ion transport properties in the material using theoretical approach. ${ }^{[120]}$ The Voronoi-Dirichlet partitioning and BVS approaches predicted 1D pathway along [010] axis, however, density functional theory revealed additional low energy transitions indicating presence of 3D pathways (Figure 6f). They also predicted the possibility of only one Li (de)insertion in the stable operating voltage window of existing commercial electrolytes.

Exploring Mn chemistry, $\mathrm{Li}_{2} \mathrm{MnPO}_{4} \mathrm{~F}$ (L2MPF) was obtained by ion exchange from $\mathrm{Na}_{2} \mathrm{MnPO}_{4} \mathrm{~F}$. It was found to be isostructural to the parent phase. ${ }^{[121]} 2 \mathrm{D}$ Li-diffusion pathways were predicted using BVS calculation. It exhibited a discharge capacity of $140 \mathrm{mAh} \mathrm{g}^{-1}$ at an average cell potential of $3.9 \mathrm{~V}$ versus $\mathrm{Li} / \mathrm{Li}^{+}$. Ni-based fluorophosphate, $\mathrm{Li}_{2} \mathrm{NiPO}_{4} \mathrm{~F}$ (L2NPF) was first reported in 1999 without any electrochemical activity due to decomposition of commercial electrolytes at high voltages. ${ }^{[122]}$ Several attempts have been reported in literature to enhance the electrolyte voltage stability window beyond $5.5 \mathrm{~V}$. Glutaronitrile or adiponitrile-based solvents were found to be stable till $8.0 \mathrm{~V}$ versus $\mathrm{Li} / \mathrm{Li}^{+}$for electrochemical doublelayer capacitors. ${ }^{[123]}$ Abu-Lebdeh proposed that addition of EC as a cosolvent to adiponitrile or glutaronitrile-based solvent to enhance the stability window to $6.0 \mathrm{~V}$ for LIBs. ${ }^{[124,125]}$ Addition of EC cosolvent to dinitrile solvent reduces the viscosity of the electrolyte and enhances the conductivity. However, aluminium corrosion is observed at such high voltages using dinitrile-based electrolytes. Okada group employed $1 \mathrm{M} \mathrm{LiBF}_{4}$ in EC/DMC/ sebaconitrile $(25: 25: 50$ by vol\%) electrolyte, which is stable up to $6 \mathrm{~V}$ versus $\mathrm{Li} / \mathrm{Li}^{+} .{ }^{[126]}$ Utilizing this electrolyte, $\mathrm{Li}_{2} \mathrm{NiPO}_{4} \mathrm{~F}$ was shown to work as a $5.3 \mathrm{~V}$ battery cathode material for the first time. Employing classical atomistic simulation, 3D Li-ion 33 conducting pathways were predicted along with occurrence of 34 $\mathrm{Li} / \mathrm{Ni}$ antisite defects. ${ }^{[127]}$

\subsection{Fluorophosphates for Sodium-Ion Batteries}

\subsubsection{Vanadium-Based Fluorophosphates}

$\mathrm{NaVPO}_{4} \mathrm{~F}$ (NVPF) is known to exist in two polymorphs: a 42 high temperature tetragonal phase and a low-temperature 43 monoclinic phase. The tetragonal phase is isostructural with 44 $\mathrm{Na}_{3} \mathrm{Al}_{2}\left(\mathrm{PO}_{4}\right)_{3} \mathrm{~F}_{2}$ with an $I 4 / \mathrm{mmm}$ symmetry. ${ }^{[54]}$ It has a $3 \mathrm{D} 45$ structure built from $\left[\mathrm{VO}_{4} \mathrm{~F}_{2}\right]$ octahedra connected with $\left[\mathrm{PO}_{4}\right]$ tet- 46 rahedra rendering open channels where $\mathrm{Na}^{+}$ions are located. 47 Barker et al. first reported the tetragonal NVPF phase in 200348 synthesized via solid state route. ${ }^{[52]}$ They fabricated a full-cell 49 using hard carbon as anode delivering a discharge capacity 50 of $82 \mathrm{mAh} \mathrm{g}^{-1}$ at an average cell voltage of $3.7 \mathrm{~V}\left(\mathrm{vs} \mathrm{Na} / \mathrm{Na}^{+}\right) \quad 51$ involving $\mathrm{V}^{4+} / \mathrm{V}^{3+}$ redox activity. A two-step (dis)charge profile 52 was observed.

The monoclinic polymorph of NVPF (with C2/c symmetry) 54 was proposed by Zhuo et al. and Liu et al. (Figure 7a).[128,129] 55 However, its detail structural analysis still remains an open 56 issue. Boivin et al. reported a tavorite based $\mathrm{NaVPO}_{4} \mathrm{~F}$ in which 57 they observed the oxidation state of vanadium to be slightly 58 higher than $\mathrm{V}^{3+}$ (Figure $7 \mathrm{~b}$ ). However, they could extract only 59 


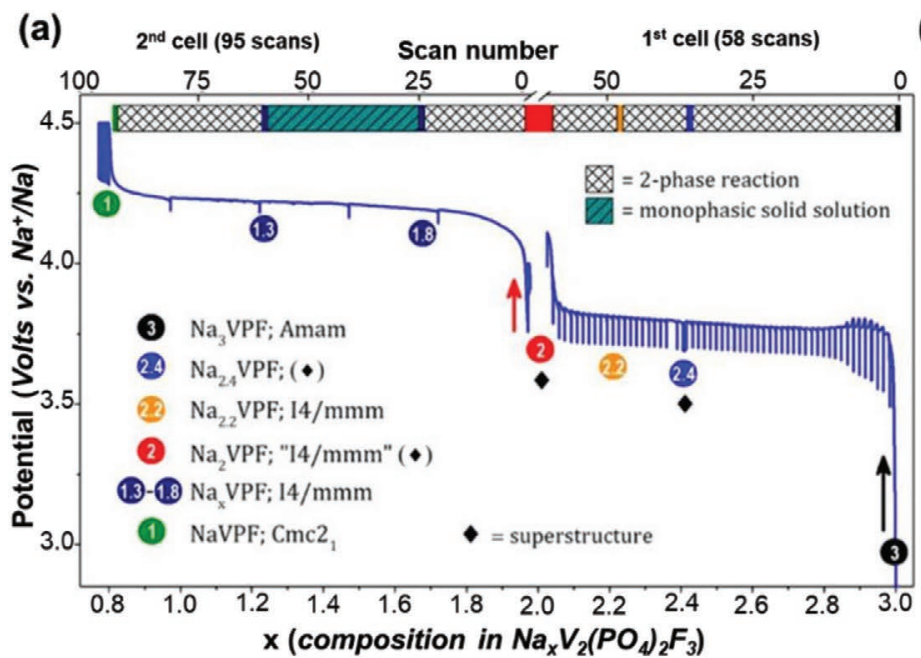

(c)

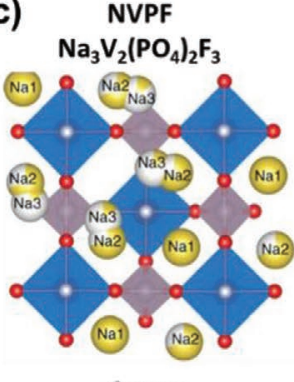

Amam

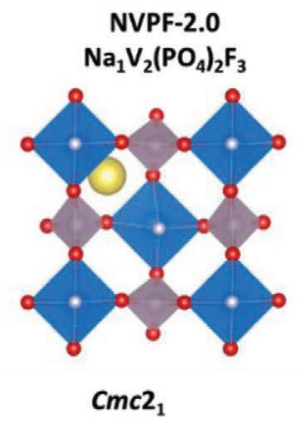

NVPF-2.0

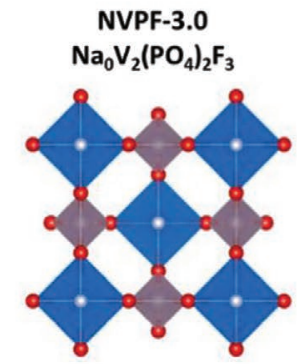

$14 / \mathrm{mmm}$ (b)

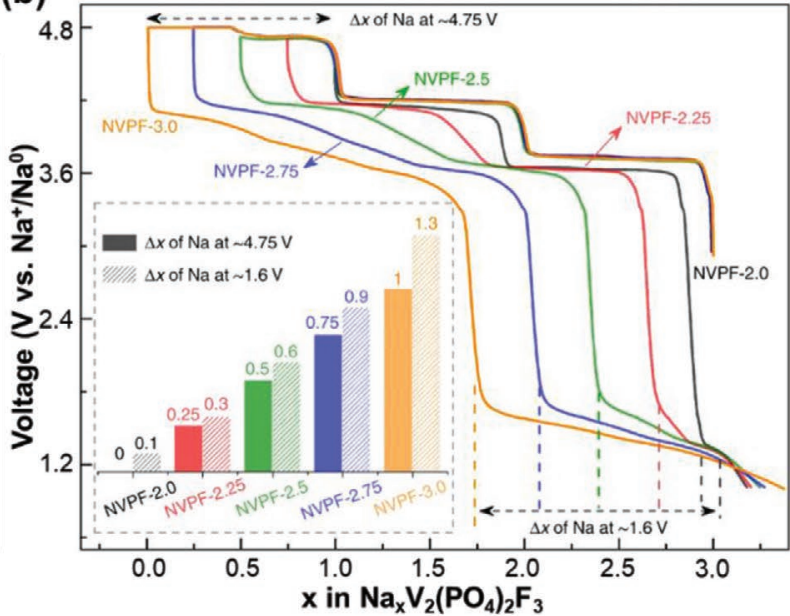

1

2

3

4

5

6

7

8

10

11

12

13

14

15

16

17

18

19

20

21

22

23

24

25

26

27

28

29

30

31

32

33

34 
the planes. ${ }^{[143]}$ Broux et. al. studied the temperature dependence of structural properties of N3VPF leading to the formation of more symmetrical tetragonal structure and complete disorder on the sodium sites. ${ }^{[144]}$ They observed order-disorder transition at $125{ }^{\circ} \mathrm{C}$, which affects the ionic properties of the material by decreasing the activation energy barrier. The electrochemical properties of N3VPF was first reported by Barker group in 2006 where they tested it as a positive electrode material for LIBs yielding a capacity of $120 \mathrm{mAh} \mathrm{g}^{-1} \cdot{ }^{[22,145]}$ Shakoor et al. first demonstrated reversible $\mathrm{Na}$-ion intercalation in this material. ${ }^{[146]}$ However, the (dis)charge profile was contrary to Li-intercalation and exhibited two voltage plateaus at 3.7 and $4.2 \mathrm{~V}$. The underlying structural changes in N3VPF are widely investigated using variety of characterization techniques. ${ }^{[147-149]}$ Bianchini et. al. used high angular resolution synchrotron diffraction to unravel four different phases (Figure 8a). ${ }^{[149]}$ Interestingly, only one of these phases was found to exhibit solid-solution process in the range of $x=1.8-1.3$ during deintercalation, while the completely discharged product was found to have $C m c 2_{1}$ symmetry. They studied the symmetry differences in between these phases by resolving weak Bragg reflections. They also examined the crystal structure using direct operando measurements for the first time. Masquelier group also carried out operando X-ray absorption spectroscopy and ${ }^{51} \mathrm{~V}$ solid-state NMR studies showing $\mathrm{V}^{\mathrm{IV}}$ disproportionation. ${ }^{[150]}$ Using vanadium K-edge XANES study, they showed the phenomenon of disproportionation occurs immediately after the extraction of one sodium-ion and not only at the end of charge. The structural changes were further studied using ${ }^{23} \mathrm{Na}$ and ${ }^{31} \mathrm{P}$ solidstate NMR studies. ${ }^{[148]}$ It identified $\mathrm{V}^{4+}$ defects in the structure leading to increase in the Na mobility during charge process. Assuming 3 electron transfer, N3VPF can deliver a theoretical discharge capacity of $256 \mathrm{mAh} \mathrm{g}^{-1}$ but only capacity corresponding to one electron transfer can be practically realized. Electrochemically inactive $\mathrm{Ga}^{3+}$ ions were doped in the $\mathrm{V}^{3+}$ sites in order to identify whether the overall capacity is limited due to $\mathrm{V}$ site. ${ }^{[151]} \mathrm{Na}_{3} \mathrm{GaV}\left(\mathrm{PO}_{4}\right){ }_{2} \mathrm{~F}_{3}$ delivered a capacity of $141 \mathrm{mAh} \mathrm{g}^{-1}$ indicating that $\mathrm{Na}_{3} \mathrm{GaV}\left(\mathrm{PO}_{4}\right)_{2} \mathrm{~F}_{3}$ is site-limited and not redoxlimited. Constant efforts have been made to enhance the energy density of the material to inch closer to commercialization with performance comparable to existing lithium cathodes. One such possible route is by activating the third sodium ion present in the structure. However, this process is not trivial since it is theoretically predicted that the third sodium ion can be removed from the structure at $>4.9 \mathrm{~V}$ versus $\mathrm{Na} / \mathrm{Na}^{+}$, which is too high for the existing electrolytes. However, Tarascon group recently demonstrated the removal of third sodium ion from the pristine structure during charge leading to formation of a disordered phase of tetragonal symmetry capable of intaking three sodium ions during subsequent discharge when cycled in voltage range of 1-4.8 $\mathrm{V}$ with the last sodium ion being inserted at $1.6 \mathrm{~V}$ (vs Na/ $\mathrm{Na}^{+}$) (Figure $\left.8 \mathrm{~b}\right) \cdot{ }^{[152]}$ It remains disordered upon cycling. They also studied the distribution of sodium inside the crystal structure of N3VPF at various states of charge by recording ex situ X-ray diffraction patterns (Figure 8c). A full cell was also fabricated using disordered N3VPF showing an increase in energy density by $10-20 \%$. The electrochemical performance of the material is limited by low intrinsic electrical conductivity and large particle size, that can be improved by carbon-coating, particle downsizing and/or alkali/metal- 1 ion doping. ${ }^{[153-156]}$ Carbon coating enhances the electronic 2 conductivity, smaller particle size implies shorter diffusion 3 length hence improving the performance at higher $\mathrm{C}$ rates, 4 while metal/alkali ion doping broadens the diffusion pathway 5 inside the structure. Carbon-coated N3VPF delivered a dis- 6 charge capacity of $130 \mathrm{mAh} \mathrm{g}^{-1}$ with good cycling stability up to 7 3000 cycles. N3VPF@C/CNT composite synthesized via spray 8 drying technique showed a discharge capacity of $85 \mathrm{mAh} \mathrm{g}^{-1} 9$ even at a fast current rate of $30 \mathrm{C}$. High tap density was 10 obtained from N3VPF/C@RGO composites. Moderate substi- 11 tution of potassium in some vanadium sites led to broadened 12 ion diffusion pathways, hence improving the overall electro- 13 chemical performance. It delivered superior electrochemical 14 performance than pristine N3VPF and N3VPF@CNT com- 15 posite. A capacity of $120 \mathrm{mAh} \mathrm{g}^{-1}$ was achieved at $1 \mathrm{C}$ rate and 16 over $90 \mathrm{mAh} \mathrm{g}^{-1}$ was achieved at $10 \mathrm{C}$ rate after 1600 cycles. ${ }^{[157]} 17$ Even at $50 \mathrm{C}$, the cell was able to retain $90 \%$ of the capacity after 18 6000 cycles. Broux et al. recently assembled 18650 prototype 19 cells using N3VPF as cathode and hard carbon anode delivering 20 an energy density of $75 \mathrm{Wh} \mathrm{kg}^{-1}$ with excellent cyclability and 21 rate capability. The carbon-coated N3VPF showed good electro- 22 chemical performance even at $0{ }^{\circ} \mathrm{C}$. ${ }^{[158]}$ Nguyen et al. reported 23 the solid solution between $\mathrm{Na}_{3} \mathrm{~V}_{2}\left(\mathrm{PO}_{4}\right)_{2} \mathrm{~F}_{3}$ and $\mathrm{Na}_{3} \mathrm{~V}_{2}\left(\mathrm{PO}_{4}\right) \quad 24$ ${ }_{2} \mathrm{FO}_{2} \cdot{ }^{[159]}$ The solid solution was further studied by density func- 25 tional theory method and ${ }^{31} \mathrm{P}$ and ${ }^{23} \mathrm{Na}$ magic-angle spinning 26 NMR study. ${ }^{[160]}$ They observed complex spin transfer mecha- 27 nism between the two materials because of the peculiar nature 28 of electronic structure of $\mathrm{V}$-ions.

The $\mathrm{Na}_{3}\left(\mathrm{VO}_{1-x} \mathrm{PO}_{4}\right)_{2} \mathrm{~F}_{1+2 x}(0 \leq x \leq 1)(\mathrm{N} 3 \mathrm{VOPF})$ family of 30 vanadium fluorophosphates involving both $\mathrm{V}^{4+} / \mathrm{V}^{3+}$ oxida- 31 tion states can be obtained by oxygenation of N3VPF. In this 32 family, $\mathrm{Na}_{3}(\mathrm{VO})_{2}\left(\mathrm{PO}_{4}\right)_{2} \mathrm{~F}$ (N3VOPF) has a theoretical capacity of 33 $130 \mathrm{mAh} \mathrm{g}^{-1}$ with high energy density. First reported by Sau- 34 vage et al. and Massa et al., it crystallizes in tetrahedral struc- 35 ture with $I 4 / \mathrm{mnm}$ space group. ${ }^{[161,162]}$ Tsirlin et al. reported a 36 different room temperature polymorph with $\mathrm{P}_{2} / \mathrm{mnm}$ space 37 group as shown in Figure 9a. ${ }^{[163]}$ Both N3VPF and N3VOPF 38 exhibit similar structures with replacement of one of the F-atom 39 by O-atom. Sauvage et al. were the first to study the electro- 40 chemical activity in this system, reporting a discharge capacity 41 of $87 \mathrm{mAh} \mathrm{g}^{-1}$ at C/100 rate having with two voltage plateaus at 42 3.6 and $4.0 \mathrm{~V}$ (vs Na/Na+). ${ }^{[161]} \mathrm{Na}_{3}\left(\mathrm{VO}_{1-\mathrm{brx}} \mathrm{PO}_{4}\right)_{2} \mathrm{~F}_{1+2 x}$ family was 43 reported by Rojo group in 2012.[164] N3VOPF with mixed $\mathrm{V}^{4+} / \mathrm{V}^{3+} 44$ valence state was demonstrated by Park et al. and Qi et al. ${ }^{[165,166]} 45$ $\mathrm{Na}_{3} \mathrm{~V}_{2} \mathrm{O}_{2}\left(\mathrm{PO}_{4}\right)_{2} \mathrm{~F}$ prepared by solvothermal route delivered a 46 discharge capacity of $73 \mathrm{mAh} \mathrm{g}^{-1}$ at $10 \mathrm{C}$ rate along with $90 \% \quad 47$ of capacity retention at $2 \mathrm{C}$ rate for 1200 cycles. ${ }^{[165]}$ Mono crys- 48 talline 3D nanostructured N3VOPF formed on flexible gra- 49 phene exhibited superior rate capability delivering a discharge 50 capacity of $45 \mathrm{mAh} \mathrm{g}^{-1}$ even at $60 \mathrm{C}$ rate (Figure 9b). ${ }^{[167]}$ This 51 performance was attributed to low in-plane energy barrier, fast 52 ion transport within $a b$-plane and minimal volumetric change 53 during (de)intercalation. The structural evolution during cycling 54 was studied by various groups and both solid-solution and two- 55 phase reaction were observed. ${ }^{[168-170]}$ Redox transitions and rela- 56 tionship between $\mathrm{V}^{4+} / \mathrm{V}^{3+}$ and $\mathrm{V}^{5+} / \mathrm{V}^{4+}$ redox reactions along 57 with $\mathrm{Na}^{+}$intercalation mechanism during charge storage pro- 58 cess were studied by Park et al. The energy density of N3VOPF 59 
(a)

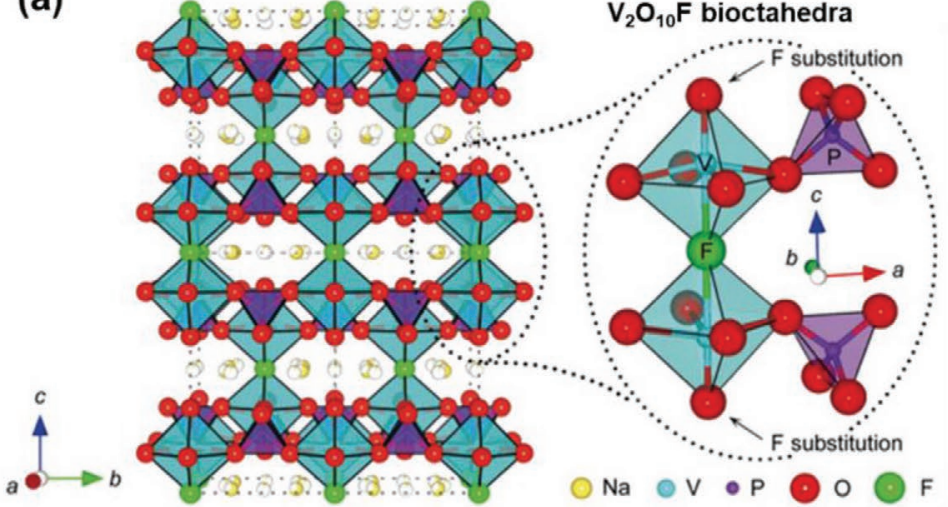

(c)

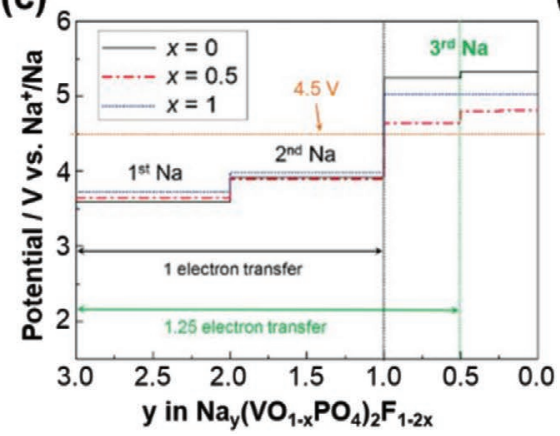

(d)

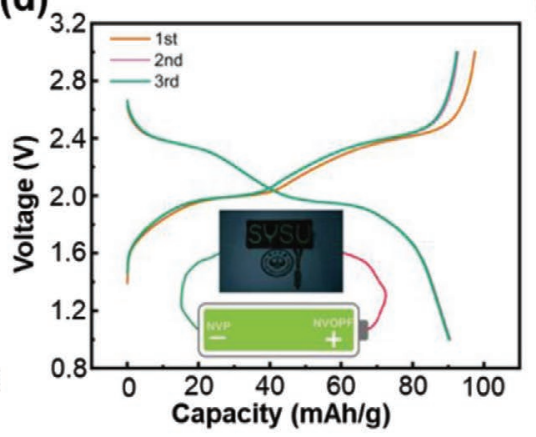

(b)

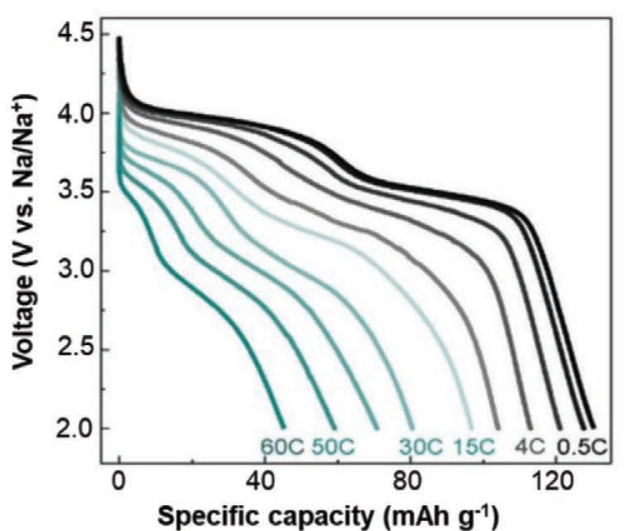

(e)

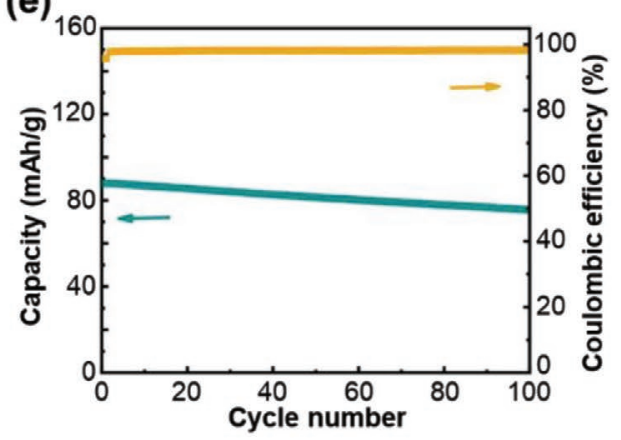

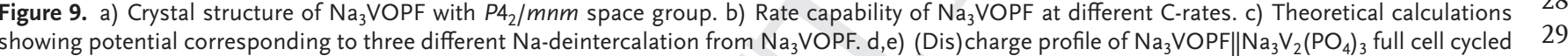

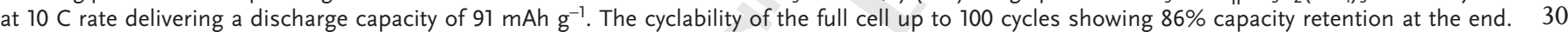

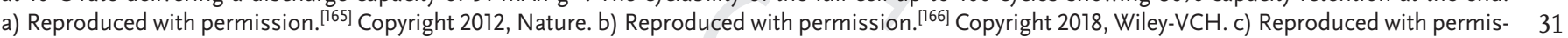
sion. [170] Copyright 2014, Wiley-VCH. d,e) Reproduced with permission. ${ }^{[183]}$ Copyright 2019, Wiley-VCH.

can be further increased if the third Na-ion can also be extracted out of the system. But it is restricted due to high operating voltage of $5.3 \mathrm{~V} \mathrm{Na} / \mathrm{Na}^{+}$(Figure 9c). However, theoretical calculations predicted replacing $\mathrm{O}$ with $\mathrm{Cl}$ to form $\mathrm{Na}_{3} \mathrm{~V}_{2} \mathrm{Cl}_{2}\left(\mathrm{PO}_{4}\right)_{2} \mathrm{~F}$ can increase the energy density to $758 \mathrm{mAh} \mathrm{g}^{-1}$. ${ }^{[171]} \mathrm{N} 3 \mathrm{VOPF}$ also suffers from low intrinsic electronic conductivity that can be circumvented by modifying the synthesis technique, carbon coating, particle nanosizing and by adding various additives. ${ }^{[172-178]}$ Carbon-coated N3VOPF delivered a discharge capacity of $68 \mathrm{mAh} \mathrm{g}^{-1}$ at $1 \mathrm{C}$ rate. ${ }^{[173]} \mathrm{N} 3 \mathrm{VOPF} / \mathrm{rGO}$ composite exhibited a discharge capacity of $120 \mathrm{mAh} \mathrm{g}^{-1}$ at C/20 rate and 91.4\% capacity was retained after 200 cycle at C/10 rate. ${ }^{[172]}$ Jin et al. reported 3D N3VOPF@C/graphene composite delivering a capacity of $136 \mathrm{mAh} \mathrm{g}^{-1}{ }^{[179]} \mathrm{RuO}_{2}$ coated N3VOPF nanowires provided long term cycling stability up to 1000 cycles and a high rate capability with $95 \mathrm{mAh} \mathrm{g}^{-1}$ at $20 \mathrm{C}$ rate. ${ }^{[180]}$ Full cell with hard carbon anode delivered a specific capacity of $120 \mathrm{mAh} \mathrm{g}^{-1}$ at a working voltage of $3.1 \mathrm{~V} \cdot{ }^{[181]}$ Recently carbon encapsulated N3VOPF was synthesized by rapid microwave-assisted technique and delivered a capacity of $127.9 \mathrm{mAh} \mathrm{g}^{-1}$ with $82.1 \%$ retention after 2000 cycles at $20 \mathrm{C}$ rate. ${ }^{[182]}$ It also led to good rate kinetics and cycling performances of N3VOPF in lithium half-cell configuration. Zhang et al. fabricated a full-cell with $\mathrm{Na}_{3} \mathrm{VOPF} / \mathrm{rGO}$ composite cathode and $\mathrm{Na}_{3} \mathrm{~V}_{2}\left(\mathrm{PO}_{4}\right)_{3}$ anode and it delivered a capacity of $91 \mathrm{mAh} \mathrm{g}^{-1}$ at $10 \mathrm{C}$ rate with $86 \%$ retention after 100 cycles as shown in Figure 9d,e. ${ }^{[183]}$ A specific capacity of $79 \mathrm{mAh} \mathrm{g}^{-1}$ was obtained at $60 \mathrm{C}$ rate with the full cell and remains the best rate capability reported in literature till date. Overall, vanadium-based fluorophosphates form a rich family of sodium insertion materials with structural diversity, chemical/thermal stability, efficient electrochemical activity, and potential practical applications.

\subsubsection{Fluorophosphates with General Formula $\mathrm{Na}_{2} \mathrm{MPO}_{4} \mathrm{~F}$ $(\mathrm{M}=\mathrm{Fe}, \mathrm{Co}, \mathrm{Mn}, \mathrm{Ni})$}

Exploring fluorophosphate chemistry, Nazar group reported $\mathrm{Na}_{2} \mathrm{FePO}_{4} \mathrm{~F}$ (NFPF) as a multifunctional cathode material in $2007 .{ }^{[18]}$ It has an orthorhombic structure (s.g. $\mathrm{Pbcn}$ ) built from $\mathrm{FeO}_{4} \mathrm{~F}_{2}$ octahedra, which are face-shared to form $\mathrm{Fe}_{2} \mathrm{O}_{7} \mathrm{~F}_{2}$ bioctahedra units. These bioctahedra units are connected by bridging $\mathrm{F}$-atom to form chains, which are interconnected by $\mathrm{PO}_{4}$-group to form $\left[\mathrm{FePO}_{4} \mathrm{~F}\right]$ slabs. Na-atoms are present in two different crystallographic sites facilitating 2D diffusion pathways. When tested for its (de)intercalating properties in Li-ion half-cell configuration, a discharge capacity of $115 \mathrm{mAh} \mathrm{g}^{-1}$ was obtained at an average cell potential of $3.5 \mathrm{~V}\left(\mathrm{vs} \mathrm{Li} / \mathrm{Li}^{+}\right)$. The (dis)charge profiles exhibited a sloppy nature suggesting the presence of quasi solid-solution behavior. It exhibits one electron redox activity with no possibility to extract the second $\mathrm{Na}$ ion due to the high potential and structural instability associated with 

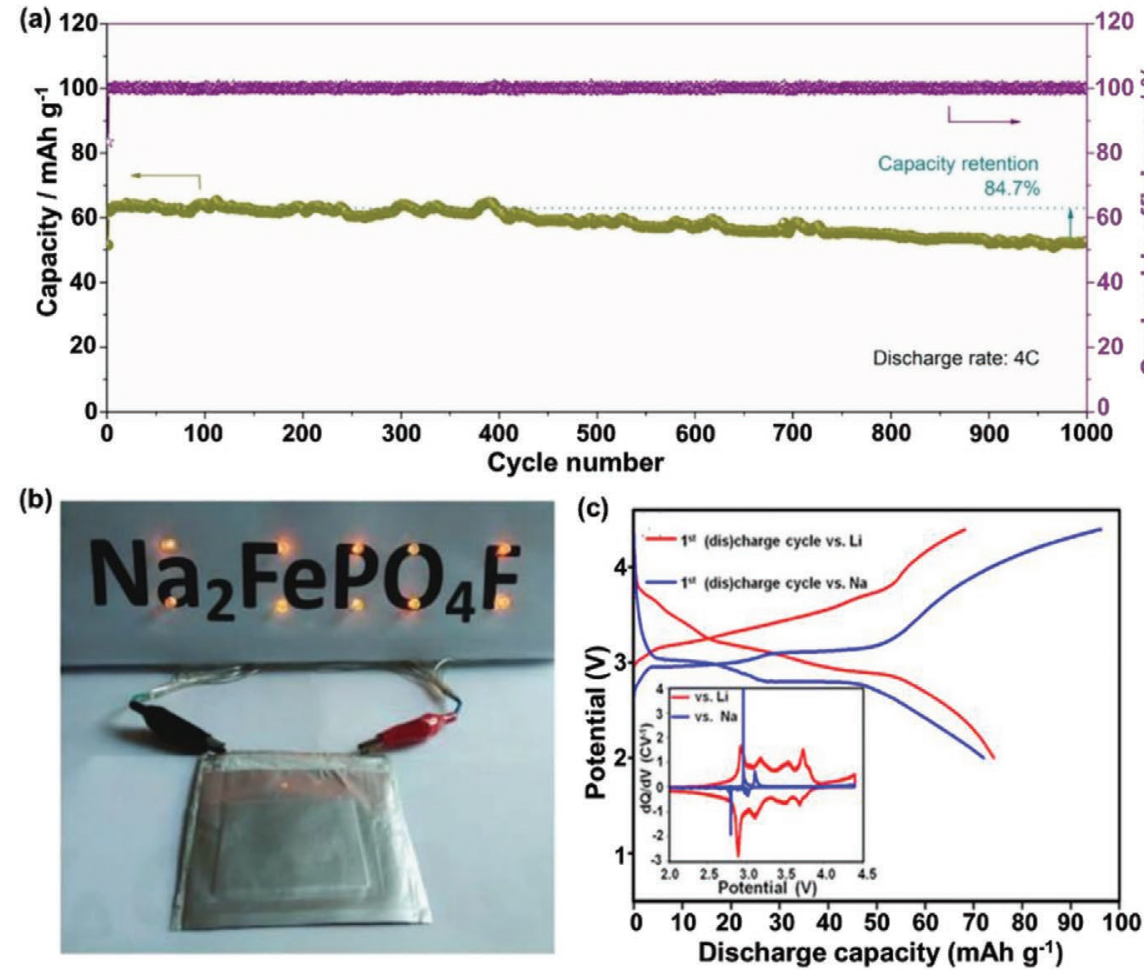

(d)

Figure 10. a) Cyclability of $\mathrm{Na}_{2} \mathrm{FePO}_{4} \mathrm{~F} / \mathrm{C}$ at $4 \mathrm{C}$ rate for 1000 cycles showing $84.7 \%$ capacity retention at the end. b) Picture of the pouch cell assembled using $\mathrm{Na}_{2} \mathrm{FePO}_{4} \mathrm{~F} @ \mathrm{C}$ nanofibers cathode and carbon nanofibers anode. c) Different nature of (dis) charge profiles of NFPF when cycled in lithium halfcell configuration and sodium half-cell configuration. (Inset) dQ/dV plots of $\mathrm{Na}_{2} \mathrm{FePO}_{4} \mathrm{~F}$ (dis)charge profiles. d) Rate capability of $\mathrm{Na}_{2} \mathrm{CoPO} \mathrm{F}_{4} \mathrm{~F}$ at various cycling rates. e) The (dis)charge profile of $\mathrm{Na}_{2} \mathrm{MnPO}_{4} \mathrm{~F}$ cycled between 1.5 and $4.5 \mathrm{~V}$ at $6.2 \mathrm{~mA} \mathrm{~g}^{-1}$ up to 50 cycles. a) Reproduced with permission. ${ }^{[192]}$ Copyright 2017, American Chemical Society. b) Reproduced with permission. ${ }^{[197]}$ Copyright 2019, Wiley-VCH. d) Reproduced with permission. ${ }^{[207]}$ Copyright 2015, The Electrochemical Society. e) Reproduced with permission. ${ }^{[208]}$ Copyright 2014, Royal Society of Chemistry.

$\mathrm{Fe}^{4+} / \mathrm{Fe}^{3+}$ redox activity. Recham et al. first tested the ionothermally synthesized NFPF for Na-intercalation. ${ }^{[19]}$ The nanoscale particles showed efficient $\mathrm{Na}$-(de)intercalation leading to a first discharge capacity of $120 \mathrm{mAh} \mathrm{g}^{-1}\left(Q_{\mathrm{Th}}=124 \mathrm{mAh} \mathrm{g}^{-1}\right)$ at $3.0 \mathrm{~V}\left(\mathrm{vs} \mathrm{Na} / \mathrm{Na}^{+}\right)$.

It has been observed that the particle size and morphology plays a key role in the electrochemistry of cathode materials, hence many synthesis methods for NFPF have been reported till date. ${ }^{[184-195]}$ Deng et al. reported a green route based synthesis technique where Vitamin $\mathrm{C}$ was used as a carbon source to yield $\mathrm{Na}_{2} \mathrm{FePO}_{4} \mathrm{~F} / \mathrm{C} \cdot{ }^{[192]}$ They reported $84.7 \%$ of capacity retention at $4 \mathrm{C}$ rate after 1000 cycles as shown in Figure 10a. NFPF is a poor electrical conductor, thus warranting carbon coating to improve the electrochemical performance. Komaba group first demonstrated the positive effect of carbon coating of NFPF by adding citric acid. Sharma et al. reported an economic combustion synthesis route to obtain carbon coated nanoparticles with porous morphology using $\mathrm{Fe}(\mathrm{III})$ based precursor. They reported a discharge capacity over $100 \mathrm{mAh} \mathrm{g}^{-1}$ at $3.0 \mathrm{~V}$ ( $\left.\mathrm{vs} \mathrm{Na} / \mathrm{Na}^{+}\right)$. rGO-coated NFPF was found to deliver a discharge capacity of $60 \mathrm{mAh} \mathrm{g}^{-1}$ at $1 \mathrm{C}$ current rate and $70 \%$ of it was retained at the end of 5000 cycles. Jin et al. used DFT calculations to find out optimum dopants to improve the intrinsic electrical conductivity of the material. ${ }^{[196]}$ They observed Co-doped NFPF as the most promising candidate. The $\mathrm{Na}_{2} \mathrm{Fe}_{0.94} \mathrm{Co}_{0.06} \mathrm{PO}_{4} \mathrm{~F} / \mathrm{C}$ delivered a capacity of $99.93 \mathrm{mAh} \mathrm{g}^{-1}$ at $0.2 \mathrm{C}$ and observed a capacity retention of $62 \%$ after 400 cycles at $1 \mathrm{C}$ current rate. Wang et al. 34 synthesized nanometric NFPF particles embedded in porous 35 $\mathrm{N}$-doped carbon nanofibers to obtain a high reversible capacity 36 of $117.8 \mathrm{mAh} \mathrm{g}^{-1}$ at $0.1 \mathrm{C}$ rate with excellent cycling stability up 37 to 2000 cycles. ${ }^{[197]}$ Pouch cells were assembled using NFPF@C 38 nanofibers cathode and carbon nanofibers anode to deliver an 39 energy density of $135.8 \mathrm{Wh} \mathrm{kg}^{-1}$ (Figure 10b).

However, the (dis)charge profile during Li-and Na- interca- 41 lation is different indicating different underlying structural 42 transitions (Figure 10c). ${ }^{[198]}$ During lithium (de)intercalation, a 43 sloppy profile is observed while in case of sodium two distinct 44 plateaus are observed. The small size of $\mathrm{Li}^{+}$cation leads to 45 random occupancy of the $\mathrm{Na} 1$ and $\mathrm{Na} 2$ sites during interca- 46 lation implying no specific ordering of $\mathrm{Li}$ in the structure. 47 Whereas, the two different site energies related to two crystallo- 48 graphic sites $\mathrm{Na} 1$ and $\mathrm{Na} 2$ lead to different intercalating voltage. 49 Nevertheless, the structural transition is worth studying in 50 both cases. Smiley et al. employed ex situ ${ }^{23} \mathrm{Na}$ solid-state NMR 51 spectroscopy to probe the ion mobility during cycling. ${ }^{[199]}$ From 52 NMR study, they proposed a biphasic extraction process of Na- 53 ions from the structure. However, no intermediate phase was 54 detected with coexistence of $\mathrm{Na}_{2} \mathrm{FePO}_{4} \mathrm{~F}$ and $\mathrm{NaFePO}_{4} \mathrm{~F}$ end 55 phases. The role of semilabile oxygen, i.e., the oxygen linked 56 only to P and alkali atoms was studied by Abakumov group. ${ }^{[200]} 57$ They observed an identical coordination environment for both 58 sites of sodium and proposed different intercalating behavior 59 
1 due to different number of bonds to the semilabile oxygen

2 atoms. The site having large cation-semilabile oxygen interac3 tion is characterized by higher deintercalation potential while 4 the sites with low interaction exhibits lower potential. They 5 observed a solid-solution mechanism during delithiation while 6 an intermediate monoclinic phase $\mathrm{Na}_{1.5} \mathrm{FePO}_{4} \mathrm{~F}\left(P 2_{1} / b\right)$ was 7 observed during desodiation. $\mathrm{Fe}(\mathrm{II}) / \mathrm{Fe}(\mathrm{III})$ charge ordering 8 along with $\mathrm{Na}$ vacancy ordering was also observed. Yang group 9 combined ex situ experiments with theoretical calculations to 10 further analyze the structural changes in the material during 11 cycling. ${ }^{[201]}$ They found the cycling process is dominated by 12 two biphasic reactions during various states of charge keeping 13 the sodium in Na1 site intact. The structure of intermediate 14 phase $\mathrm{Na}_{1.5} \mathrm{FePO}_{4} \mathrm{~F}$ was indexed to monoclinic structure (s.g. $15 P 2_{1} / c$ ) with the help of DFT calculations and ex situ ${ }^{23} \mathrm{Na}$ NMR 16 studies. Yamashita group employed first principle calculation 17 along with Monte Carlo method to analyze the (dis)charge 18 mechanism of NFPF. ${ }^{[202]}$ They found the most stable struc19 ture of $\mathrm{Na}_{1.5} \mathrm{FePO}_{4} \mathrm{~F}$ having monoclinic structure (s.g. $P 2_{1} / b 11$ ). 20 Indeed, structural evolution during (de)insertion in $\mathrm{Na}_{2} \mathrm{FePO}_{4} \mathrm{~F}$ 21 still remains vague warranting further research. While the 22 extraction of second sodium ion is difficult, $\mathrm{Wu}$ et al. reported 23 a 1.46 electron transfer per formula unit at $60{ }^{\circ} \mathrm{C}$ when cycled 24 between 1.5 and $4.6 \mathrm{~V}$ in Li-cell.. ${ }^{203]}$ Avdeev et al. studied the 25 magnetic structure of NFPF observing a long-range antiferro26 magnetic ordering transition at $3.4 \mathrm{~K} \cdot{ }^{[204]}$
The isostructural Co-analog, $\mathrm{Na}_{2} \mathrm{CoPO}_{4} \mathrm{~F} \quad(\mathrm{NCPF})$ was reported by Nazar group in 2010. ${ }^{[205]}$ Following, Komaba group reported its first electrochemical report in 2014. ${ }^{[206]}$ The solidstate synthesized material was reported as a high-voltage ( $\approx 4.4 \mathrm{~V}$ vs $\mathrm{Na} / \mathrm{Na}^{+}$) sodium battery cathode with a discharge capacity of $71 \mathrm{mAh} \mathrm{g}^{-1}$. The large irreversible capacity loss during first cycle was attributed to decomposition of electrolytes at higher voltages as shown in Figure 10d. ${ }^{[195]}$ Later, Yang group came up with spray drying synthesis technique to form NCPF with spherical morphology yielding a discharge capacity of $107 \mathrm{mAh} \mathrm{g}^{-1}$ at an average cell voltage of $4.5 \mathrm{~V}$ albeit with large capacity fading. ${ }^{[207]}$

Deviating from orthorhombic $\mathrm{Na}_{2} \mathrm{FePO}_{4} \mathrm{~F}$ and $\mathrm{Na}_{2} \mathrm{CoPO}_{4} \mathrm{~F}$, $\mathrm{Na}_{2} \mathrm{MnPO}_{4} \mathrm{~F}$ (NMPF) assumes a monoclinic framework with $P 2_{1} / n$ symmetry. It consists of corner shared $\mathrm{MnO}_{4} \mathrm{~F}_{2}$ octahedra connected by F-atoms to form $\mathrm{Mn}_{2} \mathrm{O}_{8} \mathrm{~F}_{2}$ bioctahedra chains, which are abridged by $\mathrm{PO}_{4}$ tetrahedra giving rise to a 3D structure. Despite having open pathway for $\mathrm{Na}^{+}$diffusion, NMPF was found to be electrochemically inactive. ${ }^{[19,205]} \mathrm{Wu}$ et al. synthesized carbon coated NMPF and reported a discharge capacity of $98 \mathrm{mAh} \mathrm{g}^{-1}$ at $60^{\circ} \mathrm{C}$, but with poor cyclability. ${ }^{[203]}$ The diffusion kinetics and electrochemical activity was analyzed by Kim et al. by combining experiments results with DFT calculations. ${ }^{[121]}$ In the solid-state synthesized sample, the $\mathrm{Na}^{+}$diffusion is along $b$-direction. They also synthesized $\mathrm{Li}_{2} \mathrm{MnPO}_{4} \mathrm{~F}$ by ion-exchange method exhibiting superior electrochemical activity, which was attributed to an additional diffusion pathway perpendicular obtained with a discharge capacity of $110 \mathrm{mAh} \mathrm{g} \mathrm{g}^{-1}$ by carboncoated NMPF hollow spheres synthesized via spray drying route (Figure 10e). ${ }^{[208]}$ The material was found to be structurally stable even at higher voltages. $\mathrm{Na}_{2} \mathrm{NiPO}_{4} \mathrm{~F}$ (NNPF) has been synthesized without any report on electrochemical study as it is active to $\mathrm{F}^{-}$backbone. Enhanced electrochemical performance was
$>5 \mathrm{~V}$, where the conventional electrolytes start to decompose. ${ }^{[205]} 1$ Overall, this class of material is very attractive in terms of real- 2 izing high voltage cathode materials for Na-ion batteries. Espe- 3 cially $\mathrm{Na}_{2} \mathrm{FePO}_{4} \mathrm{~F}$ form an economic sodium insertion material 4 with moderate energy density suitable for stationary applications.

\subsubsection{Fluorophosphates in Aqueous Batteries}

Fluorophosphate based insertion materials can also be implemented in aqueous systems. Aqueous batteries enhance the ionic conductivity and impart operational safety. Care must be taken to avoid water splitting beyond the narrow safe operating voltage window. Consequently, not all high voltage materials can be tested in aqueous electrolytes. However, suitable additives and highly concentrated electrolytes broaden the working voltage window making it possible to test high-voltage cathode materials in aqueous media. NASICON type $\mathrm{NaVPO}_{4} \mathrm{~F}$ was the first fluorophosphate to be tested in aqueous electrolytes. It delivered a discharge capacity of $54 \mathrm{mAh} \mathrm{g}^{-1}$ in $5 \mathrm{M} \mathrm{NaNO}_{3}$ solution with two plateaus at 0.8 and $0.2 \mathrm{~V}$ (vs SCE). ${ }^{[209]}$ Kumar et al. reported electrochemical properties of $\mathrm{Na}_{3} \mathrm{~V}_{2} \mathrm{O}_{2}\left(\mathrm{PO}_{4}\right)_{2} \mathrm{~F}$-multiwall carbon nanotubes (MWCNT) nanocomposites in aqueous electrolyte, delivering a discharge capacity of $35 \mathrm{mAh} \mathrm{g}^{-1}$ at $1 \mathrm{C}$ rate in half-cell configuration. ${ }^{[175]}$ The $\mathrm{Na}_{3} \mathrm{~V}_{2} \mathrm{O}_{2}\left(\mathrm{PO}_{4}\right)_{2} \mathrm{~F}$ -MWCNT \| $\mathrm{NaTi}_{2}\left(\mathrm{PO}_{4}\right)_{3}$-MWCNT full cell gave a discharge capacity of $42 \mathrm{mAh} \mathrm{g}^{-1}$ at $1 \mathrm{C}$ rate. Recently, Sharma et al. tested $\mathrm{Na}_{2} \mathrm{FePO}_{4} \mathrm{~F}$ (NFPF) by employing $17 \mathrm{M} \mathrm{NaClO}_{4}$ aqueous electrolyte. ${ }^{[210]}$ Using this supersaturated electrolyte, the operating voltage window can be enlarged to $2.8 \mathrm{~V}$ in $17 \mathrm{M} \mathrm{NaClO}_{4}$ visa-vis $1.23 \mathrm{~V}$ in conventional water-based electrolytes. ${ }^{[211]}$ The NFPF half-cell delivered a reversible discharge capacity of 84 $\mathrm{mAh} \mathrm{g}^{-1}$ when cycled in an optimized voltage range of -0.9 to $0.9 \mathrm{~V}$ versus $\mathrm{Ag} / \mathrm{AgCl}$ reference electrode at $1 \mathrm{~mA} \mathrm{~cm} \mathrm{~cm}^{-2}$ current density as shown in Figure 11a. It exhibited good cycling stability and rate kinetics. A full-cell was also assembled with NASICON-type $\mathrm{NaTi}_{2}\left(\mathrm{PO}_{4}\right)_{3}$ anode giving a specific capacity of $85 \mathrm{mAh} \mathrm{g}^{-1}$ at an average cell potential of $0.7 \mathrm{~V}$ (Figure 11b). Recently, $\mathrm{Na}_{3} \mathrm{~V}_{2}\left(\mathrm{PO}_{4}\right)_{2} \mathrm{~F}_{3}$-single walled carbon nanotubes (SWCNT) composites were also tested in $17 \mathrm{M} \mathrm{NaClO}_{4}$ electrolyte. ${ }^{[212]}$ The half-cell configuration delivered a discharge capacity of $81.3 \mathrm{mAh} \mathrm{g}^{-1}$ but with poor coulombic efficiency due to the formation of solid-state interface (SEI) (Figure 11c). The $\mathrm{Na}_{3} \mathrm{~V}_{2}\left(\mathrm{PO}_{4}\right)_{2} \mathrm{~F}_{3}$-SWCNT \| $\mathrm{NaTi}_{2}\left(\mathrm{PO}_{4}\right)_{3}$-MWCNT full cell delivered an energy density of $150 \mathrm{Wh} \mathrm{kg}^{-1}$ at $1.92 \mathrm{~V}$ in the voltage range of $0.6-2.1 \mathrm{~V}$ (Figure 11d). It is possible to exploit many fluorophosphate insertion compounds in aqueous batteries with appropriate optimization of electrolytes, stabilizing additives and voltage operation window.

\subsection{Fluorophosphates for Potassium-Ion Batteries}

Graphite, being a standard anode for Li-ion batteries, does not serve the same purpose for Na-ion batteries as $\mathrm{Na}^{+}$(de)insertion is energetically not favorable in graphitic domains. Hence, hard carbon is utilized as an anode for SIBs. However, hard carbon delivers poorer performance than graphite, reducing the overall energy density by $20 \%$ as compared to LIBs. In contrast, 

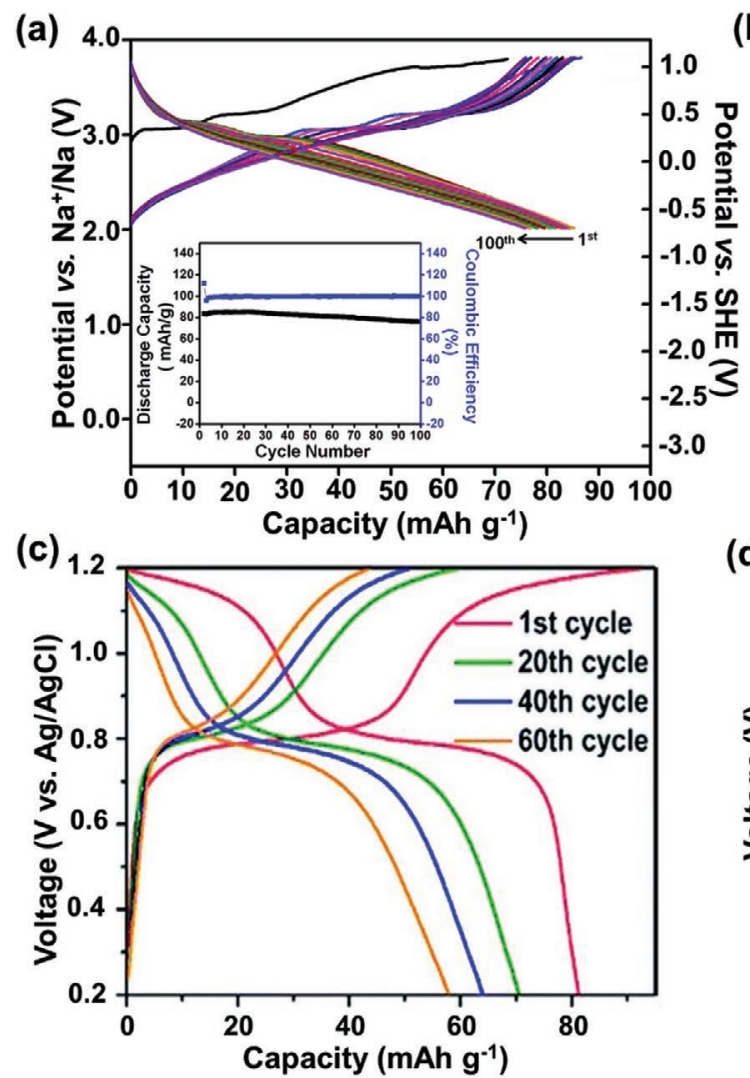

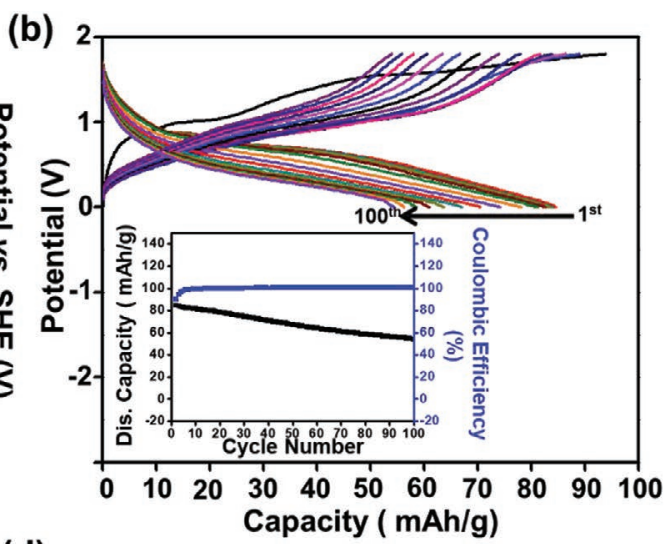

(d)

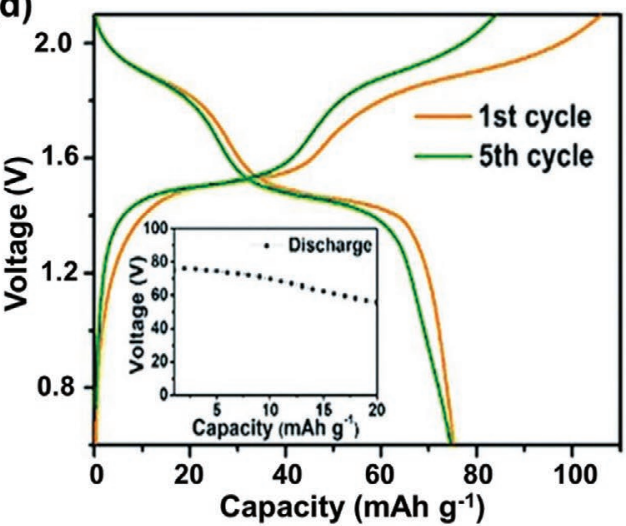

1

Figure 11. a) The (dis)charge profile of NFPF in hall cell configuration using $17 \mathrm{M} \mathrm{NaClO}$ as aqueous electrolyte in the voltage range of -0.9 to $0.9 \mathrm{~V} \quad 30$ versus $\mathrm{Ag} / \mathrm{AgCl}$. (Inset) Cyclability of half-cell up to 100 cycles. b) The (dis)charge profile of NFPF $\| \mathrm{NaTi}_{2}\left(\mathrm{PO}_{4}\right)_{3}$ full-cell using $17 \mathrm{M} \mathrm{NaClO}{ }_{4}$ as an 31 electrolyte. (Inset) Cyclability of full-cell up to 100 cycles. c) The (dis)charge profile of $\mathrm{Na}^{2} \mathrm{VPF}-\mathrm{SWCNT}$ in hall-cell configuration using $17 \mathrm{M} \mathrm{NaClO} 4$ aqueous electrolyte. d) The (dis)charge profile of Na3VPF-SWCNT \| NaTi ${ }_{2}\left(\mathrm{PO}_{4}\right)_{3}-\mathrm{MWCNT}$ full-cell using $17 \mathrm{M} \mathrm{NaClO}{ }_{4}$ electrolyte. c,d) Reproduced with permission. ${ }^{[212]}$ Copyright 2019, Royal Society of Chemistry.

a facile potassium (de)insertion is feasible in graphite. ${ }^{[213]}$ This, coupled with its lower standard redox potential than sodium and high elemental abundance, has ushered scientific interest to develop potassium-ion batteries (KIBs). ${ }^{[214]}$ The large ionic size of potassium creates a bottleneck in terms of designing appropriate host materials. Many oxide-based materials have been studied for their potassium (de)intercalating properties. ${ }^{[215-220]}$ However, Tarascon group first utilized the fluorine chemistry when they reported $\mathrm{KFeSO}_{4} \mathrm{~F}$ similar to $\mathrm{KTiOPO}_{4}$ (KTP) structure. ${ }^{[221]}$ On a similar note, Antipov group unveiled $\mathrm{KVPO}_{4} \mathrm{~F}$ (KVPF) in 2016 adopting KTP structure, tested for Li (de)insertion. ${ }^{[222]}$ It consists of helical chains of $\mathrm{VO}_{4} \mathrm{~F}_{2}$ octahedra and $\mathrm{PO}_{4}$ tetrahedra giving rise to a rigid framework with 3D pathways for K-ion diffusion. KVPF was first oxidized until $4.8 \mathrm{~V}$ in a potassium based half-cell, where it was kept under hold for $5 \mathrm{~h}$ at constant voltage to obtain $\mathrm{K}_{0.15} \mathrm{VPO}_{4} \mathrm{~F}$ phase. This electrode, when cycled in a lithium half-cell between 2 and $4.7 \mathrm{~V}$, was found to intercalate $0.7 \mathrm{Li}$ ion per formula unit at an average cell voltage of $4 \mathrm{~V}\left(\mathrm{vs} \mathrm{Li} / \mathrm{Li}^{+}\right)$. The lithiated material was found to have Pnma space group in contrast to pristine KVPF having Pna $_{1}$ symmetry. Involving $1 \mathrm{D} \mathrm{\textrm {Li } ^ { + }}$ diffusion, it exhibited electrochemical activity even at high current rates of $40 \mathrm{C}$. Komaba group demonstrated the potassium intercalation in $\mathrm{KVPF}$ for the first time. ${ }^{[223]}$ Utilizing $0.7 \mathrm{M} \mathrm{KPF}_{6}$ in EC:diethyl carbonate (DEC) as electrolyte, they cycled the material between
2.0 and $4.8 \mathrm{~V}$ yielding a first discharge capacity of $70 \mathrm{mAh} \mathrm{g}^{-1} 35$ with $\mathrm{V}^{4+} / \mathrm{V}^{3+}$ redox potential centered at $4.02 \mathrm{~V}$ (Figure 12a). 36 Despite irreversible capacity loss in the first cycle due to electro- 37 lyte decomposition at high voltage, excellent rate capability was 38 observed with $90 \%$ capacity retention at $5 \mathrm{C}$ rate. It is attributed 39 to the lower Lewis acidity of $\mathrm{K}^{+}$ions as compared to $\mathrm{Li}^{+}$ions 40 and the open structure of KVPF. In situ XRD measurements 41 revealed single-phase structural evolution while charging from 42 OCV to $4.8 \mathrm{~V}$ (Figure 12b). When charged till 5.0 V, a stable 43 discharge capacity of $80 \mathrm{mAh} \mathrm{g}^{-1}$ was observed with an average 44 redox potential of $4.13 \mathrm{~V}$. When $1 \mathrm{M} \mathrm{KPF}_{6}$ in EC:propylene 45 carbonate (PC) (1:1, v:v) was used as electrolyte, minimal ini- 46 tial capacity loss and a discharge capacity of $92 \mathrm{mAh} \mathrm{g}^{-1}$ was 47 observed. In contrast, Ceder group demonstrated the presence 48 of several biphasic reactions during potassium (de)intercala- 49 tion in KVPF. ${ }^{[214]}$ When cycled between 3 and $5 \mathrm{~V}$, four distinct 50 plateaus were observed, which was confirmed by the differen- 51 tial capacity plots (Figure 12c). A capacity of $105 \mathrm{mAh} \mathrm{g}^{-1}$ at a 52 nominal voltage of $4.33 \mathrm{~V}\left(\mathrm{vs} \mathrm{K} / \mathrm{K}^{+}\right.$) was observed. They studied 53 the structural evolution using ex-situ XRD and ab-initio calcula- 54 tions showing the formation of stable intermediate compounds 55 at $x=0.75,0.625$, and 0.5 . They also demonstrated that oxy- 56 genation of KVPF led to a more disordered structure along with 57 disappearance of plateaus. Partial substitution of fluorine by 58 oxygen was found to decrease the capacity and nominal voltage. 59 

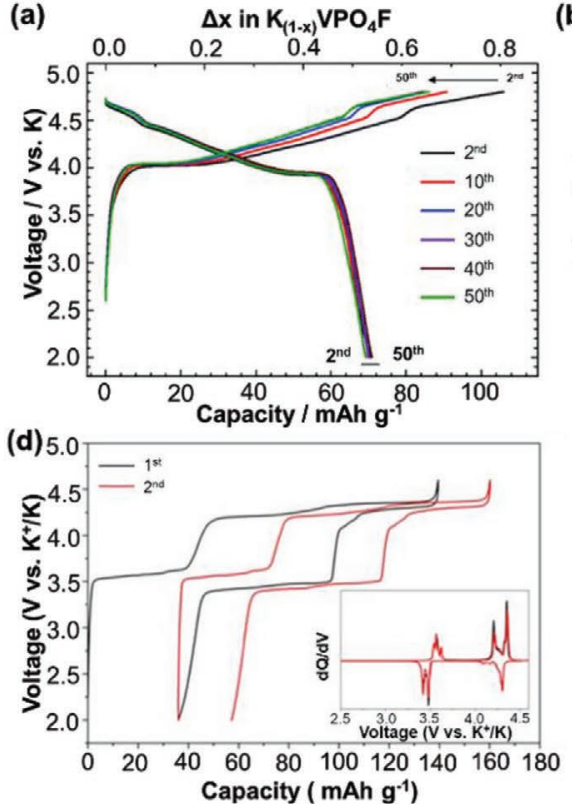

(b)

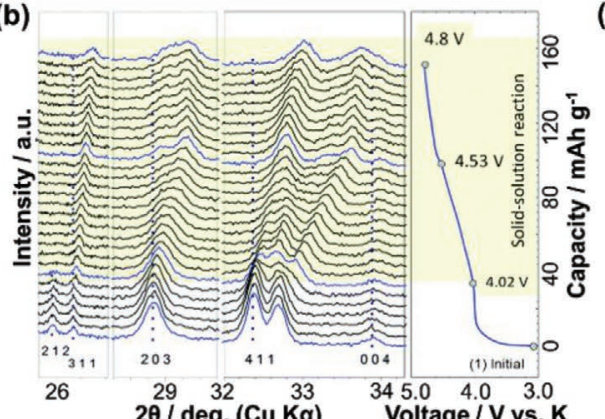

(e) (c)

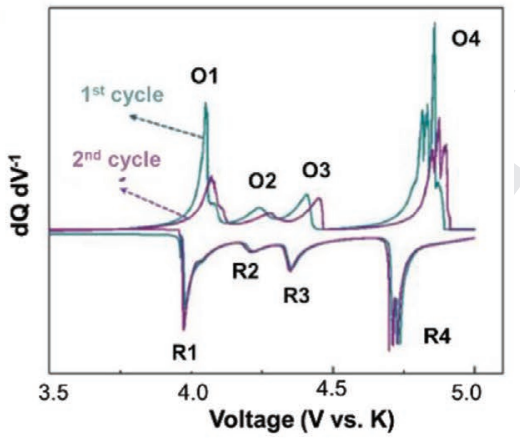

1 2 3 4 5 6 7 8 9 10 11

Recently, $\mathrm{K}_{3} \mathrm{~V}_{2}\left(\mathrm{PO}_{4}\right)_{2} \mathrm{~F}_{3}$ (K3VPF) phase was obtained by electrochemical ion exchange from $\mathrm{Na}_{3} \mathrm{~V}_{2}\left(\mathrm{PO}_{4}\right)_{2} \mathrm{~F}_{3} \cdot{ }^{[213]}$ It was found to crystallize in an orthorhombic structure with $\mathrm{Cmcm}$ space group. A potassium-based half-cell was assembled and it was charged up to $4.6 \mathrm{~V}$ to extract $\mathrm{Na}^{+}$ions. Upon progressive cycling, some structural change occurred in the material upon $\mathrm{K}$ intercalation leading to the switching of $\mathrm{K}^{+}$and $\mathrm{Na}^{+}$site and hence making all Na-sites accessible for (de)intercalation. The structural reorientation during subsequent cycling was also studied. On cycling between 2.0 and $4.6 \mathrm{~V}$, a discharge capacity of $104 \mathrm{mAh} \mathrm{g}^{-1}$ was obtained at $3.7 \mathrm{~V}$ versus $\mathrm{K}^{+} / \mathrm{K}$ at a current density of $10 \mathrm{~mA} \mathrm{~g} \mathrm{~g}^{-1}$ (Figure 12d). Structural variation was observed in fully charged and fully discharged samples using Rietveld refinement (Figure 12e). Full cell assembled using K3VPF cathode with graphite anode showed a $3.4 \mathrm{~V}$ KIB activity with stable performance. The recent developments in KIBs by utilizing fluorophosphates based host materials are very promising. At this nascent juncture, a variety of fluorophosphate chemistry, particularly isostructural to Na-based compositions, can be developed for high-voltage KIBs with due optimization in structure/morphology of cathodes, binders, and electrolytes.

\section{Electrocatalysis}

\subsection{Fluorophosphates as Electrocatalysts}

Existing intercalation-based battery technologies like LIBs and SIBs are not able to cope up with the ever-growing global energy demand. In the quest to achieve high energy density $\mathrm{O}_{2}-\mathrm{H}_{2} \mathrm{O}$ chemistry are widely being investigated to deliver high energy density compared to the existing state-of-the-art LIBs. ${ }^{[224]}$ For example, Li-air battery can deliver an energy

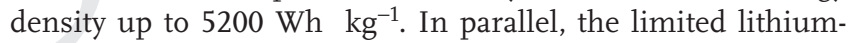
based mineral reserves, cost and safety have led to the emergence of sodium-air batteries. ${ }^{[225,226]}$ These storage systems hold promise for greener energy economy relying on electrochemical water splitting. Hydrogen evolution and oxidation (HER and HOR) as well as oxygen reduction and evolution (ORR and OER) are central redox processes for hydrogen production, fuel cells and metal-air batteries. While HER/HOR occurs at $E^{0}=0 \mathrm{~V}$ (vs RHE), ORR/OER need a catalyst to Metal-air batteries and fuel cells work on ORR and OER processes. ${ }^{[227-229]}$ Since both processes involve four-electron transfer mechanism with inherently sluggish kinetics, they require catalysts to overcome the activation barrier. This sector employs materials based on precious metals like platinum $(\mathrm{Pt})$, iridium (Ir), and ruthenium $(\mathrm{Ru})$. However, their practical usage is limited owing to their high cost, low abundance, stability, and the selective catalysis nature. ${ }^{[230]}$ While Pt/C is the best catalyst for ORR, Ir- and Ru-based oxides catalyze OER reaction effectively. OER and ORR reactions occur during the charging and discharging of metal-air batteries. Moreover, the performance of the metal-air battery in nonaqueous (organic) electrolyte is largely affected due to the formation of insoluble discharge products, which clog the active sites on the surface of electrode so as to reduce the net efficiency. This issue can be circumvented by using aqueous hybrid metal-air battery where the discharge products are soluble. ${ }^{[231]}$ Overall, these storage systems, rechargeable metal-air batteries based on overcome the overpotential to drive the reaction (Figure 13a). 
(a)

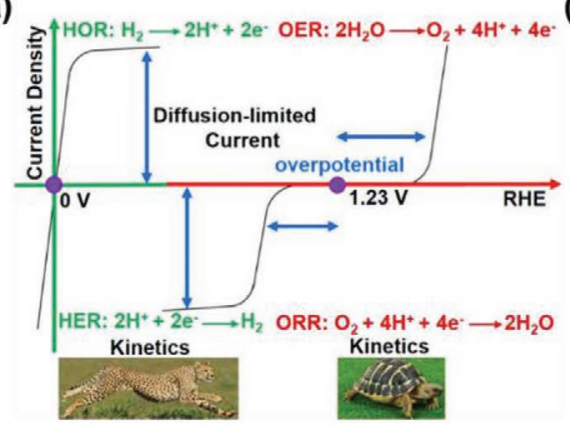

(d)

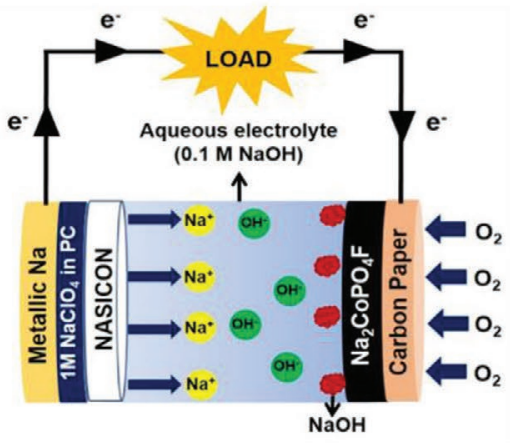

(b)

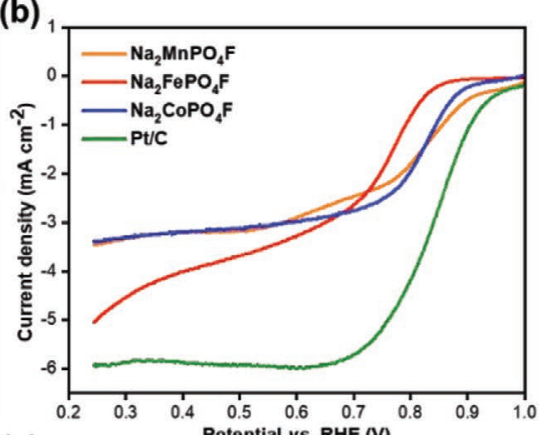

(e)

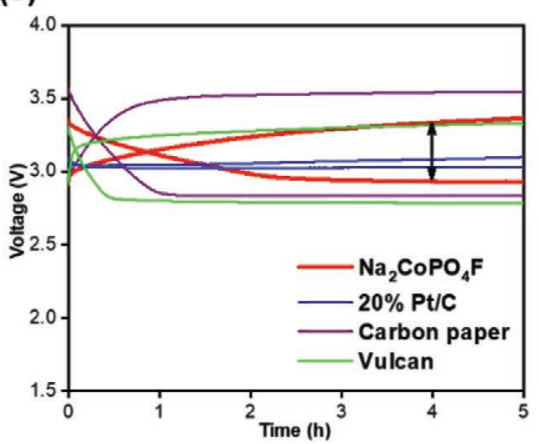

(c)

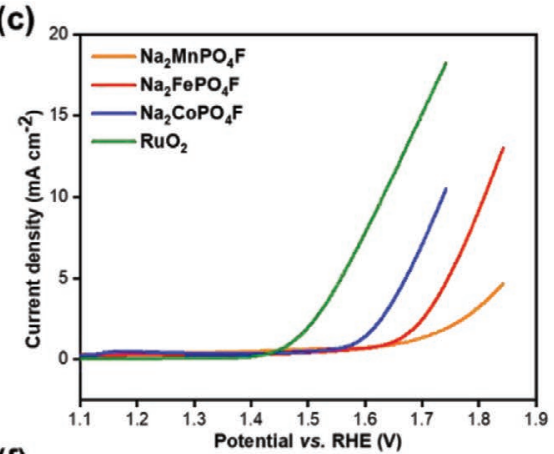

(f)

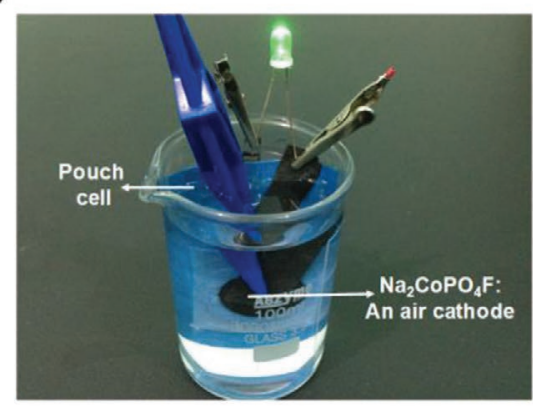

1

2

3

4

5

6

7

8

9

Figure 13. a) Schematic representation of polarization curves for $\mathrm{HER} / \mathrm{HOR}$ and ORR/OER along with the reactions involved. Green line indicates reac- 26 tion involving hydrogen while red line indicates for oxygen. b) Linear sweep voltammograms (LSV) for $\mathrm{Na}_{2} \mathrm{CoPO}_{4} \mathrm{~F}, \mathrm{Na}_{2} \mathrm{FePO}_{4} \mathrm{~F}, \mathrm{Na}_{2} \mathrm{MnPO}_{4} \mathrm{~F}$, and $20 \%$ $\mathrm{Pt} / \mathrm{C}$ recorded at $1600 \mathrm{rpm}$ in $0.1 \mathrm{M} \mathrm{KOH}$ electrolyte during ORR reaction. c) LSV plots of $\mathrm{Na}_{2} \mathrm{CoPO}_{4} \mathrm{~F}, \mathrm{Na}_{2} \mathrm{FePO}_{4} \mathrm{~F}, \mathrm{Na}_{2} \mathrm{MnPO}_{4} \mathrm{~F}$, and $\mathrm{RuO}_{2}$ recorded at $1600 \mathrm{rpm}$ in $0.1 \mathrm{M} \mathrm{KOH}$ electrolyte during OER reaction. d) Schematic diagram of hybrid Na-air battery. e) Comparison of NCPF as an air cathode with carbon-paper, Vulcan carbon and Pt/C. f) A practical demonstration to lit up an LED using the power withdrawn from hybrid Na-air battery utilizing the properties of $\mathrm{Na}_{2} \mathrm{CoPO}_{4} \mathrm{~F}$ as an air cathode.

metal-air batteries warrant the development of economic and bifunctional air cathodes.

At this juncture, various battery insertion materials have been investigated for their electrocatalytic properties. [227-229,231-244] Notably, transition metal-based phosphate compounds have shown promising bifunctional activity along with structural stability. Some such examples are Co-based phosphate $\left(\mathrm{NaCoPO}_{4}\right)$, pyrophosphate $\left(\mathrm{Na}_{2} \mathrm{CoP}_{2} \mathrm{O}_{7}\right)$ and metaphosphate $\left(\mathrm{NaCoP}_{3} \mathrm{O}_{9}\right)$. Inspired by efficient catalytic activity in these phosphates, Sharma et al. tested the electrocatalytic performance of fluorophosphate $\mathrm{Na}_{2} \mathrm{CoPO}_{4} \mathrm{~F}$ (NCPF) on ring rotating disc electrode using $0.1 \mathrm{M} \mathrm{NaOH}$ alkaline solution as electrolyte. ${ }^{[241,245]}$ For ORR, the $C V$ was recorded in the range of 0.1 to $-0.7 \mathrm{~V}$ versus $\mathrm{Hg} / \mathrm{HgO}$ in an $\mathrm{O}_{2}$ saturated electrolyte. The onset potential was found to be $0.903 \mathrm{~V}$ versus RHE with a current density of $3.4 \mathrm{~mA} \mathrm{~cm}$, which marks the promising ORR activity of NCPF. The stability of the material was also tested for $10 \mathrm{~h}$ with negligible current loss. The activity of NCPF system can be attributed to the extra structural stabilization imparted by $\mathrm{PO}_{4}$-group and the ionic nature in the bonds due to electronegative F-atoms. Following, the OER properties were tested in the voltage range of $0.0-0.8 \mathrm{~V}$ versus $\mathrm{Hg} / \mathrm{HgO}$ (later converted to RHE). An overpotential of $0.38 \mathrm{~V}$ versus RHE was observed with excellent current density. The efficient bifunctional activity in NCPF served as the motivation to test the electrocatalytic properties of whole fluorophosphate family. These fluorophosphates $\left(\mathrm{Na}_{2} \mathrm{MPO}_{4} \mathrm{~F}, \mathrm{M}\right.$ $=\mathrm{Fe} / \mathrm{Mn} / \mathrm{Co}$ ) were synthesized via solution combustion route leading to porous morphology and carbon coating favoring the 33 electronic conductivity and catalytic performance. The results 34 were benchmarked against 20\% Pt-C for ORR and $\mathrm{RuO}_{2}$ for 35 OER. An onset potential of 0.891 and $0.909 \mathrm{~V}$ was recorded for 36 $\mathrm{Na}_{2} \mathrm{FePO}_{4} \mathrm{~F}$ (NFPF) and $\mathrm{Na}_{2} \mathrm{MnPO}_{4} \mathrm{~F}$ (NMPF), respectively. The 37 ORR properties of fluorophosphates were comparable to $20 \% 38$ $\mathrm{Pt} / \mathrm{C}$ following an order of NCPF > NMPF > NFPF (Figure 13b). 39 While all three materials exhibited promising ORR activity, very 40 low current density was observed during OER with an over- 41 potential of 0.49 and $0.46 \mathrm{~V}$ (vs RHE) for NMPF and NFPF 42 respectively (Figure 13c). The OER activity can be attributed to 43 the tuned energy levels of the antibonding states of $\mathrm{M}-\mathrm{O}$ bonds 44 due to F-atoms. On a broader note, these fluorophosphates were 45 found to retain structural stability after prolonged ORR and 46 OER reaction. These polyanionic fluorophosphates form a new 47 class of economic and stable bifunctional electrocatalysts, with 48 $\mathrm{Na}_{2} \mathrm{CoPO}_{4} \mathrm{~F}$ delivering the best performance.

\subsection{Hybrid Na-Air Battery Fabrication}

The performance of hybrid metal-air batteries depends on 54 the air cathode, where fluorophosphates with bifunctional 55 ORR and OER activity can be a lucrative option. ${ }^{[246-248]}$ There- 56 fore, NCPF was tested as an air cathode for hybrid Na-air 57 battery. ${ }^{[245]}$ Schematic representation of hybrid Na-air battery 58 is illustrated in Figure 13d. The high ionic conductivity of $\mathrm{Na}^{+} 59$ 
1 in $\mathrm{Na}_{3} \mathrm{Zr}_{2} \mathrm{Si}_{2} \mathrm{PO}_{12}$ solid electrolyte combined with the high solu-

2 bility of discharged product resulted in high power density and

3 low overpotential. The complete redox reaction of the cell can

4 be summarized as follows

5

Anode $: \mathrm{Na}^{+}+\mathrm{e}^{-} \leftrightarrow \mathrm{Na}(\mathrm{s}) \quad E^{0}=-2.71 \mathrm{~V}$

Cathode $: \mathrm{O}_{2}+2 \mathrm{H}_{2} \mathrm{O}+4 \mathrm{e}^{-} \leftrightarrow 4 \mathrm{OH}^{-} \quad E^{0}=+0.40 \mathrm{~V}$

Stable charge and discharge voltages of 2.94 and $3.34 \mathrm{~V}$, respectively were recorded for 30 cycles with low overpotential. A round trip efficiency of $88 \%$ was observed showing comparable/superior performance than other reported air cathodes (Figure 13e,f). These preliminary results establish fluorophosphates as a new class of air-cathodes for rechargeable metal-air batteries.

\section{Perspectives}

The world is expected to see a massive growth in energy consumption in line with developments taking place in countries like India and China. In fact, the International Energy Agency estimates that India alone is likely to contribute $25 \%$ to the rise in global energy demand by 2040. To keep pace with this demand while committing to a net zero carbon emission energy system by 2050, the current energy mix that consists of over $92 \%$ fossil fuel sources needs to be aggressively transitioned toward renewable energy sources. It is widely recognized that large scale integration of renewables in the energy system mandates adequate energy storage solutions to overcome intermittency issues and to create a more robust and flexible electricity distribution system. Deploying adequate grid level energy storage is a key to break the constraint that the temporal variation in energy production rate needs to be matched by the energy consumption rate. The energy reservoir can absorb extra energy produced when demand is low and provide that energy when production is low. Such flexibility can also help with energy arbitrage, i.e., to purchase energy when demand/cost is low. Energy storage also has the potential to transform the energy distribution landscape by enabling microgrids, where individual homes, apartment buildings, universities and townships having their own energy ecosystem with a customized mix of generation, storage and immunity to power disruption. Microgrids help since the source of the problem can be easily isolated from the network. Energy storage technology is also an enabler for electric mobility that could eliminate dependency on imported oil.

In many ways, the fossil fuel based to renewables energy transition is critically dependent on access to inexpensive and reliable energy storage technology. So, what would it take to achieve the goal of making widespread deployment of energy storage technology a reality? Until now lithium-ion batteries (LIBs) have dominated energy storage technology, primarily driven by the portable electronics market. However, as demand for energy storage for electric vehicles (EV) and grid level storage applications grow, it is expected to put a severe pressure on the supply chain of raw materials used for LIBs. First of all, even though there may be enough lithium reserves in 1 the world to cater to the global energy storage needs, lithium 2 is highly unevenly distributed with over $75 \%$ of lithium situ- 3 ated in few countries like Bolivia, Chile, China, Argentina, 4 and Australia. More critically, a majority $(\approx 60 \%)$ of the cobalt 5 (Co) used in LIB cathode comes from Democratic Republic of 6 Congo. Future expansion of LIB market is expected to be ham- 7 pered by the limited supply of Li and Co. Thus, there is a great 8 risk to the expansion of the energy storage market solely based on LIB technology since availability of both $\mathrm{Li}$ and Co may be constrained by geopolitical issues. To avoid these issues world needs to look beyond the state-of-the-art lithium-ion battery technology. In fact, as different storage applications pose different requirements, it is imperative that varieties of battery technologies are available. In all these applications, however, the common requirements are that the storage technology be inexpensive, safe and have long operational time. For example, for grid scale applications, a price point of $\$ 100 \mathrm{kWh}^{-1}$ and a service life of 10000 cycles/10 years is a target that makes integration of energy storage very attractive. For EV application, specific energy target of $300 \mathrm{Wh} \mathrm{kg}^{-1}$ (at the cell level) is an additional important consideration.

The promising alternatives begin with replacing Co based cathodes in current LIBs with Co free cathode materials. Further along, sodium intercalation-based chemistries, even though not as energy dense as LIBs, are very promising for grid level storage applications since they can be very cost competitive, as both sodium and the sodium intercalation materials for use in cathodes are earth abundant. Polyanionic cathode materials for LIBs and SIBs considered in this review represent these two approaches, respectively. Before we provide a more detailed account of the chemistries involved, it is worthwhile to compare different cathode materials with respect to their energy densities. The voltage versus specific capacity and specific versus volumetric energy density plots of polyanionic cathode materials for LIBs and SIBs with conventional cathode materials are compared (Figure 14a,b). It can be noted that the relatively high standard redox potential of $\mathrm{Na} / \mathrm{Na}^{+}$leads to a lower working voltage for sodium-based materials as compared to lithium-based materials.

The energy storage technology of choice from economic and environmental point of view is highly application-dependent. ${ }^{[249]}$ Energy storage technologies are evaluated on different performance parameters and no single technology excels on all. The key performance parameters, which are important in the analysis of alternative battery chemistries are: energy density, power density, round trip efficiency (RTE), cycle life and cost. ${ }^{[250]}$ While the stringent requirements on power and energy densities encountered in electric vehicles and consumer electronics applications are significantly relaxed in stationary storage applications, they still determine the storage system's real estate footprint. Thus, it is desirable to have reasonably high volumetric energy densities without increasing the cost of storage. The round-trip efficiency takes into account energy losses from power conversion and is important determinant of operating cost of an energy storage system. ${ }^{[251]}$ On the other hand, cost and cycle life determine the capital expenditure involved in setting up the storage system. For typical stationary storage applications, assuming one or two cycles per day, 3650-7300

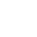

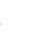

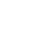

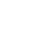
. 

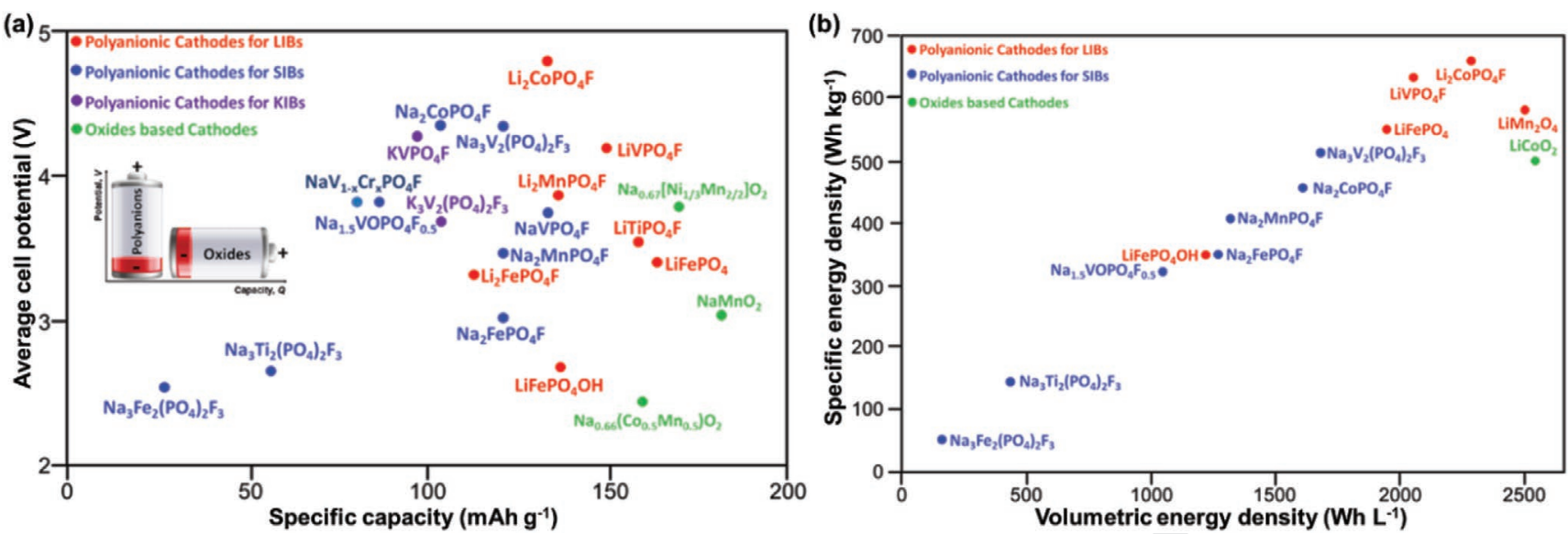

Figure 14. a) Potential versus specific capacity plot for different fluorophosphate cathode materials. b) Comparison of specific energy versus volumetric energy density of fluorophosphate cathodes with selected commercialized $\mathrm{LIB}$ cathodes (e.g., $\mathrm{LiCoO}_{2}$ ).

to lifetime cycles would be adequate to allow for a 10 -year operation. Before we analyze different fluorophosphate-based cathodes, it is worthwhile to note how existing battery energy storage technologies fare, as a reference. For example, Tesla's powerwall is a Li-ion based system with an RTE of $92 \%$, a cost of $\$ 350 \mathrm{kWh}^{-1}$ and a cycle life of 10000 . In contrast, the EOS Aurora is a zinc hybrid cathode-based system with 75\% RTE, a cost of $\$ 160 \mathrm{kWh}^{-1}$ and a cycle life of $5000 .^{[252]}$

The performance metrics of six key fluorophosphate battery chemistries were compared on the basis of their cyclability as tabulated in Table 2. Lithium-ion batteries that contained $\mathrm{LiVPO}_{4} \mathrm{~F}, \mathrm{LiFePO}_{4} \mathrm{~F}$, and sodium-ion batteries that comprised $\mathrm{NaVPO}_{4} \mathrm{~F}, \mathrm{Na}_{2} \mathrm{FePO}_{4} \mathrm{~F}, \mathrm{Na}_{3} \mathrm{~V}_{2}\left(\mathrm{PO}_{4}\right)_{2} \mathrm{~F}_{3}$ were used for the analysis. It is interesting to note that all six chemistries considered have $>90 \%$ RTE, with $\mathrm{Na}_{3} \mathrm{~V}_{2}\left(\mathrm{PO}_{4}\right)_{2} \mathrm{~F}_{3}$ having the highest value. Energy storage technologies based on these cathodes would thus be more efficient than most incumbent storage technologies that have RTE in the range of $70-85 \%$. The fact that running cost savings are directly proportional to RTE is an important consideration during selection of an appropriate storage technology. The cost metric provides an indication of how attractive the material is from the cost point of view and a higher value indicates lower cost per unit energy stored. It is important to note that Fe-based cathode materials have the lowest cost in terms of capital expenditure. Further, all these fluorophosphates are capable of reversible cycling over 3000 cycles while retaining $80 \%$ capacity.

Any analysis of the alternative battery chemistries from a commercialization perspective is not complete without a discussion about the ease of manufacturability and scale-up. 20 Generally, vanadium based materials are synthesized by solid- 21 state route which involves synthesis of vanadium phosphate 22 $\left(\mathrm{VPO}_{4}\right)$ precursor that is then utilized in further steps to obtain 23 the final products. Form manufacturability point of view, such 24 synthesis procedure adds additional steps that amounts to 25 additional energy and time consumption. Vanadium toxicity 26 further makes the commercialization of V-based products dif- 27 ficult. On the other hand, materials like $\mathrm{Na}_{2} \mathrm{FePO}_{4} \mathrm{~F}$ can be 28 synthesized using one-step method, which can be more readily 29 scaled to yield material in bulk quantities. One-minute syn- 30 thesis of $\mathrm{Na}_{2} \mathrm{FePO}_{4} \mathrm{~F}$ is also reported with good electrochemical 31 activity. ${ }^{[198]}$ Iron is present in abundance inside earth's crust 32 which implies relatively cheaper iron-based precursors. From 33 the safety point of view as well, use of flammable organic 34 electrolytes can be dangerous specially during short-circuiting 35 or over charging. With this idea, $\mathrm{Na}_{2} \mathrm{FePO}_{4} \mathrm{~F}$ was tested in 36 aqueous electrolytes as well. ${ }^{[210]}$ It exhibited excellent electro- 37 chemical activity. The excellent electrochemical performance of 38 $\mathrm{Na}_{2} \mathrm{FePO}_{4} \mathrm{~F}$ in aqueous electrolytes coupled with energy-savvy 39 and economical synthesis and elemental abundance of $\mathrm{Na} 40$ (with respect to Li) makes it a strong candidate among fluoro- 41 phosphates for possible commercialization targeting stationary 42 storage applications.

To facilitate the rapid commercialization of fluorophosphate 44 based batteries for stationary energy storage applications, we 45 identify a roadmap with the following key research and devel- 46 opment themes: 1) Analysis of alternate material choices for 47 cathode: given the vast choice of fluorophosphate based cathode 48

Table 2. Cyclablity of different materials chosen to study their future perspective as reported in literature.

\begin{tabular}{|c|c|c|c|c|c|}
\hline Material & Theoretical capacity $\left[\mathrm{mAh} \mathrm{g}^{-1}\right]$ & Experimental capacity $\left[\mathrm{mAh} \mathrm{g}^{-1}\right]$ & C-rate & \% Capacity retention [cycles] & Reference \\
\hline $\mathrm{LiVPO}_{4} \mathrm{~F}$ & 156 & 126 & $1 \mathrm{C}$ & $90(1000)$ & [79] \\
\hline $\mathrm{LiFePO}_{4} \mathrm{~F}$ & 152 & 128 & $1 \mathrm{C}$ & $71(100)$ & [97] \\
\hline $\mathrm{NaVPO}_{4} \mathrm{~F}$ & 142.6 & 100 & $5 C$ & $70(2500)$ & [135] \\
\hline $\mathrm{Na}_{2} \mathrm{FePO}_{4} \mathrm{~F}$ & 124.2 & 66.8 & $4 C$ & $84.7(1000)$ & [192] \\
\hline $\mathrm{Na}_{3} \mathrm{~V}_{2}\left(\mathrm{PO}_{4}\right)_{2} \mathrm{~F}_{3}$ & 128.2 & 102 & $10 \mathrm{C}$ & $90(2000)$ & [154] \\
\hline
\end{tabular}


materials, a critical comparison of energy and power capabilities, cost, cycle stability, depth of discharge (DoD), round trip efficiency and safety is necessary to make informed choice for a given application. For example, an energy storage solution used for resiliency (support large but short duration power demand due to disruption) versus energy storage solution used in renewable systems (require longer cycle duration batteries with large capacities) have different demands. The availability of a detailed analysis of what each cathode system is capable of would help make the right choice for a specific application. Such efforts should be focused on analysis of these materials considering practical realization of large format batteries and not restricted to coin cells. 2) Identification of high performance and electrochemically stable electrolytes that work efficiently with fluorophosphate materials. In addition to organic electrolytes, this effort should also entail formulating aqueous electrolytes that improve cost effectiveness and environmental benefits. It is important to find electrolytes that form thin and stable solid electrolyte interface (SEI) to minimize cell resistance and degradation. Additionally, effort is needed to ensure that electrolytes exhibit high conductivity and $\mathrm{Li}^{+}$or $\mathrm{Na}^{+}$ion transference number, which is critical in keeping the cell impedance low. Further, the cathode material should be stable against surface degradation during cycling in the given electrolyte environment. 3) Robust multiphysics based modeling tools for cell design provide device engineering capabilities to meet performance targets (e.g., for energy, power, and cyclability). For example, active material volume fraction, electrode thickness, electrolyte loading, binder volume fraction together affects power and energy densities of a cell and the performance dependence on these cell design parameters is highly nonintuitive. Robust and efficient battery modeling tools can provide powerful platforms to quickly iterate on design choices to arrive at optimal design as opposed to a time consuming iterative experimental only design process. Some such tools are electrochemical thermal models based on pseudo-2D approach or reduced order models (ROM) coupled with optimization algorithms and design realization. Additionally, these models can also help in determining round trip efficiency, achievable DoD, power and energy densities as well as assessing degradation and cycle life. 4) Finally, manufacturability should be an important consideration while developing fluorophosphate cathode materials. It is important to develop low-cost, scalable and environmentally friendly processes to ensure fast commercialization.

\section{Summary}

Although LIBs dominate the portable electronics market, SIBs and KIBs can be expected to play an important role in futuristic grid-level storage. Substantial development has taken place in developing new electrode materials for SIB sans KIBs in the last two decades. With the goal of having a material that is cost effective, safe, and energy dense (both high energy and high power density), a gradual shift from oxide-based materials to polyanionic materials has been taking place since the discovery of $\mathrm{LiFePO}_{4}$. While oxides deliver high capacity, the polyanions exhibit high tunable redox potential with an added advantage of high structural and thermal stability. The versatility in terms of anion substitution opens the gateway to optimize the materials for specific types of applications. Fluorine, when coupled with other anionic groups changes the chemistry substantially. Thus, the last decade has seen a booming rise in the research activity on fluorophosphates. The electronegativity of F-atom coupled with inductive effect of phosphate group increases the highest occupied molecular orbital (HOMO)-lowest unoccupied molecular orbital (LUMO) gap of central metal ion and hence increases the redox voltage. Most of the materials exhibit $3 \mathrm{D}$ pathways for ion diffusion. Materials like $\mathrm{Na}_{3} \mathrm{~V}_{2}\left(\mathrm{PO}_{4}\right)_{2} \mathrm{~F}_{3}$ and $\mathrm{Na}_{2} \mathrm{FePO}_{4} \mathrm{~F}$ exhibit high redox potential and good cyclability. Hence, we come across many full-cell based reports with good capacity and cyclability. Several fluorophosphates have also been studied in aqueous electrolytes to design economic aqueous batteries.

Fluorophosphates can also act as bifunctional electrocatalysts to realize efficient oxygen electrolysis (ORR-OER) reactions, which can be employed in (hybrid) metal-air batteries. The electrochemical activity of fluorophosphates can be improved by various strategies like ion-doping, carbon-coating, and morphology engineering. The activity can further be improved by adding suitable additives like FEC in the electrolytes in order to avoid their decomposition and SEI formation. While the vanadium-based materials can deliver high energy density, they have limited commercialization due to the toxicity of vanadium. The bottleneck for Co-based materials is the high cost of Co-based precursors. In comparison, the Ni-based materials exhibit high redox potentials, but the available electrolytes tend to decompose at higher potentials, which is an area that will require significant research in the future. The Fe-based materials are safe and cost effective due to relatively lower cost of the precursors. However, the facile oxidation of $\mathrm{Fe}^{2+}$ to $\mathrm{Fe}^{3+}$ warrants careful synthesis and material storage. Mn-based materials can offer high voltage but suffers from high polarization during cycling. Needless to say, all the materials have to be studied individually by optimizing various parameters in order to utilize the full capacity of these materials. This review is an attempt to summarize the structural and electrochemical performances of the fluorophosphates reported till date for secondary batteries. Overall, there are some challenges to be addressed in future in order to inch toward commercialization. Since most of the fluorophosphate based cathode materials exhibit high redox potential, a major challenge is to develop high voltage electrolytes capable to cycle the batteries at higher voltages enabling the activity of other available metal redox centres and increasing the energy density of the battery. The electrolyte stability can be improved either by using different solvents like dinitrile-based solvent or by adding suitable additives. Without any doubt, fluorophosphate cathodes exhibit huge potential to address the energy crisis issues at large scale level, i.e., grid storage, but more full-cell battery prototypes need to be fabricated and studied for the cycle life and stability. High temperature battery testing should also be carried out in order to see the effect of temperature on the performance. The review also pave ways for discovery and development of other fluorophosphate chemistry for (non)aqueous and metal-air batteries. Moreover, fluorophosphates can be extended to aqueous zinc battery applications. Aqueous zinc-ion batteries have witnessed a huge 3 4 5 6 7 
uprise in terms of research recently and is considered to be important candidates for grid scale energy storage due to safety and low cost. Using water-in-bisalt aqueous electrolytes, fluorophosphate materials can be tested for aqueous ( $\mathrm{Li} / \mathrm{Na} / \mathrm{Zn}$ ) battery applications. On a broader note, alkali metal fluorophosphate forms a niche class of polyanionic electrode materials exhibiting rich material chemistry, structural diversity, chemical/thermal stability coupled with robust electrochemical and electrocatalytic activities, suitable for insertion-type and metalair batteries. Some selected fluorophosphates can be close to commercialization in near future particularly targeting the stationary grid storage applications.

\section{Acknowledgements}

The first author is grateful to the Ministry of Human Resource Development (Govt. of India) for a doctorate fellowship. He also thanks the Electrochemical Society (ECS, USA) for a 2020 ECS Summer Fellowship. P.B. acknowledges the financial support from the Technology Mission Division (Department of Science and Technology, Govt. of India) under the Materials for Energy Storage (MES-2018) program (DST/TMD/MES/2k18/207). Research reported in this publication was partially supported by King Abdullah University of Science and Technology (KAUST). The material structures were illustrated using VESTA software. ${ }^{[253]}$

\section{Conflict of interest}

The authors declare no conflict of interest.

\section{Keywords}

batteries, capacity, cathodes, electrocatalysis, fluorophosphates, polyanions

Received: April 28, 2020

Revised: June 11, 2020 Published online:

[1] V. Etacheri, R. Marom, R. Elazari, G. Salitra, D. Aurbach, Energy Environ. Sci. 2011, 4, 3243.

[2] Y. Wang, B. Liu, Q. Li, S. Cartmell, S. Ferrara, Z. D. Deng, J. Xiao, J. Power Sources 2015, 286, 330.

[3] D. Larcher, J.-M. Tarascon, Nat. Chem. 2015, 7, 19.

[4] B. Scrosati, Electrochim. Acta 2000, 45, 2461.

[5] N. Nitta, F. Wu, J. T. Lee, G. Yushin, Mater. Today 2015, 18, 252.

[6] M. D. Slater, D. Kim, E. Lee, C. S. Johnson, Adv. Funct. Mater. 2013, 23, 947.

[7] N. Yabuuchi, K. Kubota, M. Dahbi, S. Komaba, Chem. Rev. 2014, $114,11636$.

[8] J.-Y. Hwang, S.-T. Myung, Y.-K. Sun, Chem. Soc. Rev. 2017, 46, 3529.

[9] C. Vaalma, D. Buchholz, M. Weil, S. Passerini, Nat. Rev. Mater. 2018, 3, 18013

[10] K. Kubota, S. Komaba, J. Electrochem. Soc. 2015, 162, A2538.

[11] P. Barpanda, Chem. Mater. 2016, 28, 1006.

[12] A. Manthiram, J. B. Goodenough, J. Power Sources 1989, 26, 403.

[13] A. K. Padhi, V. Manivannan, J. B. Goodenough, J. Electrochem. Soc. $1998,145,1518$.
[14] P. Barpanda, L. Lander, S. Nishimura, A. Yamada, Adv. Energy 1 Mater. 2018, 8, 1703055

[15] C. Masquelier, L. Croguennec, Chem. Rev. 2013, 113, 6552

[16] B. Senthilkumar, C. Murugesan, L. Sharma, S. Lochab, 4 P. Barpanda, Small Methods 2019, 3, 1800253.

[17] J. Barker, M. Y. Saidi, J. L. Swoyer, J. Electrochem. Soc. 2003, 150, A1394.

[18] B. L. Ellis, W. R. M. Makahnouk, Y. Makimura, K. Toghill, 7 L. F. Nazar, Nat. Mater. 2007, 6, 749.

[19] N. Recham, J.-N. Chotard, L. Dupont, K. Djellab, M. Armand, 9 J.-M. Tarascon, J. Electrochem. Soc. 2009, 156, A993.

[20] Y. Lu, S. Zhang, Y. Li, L. Xue, G. Xu, X. Zhang, J. Power Sources 11 2014, 247, 770.

[21] J. Barker, R. K. B. Gover, P. Burns, A. Bryan, M. Y. Saidi, J. L. Swoyer, J. Power Sources 2005, 146, 516.

[22] R. K. B. Gover, A. Bryan, P. Burns, J. Barker, Solid State lonics 2006, 177, 1495.

[23] H. Kim, J. Hong, K.-Y. Park, H. Kim, S.-W. Kim, K. Kang, Chem. Rev. 2014, 114, 11788.

[24] W. Li, J. R. Dahn, D. S. Wainwright, Science 1994, 264, 1115.

[25] J. Köhler, H. Makihara, H. Uegaito, H. Inoue, M. Toki, Electrochim. Acta 2000, 46, 59

[26] G. X. Wang, S. Zhong, D. H. Bradhurst, S. X. Dou, H. K. Liu, 21 J. Power Sources 1998, 74, 198.

[27] W. Li, J. R. Dahn, J. Electrochem. Soc. 1995, 142, 1742.

[28] X.-H. Liu, T. Saito, T. Doi, S. Okada, J. Yamaki, J. Power Sources 24 2009, 189, 706

[29] K. Mizushima, P. C. Jones, P. J. Wiseman, J. B. Goodenough, Mater. Res. Bull. 1980, 15, 783.

[30] M. Guilmard, C. Pouillerie, L. Croguennec, C. Delmas, Solid State 27 Ionics 2003, 160, 39

[31] T. Ohzuku, Y. Makimura, Chem. Lett. 2001, 30, 642.

32] Z Lu, D. D. MacNeil, I. R. Dahn, Electrochem. Solid-State Lett. 30 2001, 4, A191.

[33] M. M. Thackeray, C. S. Johnson, I. T. Vaughey, N. Li, S. A. Hackney, J. Mater. Chem. 2005, 15, 2257. C. Delmas, F. Cherkaoui, A. Nadiri, P. Hagenmuller, Mater. Res. 34 Bull. 1987, 22, 631.

[35] C. Delmas, A. Nadiri, Mater. Res. Bull. 1988, 23, 65.

[36] C. Delmas, A. Nadiri, J. L. Soubeyroux, Solid State lonics 1988, 28-30, 419.

[37] N. Ravet, J. B. Goodenough, S. Besner, M. Simoneau, 38 P. Hovington, M. Armand, presented at Proc. of 196th Meeting of 39 the Electrochemical Society, Honolulu, HI, 1999, Abstract 127.

[38] N. Ravet, Y. Chouinard, J. F. Magnan, S. Besner, M. Gauthier, 41 M. Armand, J. Power Sources 2001, 97-98, 503.

[39] H. Huang, S.-C. Yin, L. F. Nazar, Electrochem. Solid-State Lett. 43 2001, 4, A170.

[40] A. Yamada, S.-C. Chung, K. Hinokuma, J. Electrochem. Soc. 2001, 148, A224.

[41] S. Franger, F. Le Cras, C. Bourbon, H. Rouault, Electrochem. SolidState Lett. 2002, 5, A231.

[42] P. P. Prosini, D. Zane, M. Pasquali, Electrochim. Acta 2001, 46, 48 3517.

[43] F. Croce, A. d'Epifanio, J. Hassoun, A. Deptula, T. Olczac, 50 B. Scrosati, Electrochem. Solid-State Lett. 2002, 5, A47.

[44] C. Delacourt, P. Poizot, S. Levasseur, C. Masquelier, Electrochem. 52 Solid-State Lett. 2006, 9, A352.

[45] V. Legagneur, Y. An, A. Mosbah, R. Portal, A. L. G. La Salle, A. Verbaere, D. Guyomard, Y. Piffard, Solid State lonics 2001, 139, 37.

[46] M. Armand, C. Michot, N. Ravet, M. Simoneau, P. Hovington, US Patent 6085015, 2000

[47] A. Nytén, A. Abouimrane, M. Armand, T. Gustafsson, 58 J. O. Thomas, Electrochem. Commun. 2005, 7, 156. .

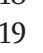

\section{.} 年 要 18 20 (12) 22

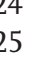

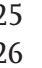

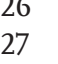

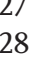

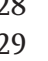
30

\section{(1)} .

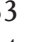
35 36 . 38 两 
[48] S. Nishimura, M. Nakamura, R. Natsui, A. Yamada, J. Am. Chem. Soc. 2010, 132, 13596.

[49] H. Zhou, S. Upreti, N. A. Chernova, G. Hautier, G. Ceder, M. S. Whittingham, Chem. Mater. 2011, 23, 293.

[50] H. Kim, S. Lee, Y.-U. Park, H. Kim, J. Kim, S. Jeon, K. Kang, Chem. Mater. 2011, 23, 3930.

[51] A. K. Padhi, K. S. Nanjundaswamy, C. Masquelier, S. Okada, J. B. Goodenough, J. Electrochem. Soc. 1997, 144, 1609.

[52] J. Barker, M. Y. Saidi, J. L. Swoyer, Electrochem. Solid-State Lett. 2003, 6, A1.

[53] H. Huang, T. Faulkner, J. Barker, M. Y. Saidi, J. Power Sources 2009, $189,748$.

[54] J.-M. Le Meins, M.-P. Crosnier-Lopez, A. Hemon-Ribaud, G. Courbion, J. Solid State Chem. 1999, 148, 260.

[55] J. Barker, M. Y. Saidi, J. L. Swoyer, J. Electrochem. Soc. 2004, 151, A1670.

[56] J. Barker, R. K. B. Gover, P. Burns, A. Bryan, Electrochem. SolidState Lett. 2005, 8, A285.

[57] J. Barker, R. K. B. Gover, P. Burns, A. Bryan, M. Y. Saidi, J. L. Swoyer, J. Electrochem. Soc. 2005, 152, A1776.

[58] B. L. Ellis, T. N. Ramesh, L. J. M. Davis, G. R. Goward, L. F. Nazar, Chem. Mater. 2011, 23, 5138.

[59] J.-M. Ateba Mba, C. Masquelier, E. Suard, L. Croguennec, Chem. Mater. 2012, 24, 1223.

[60] R. J. Messinger, M. Ménétrier, E. Salager, A. Boulineau, M. Duttine, D. Carlier, J.-M. Ateba Mba, L. Croguennec, C. Masquelier, D. Massiot, Chem. Mater. 2015, 27, 5212.

[61] J. Barker, M. Y. Saidi, R. K. B. Gover, P. Burns, A. Bryan, J. Power Sources 2007, 174, 927.

[62] C. H. Chen, J. Liu, M. E. Stoll, G. Henriksen, D. R. Vissers, K. Amine, J. Power Sources 2004, 128, 278.

[63] Y. Jang, B. Huang, H. Wang, D. R. Sadoway, G. Ceder, Y. Chiang, H. Liu, H. Tamura, J. Electrochem. Soc. 1999, 146, 862.

[64] G. Ceder, Y.-M. Chiang, D. R. Sadoway, M. K. Aydinol, Y.-I. Jang, B. Huang, Nature 1998, 392, 694.

[65] Y.-I. Jang, B. Huang, H. Wang, G. R. Maskaly, G. Ceder, D. R. Sadoway, Y.-M. Chiang, H. Liu, H. Tamura, J. Power Sources 1999, 81-82, 589.

[66] L. S. Plashnitsa, E. Kobayashi, S. Okada, J. Yamaki, Electrochim. Acta 2011, 56, 1344.

[67] F. Zhou, X. Zhao, J. R. Dahn, Electrochem. Commun. 2009, 11, 589.

[68] K. Cui, S. Hu, Y. Li, J. Power Sources 2016, 325, 465.

[69] Z. Yu, L. Jiang, Solid State lonics 2016, 291, 20.

[70] Y. Wang, H. Zhao, Y. Ji, L. Wang, Z. Wei, Solid State lonics 2014, $268,169$.

[71] Z. Liu, W. Peng, Y. Fan, X. Li, Z. Wang, H. Guo, J. Wang, J. Alloys Compd. 2015, 639, 496.

[72] J. Wang, X. Li, Z. Wang, B. Huang, Z. Wang, H. Guo, J. Power Sources 2014, 251, 325.

[73] J. Wang, Z. Liu, G. Yan, H. Li, W. Peng, X. Li, L. Song, K. Shih, J. Power Sources 2016, 329, 553.

[74] Z. Liu, W. Peng, Z. Xu, K. Shih, J. Wang, Z. Wang, X. Lv, J. Chen, X. Li, ChemSusChem 2016, 9, 2122.

[75] X. Lv, Z. Xu, J. Li, J. Chen, Q. Liu, J. Alloys Compd. 2016, 681, 253.

[76] H. Yan, X. Wu, Y. Li, Electrochim. Acta 2015, 182, 437.

[77] E. V. Antipov, N. R. Khasanova, S. S. Fedotov, IUCrJ 2015, 2, 85.

[78] Y. Liu, Y. Xu, X. Sun, Funct. Mater. Lett. 2013, 06, 1350053.

[79] X. Sun, Y. Xu, M. Jia, P. Ding, Y. Liu, K. Chen, J. Mater. Chem. A 2013, 1, 2501.

[80] J. Wang, X. Li, Z. Wang, H. Guo, Y. Li, Z. He, B. Huang, J. Alloys Compd. 2013, 581, 836.

[81] Z. Peng, Z. Gan, K. Du, Y. Cao, X. Xie, Y. Wang, Y. Li, G. Hu, J. Alloys Compd. 2018, 730, 261.

[82] X. Sun, Y. Xu, G. Chen, P. Ding, X. Zheng, Solid State lonics 2014, $268,236$.
[83] X. Lv, Z. Xu, J. Li, J. Chen, Q. Liu, J. Solid State Chem. 2016, 239, 1 228.

[84] Y. Shi, J. Luo, R. Wang, J. Zhao, Q. Xie, Solid State lonics 2018, 327, 71.

[85] X. Yang, X. Wang, K. Wang, G. Chang, Ceram. Int. 2018, 44, 3825.

[86] J. Wu, Y. Xu, X. Sun, C. Wang, B. Zhang, J. Zhao, J. Power Sources 2018, 396, 155.

[87] J.-M. A. Mba, L. Croguennec, N. I. Basir, J. Barker, C. Masquelier, J. Electrochem. Soc. 2012, 159, A1171.

[88] Y. Piao, Y. Qin, Y. Ren, S. M. Heald, C. Sun, D. Zhou, B. J. Polzin, S. E. Trask, K. Amine, Y. Wei, Phys. Chem. Chem. Phys. 2014, 16, 3254.

[89] M. Bianchini, J. M. Ateba-Mba, P. Dagault, E. Bogdan, D. Carlier, E. Suard, C. Masquelier, L. Croguennec, J. Mater. Chem. A 2014, 2, 10182.

[90] S.-C. Yin, P. S. Herle, A. Higgins, N. J. Taylor, Y. Makimura, L. F. Nazar, Chem. Mater. 2006, 18, 1745.

[91] J. R. Long, L. S. McCarty, R. H. Holm, J. Am. Chem. Soc. 1996, 118, 4603.

[92] Y. Makimura, L. S. Cahill, Y. Iriyama, G. R. Goward, L. F. Nazar, Chem. Mater. 2008, 20, 4240.

[93] L. S. Cahill, Y. Iriyama, L. F. Nazar, G. R. Goward, J. Mater. Chem. 2010, 20, 4340.

[94] J. Barker, M. Y. Saidi, J. Swoyer, US Patent 6,528,033 2003.

[95] N. Recham, J.-N. Chotard, J.-C. Jumas, L. Laffont, M. Armand, J.-M. Tarascon, Chem. Mater. 2010, 22, 1142.

[96] T. N. Ramesh, K. T. Lee, B. L. Ellis, L. F. Nazar, Electrochem. Solid-State Lett. 2010, 13, A43.

[97] D. Chen, G.-Q. Shao, B. Li, G.-G. Zhao, J. Li, J.-H. Liu, Z.-S. Gao, H.-F. Zhang, Electrochim. Acta 2014, 147, 663.

[98] M. Prabu, M. V. Reddy, S. Selvasekarapandian, G. V. S. Rao, B. V. R. Chowdari, Electrochim. Acta 2012, 85, 572.

[99] H. Y. Asl, A. Choudhury, RSC Adv. 2014, 4, 37691.

[100] N. Goubard-Bretesché, E. Kemnitz, N. Pinna, Chem. - Eur. J. 2019, $25,6189$.

[101] S. H. Fan, G. Q. Shao, C. Zhu, F. F. Ma, J. W. Mao, A. L. Zhang, G. Z. Xie, J. L. Yan, Y. Zhang, Electrochim. Acta 2018, 280, 248.

[102] J.-L. Yan, G.-Q. Shao, S.-H. Fan, C. Zhu, Y. Zhang, J. Wang, Q. Liu, Molecules 2019, 24, 1893.

[103] P. Rangaswamy, G. S. Suresh, M. K. Mahadevan, ChemistrySelect 2016, 1, 1472 .

[104] P. Rangaswamy, G. S. Suresh, M. M. Kittappa, J. Solid State Electrochem. 2016, 20, 2619.

[105] I. M. Singh, I. B. Singh, M. Willert-Porada, Int. J. Eng. Sci. Technol. 2016, 5, 686.

[106] B. L. Ellis, T. N. Ramesh, W. N. Rowan-Weetaluktuk, D. H. Ryan, L. F. Nazar, J. Mater. Chem. 2012, 22, 4759.

[107] N. R. Khasanova, O. A. Drozhzhin, D. A. Storozhilova, C. Delmas, E. V. Antipov, Chem. Mater. 2012, 24, 4271.

[108] O. M. Karakulina, N. R. Khasanova, O. A. Drozhzhin, A. A. Tsirlin, J. Hadermann, E. V. Antipov, A. M. Abakumov, Chem. Mater. 2016, 28, 7578.

[109] S. Okada, M. Ueno, Y. Uebou, J. Yamaki, J. Power Sources 2005 146, 565.

[110] Q. D. Truong, M. K. Devaraju, Y. Ganbe, T. Tomai, I. Honma, Electrochim. Acta 2014, 127, 245.

[11] J. Hadermann, A. M. Abakumov, S. Turner, Z. Hafideddine, N. R. Khasanova, E. V. Antipov, G. Van Tendeloo, Chem. Mater. 2011, 23, 3540.

[112] N. R. Khasanova, A. N. Gavrilov, E. V. Antipov, K. G. Bramnik, H. Hibst, J. Power Sources 2011, 196, 355.

[113] D. Wang, J. Xiao, W. Xu, Z. Nie, C. Wang, G. Graff, J.-G. Zhang, J. Power Sources 2011, 196, 2241.

[114] X. Wu, Z. Gong, S. Tan, Y. Yang, J. Power Sources 2012, 220, 122.

\section{2}

3

4 
[115] J. Schoiber, R. J. F. Berger, J. Bernardi, M. Schubert, C. Yada, H. Miki, N. Hüsing, Cryst. Growth Des. 2016, 16, 4999.

[116] J. Schoiber, R. J. F. Berger, C. Yada, H. Miki, N. Hüsing, J. Electrochem. Soc. 2015, 162, A2679.

[117] T. Okumura, M. Shikano, Y. Yamaguchi, H. Kobayashi, Chem. Mater. 2015, 27, 2839

[118] S. Amaresh, K. Karthikeyan, K. J. Kim, M. C. Kim, K. Y. Chung, B. W. Cho, Y. S. Lee, J. Power Sources 2013, 244, 395.

[119] C. Chang, Z. Huang, R. Tian, X. Jiang, C. Li, J. Feng, J. Power Sources 2017, 364, 351.

[120] S. S. Fedotov, A. A. Kabanov, N. A. Kabanova, V. A. Blatov, A. Zhugayevych, A. M. Abakumov, N. R. Khasanova, E. V. Antipov, J. Phys. Chem. C 2017, 121, 3194.

[121] S. W. Kim, D. H. Seo, H. Kim, K. Y. Park, K. Kang, Phys. Chem. Chem. Phys. 2012, 14, 3299.

[122] M. Dutreilh, C. Chevalier, M. El-Ghozzi, D. Avignant, J. M. Montel, J. Solid State Chem. 1999, 142, 1.

[123] M. Ue, K. Ida, S. Mori, J. Electrochem. Soc. 1994, 141, 2989.

[124] Y. Abu-Lebdeh, I. Davidson, J. Electrochem. Soc. 2009, 156, A60.

[125] Y. Abu-Lebdeh, I. Davidson, J. Power Sources 2009, 189, 576.

[126] M. Nagahama, N. Hasegawa, S. Okada, J. Electrochem. Soc. 2010, 157, A748.

[127] S. Lee, S. S. Park, J. Solid State Chem. 2013, 204, 329.

[128] H. Zhuo, X. Wang, A. Tang, Z. Liu, S. Gamboa, P. J. Sebastian, J. Power Sources 2006, 160, 698.

[129] Z. Liu, X. Wang, W. Ying, A. Tang, S. Yang, L. He, Trans. Nonferrous Met. Soc. China 2008, 18, 346.

[130] E. Boivin, J.-N. Chotard, T. Bamine, D. Carlier, P. Serras, V. Palomares, T. Rojo, A. ladecola, L. Dupont, L. Bourgeois, J. Mater. Chem. A 2017, 5, 25044.

[131] C. Chang, Y. Li, W. He, G. Li, W. Guo, P. Zhu, M. Yao, J. Feng, Mater. Lett. 2017, 209, 82.

[132] M. Law, P. Balaya, Energy Storage Mater. 2018, 10, 102.

[133] M. Xu, C. J. Cheng, Q. Q. Sun, S. J. Bao, Y. B. Niu, H. He, Y. Li, J. Song, RSC Adv. 2015, 5, 40065.

[134] T. Jin, Y. Liu, Y. Li, K. Cao, X. Wang, L. Jiao, Adv. Energy Mater. 2017, 7, 1700087.

[135] P. Feng, W. Wang, J. Hou, K. Wang, S. Cheng, K. Jiang, Chem. Eng. J. 2018, 353, 25.

[136] M. Ling, F. Li, H. Yi, X. Li, G. Hou, Q. Zheng, H. Zhang, J. Mater. Chem. A 2018, 6, 24201.

[137] X. Ge, X. Li, Z. Wang, H. Guo, G. Yan, X. Wu, J. Wang, Chem. Eng. J. 2019, 357, 458.

[138] R. Malik, A. Abdellahi, G. Ceder, J. Electrochem. Soc. 2013, 160, A3179.

[139] O. V. Yakubovich, M. A. Simonov, O. K. Melnikov, Kristallografiya 1984, 29, 484.

[140] W. Song, X. Cao, Z. Wu, J. Chen, Y. Zhu, H. Hou, Q. Lan, X. Ji, Langmuir 2014, 30, 12438.

[141] C. Zhu, C. Wu, C.-C. Chen, P. Kopold, P. A. van Aken, J. Maier, Y. Yu, Chem. Mater. 2017, 29, 5207.

[142] T. Jiang, Y. J. Wei, W. C. Pan, Z. Li, X. Ming, G. Chen, C. Z. Wang, J. Alloys Compd. 2009, 488, L26.

[143] M. Bianchini, N. Brisset, F. Fauth, F. Weill, E. Elkaim, E. Suard, C. Masquelier, L. Croguennec, Chem. Mater. 2014, 26, 4238.

[144] T. Broux, B. Fleutot, R. David, A. Brüll, P. Veber, F. Fauth, M. Courty, L. Croguennec, C. Masquelier, Chem. Mater. 2018, 30, 358.

[145] J. Barker, R. K. B. Gover, P. Burns, A. J. Bryan, Electrochem. SolidState Lett. 2006, 9, A190.

[146] R. A. Shakoor, D.-H. Seo, H. Kim, Y.-U. Park, J. Kim, S.-W. Kim, H. Gwon, S. Lee, K. Kang, J. Mater. Chem. 2012, 22, 20535.

[147] W. Song, X. Ji, Z. Wu, Y. Yang, Z. Zhou, F. Li, Q. Chen, C. E. Banks, J. Power Sources 2014, 256, 258.

[148] Z. Liu, Y.-Y. Hu, M. T. Dunstan, H. Huo, X. Hao, H. Zou, G. Zhong, Y. Yang, C. P. Grey, Chem. Mater. 2014, 26, 2513.
[149] M. Bianchini, F. Fauth, N. Brisset, F. Weill, E. Suard, C. Masquelier, 1 L. Croguennec, Chem. Mater. 2015, 27, 3009.

[150] T. Broux, T. Bamine, L. Simonelli, L. Stievano, F. Fauth, 3 M. Ménétrier, D. Carlier, C. Masquelier, L. Croguennec, J. Phys. 4 Chem. C 2017, 121, 4103.

[151] I. L. Matts, S. Dacek, T. K. Pietrzak, R. Malik, G. Ceder, Chem. Mater. 2015, 27, 6008.

[152] G. Yan, S. Mariyappan, G. Rousse, Q. Jacquet, M. Deschamps, R. David, B. Mirvaux, J. W. Freeland, J.-M. Tarascon, Nat. Commun. 2019, 10, 1.

[153] Q. Liu, D. Wang, X. Yang, N. Chen, C. Wang, X. Bie, Y. Wei, 10 G. Chen, F. Du, J. Mater. Chem. A 2015, 3, 21478.

[154] C. Shen, H. Long, G. Wang, W. Lu, L. Shao, K. Xie, J. Mater. Chem. A 2018, 6, 6007.

[155] L. Li, Y. Xu, X. Sun, S. He, L. Li, Chem. Eng. J. 2018, 331, 712.

[156] Q. Liu, X. Meng, Z. Wei, D. Wang, Y. Gao, Y. Wei, F. Du, G. Chen, ACS Appl. Mater. Interfaces 2016, 8, 31709.

[157] L. Li, X. Liu, L. Tang, H. Liu, Y.-G. Wang, J. Alloys Compd. 2019, 790, 203.

[158] T. Broux, F. Fauth, N. Hall, Y. Chatillon, M. Bianchini, T. Bamine, J. Leriche, E. Suard, D. Carlier, Y. Reynier, Small Methods 2019, 3, 1800215.

[159] L. H. B. Nguyen, T. Broux, P. S. Camacho, D. Denux, L. Bourgeois, 21 S. Belin, A. Iadecola, F. Fauth, D. Carlier, J. Olchowka, Energy 22 Storage Mater. 2019, 20, 324.

[160] L. H. B. Nguyen, P. Sanz Camacho, T. Broux, J. Olchowka, 24 C. Masquelier, L. Croguennec, D. Carlier, Chem. Mater. 2019, 31, 9759.

[161] F. Sauvage, E. Quarez, J.-M. Tarascon, E. Baudrin, Solid State Sci. 2006, 8, 1215.

[162] W. Massa, O. V. Yakubovich, O. V. Dimitrova, Solid State Sci. 2002, 4, 495.

[163] A. A. Tsirlin, R. Nath, A. M. Abakumov, Y. Furukawa, 30 D. C. Johnston, M. Hemmida, H.-A. K. von Nidda, A. Loidl, 31 C. Geibel, H. Rosner, Phys. Rev. B 2011, 84, 14429.

[164] P. Serras, V. Palomares, A. Goni, I. G. de Muro, P. Kubiak, 33 L. Lezama, T. Rojo, J. Mater. Chem. 2012, 22, 22301.

[165] Y. Qi, L. Mu, J. Zhao, Y. Hu, H. Liu, S. Dai, Angew. Chem., Int. Ed. 2015, 54, 9911.

[166] Y.-U. Park, D.-H. Seo, B. Kim, K.-P. Hong, H. Kim, S. Lee, R. A. Shakoor, K. Miyasaka, J.-M. Tarascon, K. Kang, Sci. Rep. 2012, 2, 1.

[167] D. Chao, C. Lai, P. Liang, Q. Wei, Y. Wang, C. Zhu, G. Deng, 38 V. V. T. Doan-Nguyen, J. Lin, L. Mai, Adv. Energy Mater. 2018, 8, 39 1800058.

[168] Y.-U. Park, D.-H. Seo, H.-S. Kwon, B. Kim, J. Kim, H. Kim, I. Kim, 41 H.-I. Yoo, K. Kang, J. Am. Chem. Soc. 2013, 135, 13870.

[169] N. Sharma, P. Serras, V. Palomares, H. E. A. Brand, J. Alonso, 43 P. Kubiak, M. L. Fdez-Gubieda, T. Rojo, Chem. Mater. 2014, 26, 3391.

[170] Y. Park, D. Seo, H. Kim, J. Kim, S. Lee, B. Kim, K. Kang, Adv. Funct. Mater. 2014, 24, 4603.

[171] M. Xu, P. Xiao, S. Stauffer, J. Song, G. Henkelman, J. B. Goodenough, Chem. Mater. 2014, 26, 3089.

[172] M. Xu, L. Wang, X. Zhao, J. Song, H. Xie, Y. Lu, J. B. Goodenough, Phys. Chem. Chem. Phys. 2013, 15, 13032.

[173] P. Serras, V. Palomares, P. Kubiak, L. Lezama, T. Rojo, Electrochem. Commun. 2013, 34, 344.

[174] H. Jin, J. Dong, E. Uchaker, Q. Zhang, X. Zhou, S. Hou, J. Li, 53 G. Cao, J. Mater. Chem. A 2015, 3, 17563.

[175] P. R. Kumar, Y. H. Jung, J. E. Wang, D. K. Kim, J. Power Sources 2016, 324, 421.

[176] Y. Yin, F. Xiong, C. Pei, Y. Xu, Q. An, S. Tan, Z. Zhuang, J. Sheng, Q. Li, L. Mai, Nano Energy 2017, 41, 452.

[177] Y. Qi, J. Zhao, C. Yang, H. Liu, Y. Hu, Small Methods 2019, 3, 58 1800111. 14

\section{政} 17

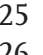

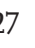
(2) (1.20 34 (1) 44 51

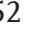

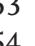

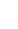
5

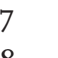
. 13 is

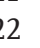

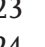


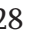
年

\section{.}

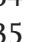
.6. , 38 40 43

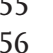


[178] J. Zhao, L. Mu, Y. Qi, Y.-S. Hu, H. Liu, S. Dai, Chem. Commun. 2015, 51, 7160.

[179] H. Jin, M. Liu, E. Uchaker, J. Dong, Q. Zhang, S. Hou, J. Li, G. Cao, CrystEngComm 2017, 19, 4287.

[180] M. Peng, B. Li, H. Yan, D. Zhang, X. Wang, D. Xia, G. Guo, Angew. Chem., Int. Ed. 2015, 54, 6452.

[181] B. Shen, Y. You, Y. Niu, Y. Li, C. Dai, L. Hu, B. Guo, J. Jiang, S. Bao, M. Xu, ACS Appl. Mater. Interfaces 2018, 10, 16581.

[182] Y. Hou, K. Chang, Z. Wang, S. Gu, Q. Liu, J. Zhang, H. Cheng, S. Zhang, Z. Chang, Z. Lu, Sci. China Mater. 2019, 62, 474.

[183] Z. Zhang, Z. Chen, Z. Mai, K. Peng, Q. Deng, A. Bayaguud, P. Zhao, Y. Fu, Y. Yu, C. Zhu, Small 2019, 15, 1900356.

[184] Y. Kawabe, N. Yabuuchi, M. Kajiyama, N. Fukuhara, T. Inamasu, R. Okuyama, I. Nakai, S. Komaba, Electrochem. Commun. 2011, 13, 1225.

[185] N. V. Kosova, V. R. Podugolnikov, E. T. Devyatkina, A. B. Slobodyuk, Mater. Res. Bull. 2014, 60, 849.

[186] M. Brisbois, N. Krins, R. P. Hermann, A. Schrijnemakers, R. Cloots, B. Vertruyen, F. Boschini, Mater. Lett. 2014, 130, 263.

[187] D. Cui, S. Chen, C. Han, C. Ai, L. Yuan, J. Power Sources 2016, 301, 87.

[188] L. Sharma, P. K. Nayak, E. De La Llave, H. Chen, S. Adams, D. Aurbach, P. Barpanda, ACS Appl. Mater. Interfaces 2017, 9, 34961.

[189] M. Law, V. Ramar, P. Balaya, RSC Adv. 2015, 5, 50155.

[190] R. Ling, S. Cai, D. Xie, W. Shen, X. Hu, Y. Li, S. Hua, Y. Jiang, X. Sun, J. Mater. Sci. 2018, 53, 2735.

[191] A. Langrock, Y. Xu, Y. Liu, S. Ehrman, A. Manivannan, C. Wang, J. Power Sources 2013, 223, 62.

[192] X. Deng, W. Shi, J. Sunarso, M. Liu, Z. Shao, ACS Appl. Mater. Interfaces 2017, 9, 16280.

[193] J. S. Ko, V. V. T. Doan-Nguyen, H.-S. Kim, X. Petrissans, R. H. DeBlock, C. S. Choi, J. W. Long, B. S. Dunn, J. Mater. Chem. A 2017, 5, 18707.

[194] R. Ling, S. Cai, S. Shen, X. Hu, D. Xie, F. Zhang, X. Sun, N. Yu, F. Wang, J. Alloys Compd. 2017, 704, 631.

[195] J. Yan, X. Liu, B. Li, Electrochem. Commun. 2015, 56, 46.

[196] D. Jin, H. Qiu, F. Du, Y. Wei, X. Meng, Solid State Sci. 2019, 93, 62.

[197] F. Wang, N. Zhang, X. Zhao, L. Wang, J. Zhang, T. Wang, F. Liu, Y. Liu, L. Fan, Adv. Sci. 2019, 6, 1900649.

[198] L. Sharma, A. Bhatia, L. Assaud, S. Franger, P. Barpanda, lonics 2018, 24, 2187.

[199] D. L. Smiley, G. R. Goward, Chem. Mater. 2016, 28, 7645.

[200] I. V. Tereshchenko, D. A. Aksyonov, O. A. Drozhzhin, I. A. Presniakov, A. V. Sobolev, A. Zhugayevych, D. Striukov, K. J. Stevenson, E. Antipov, A. M. Abakumov, J. Am. Chem. Soc. 2018, 140, 3994.

[201] Q. Li, Z. Liu, F. Zheng, R. Liu, J. Lee, G. Xu, G. Zhong, X. Hou, R. Fu, Z. Chen, Angew. Chem., Int. Ed. 2018, 57, 11918.

[202] C. Shinagawa, Y. Morikawa, S. Nishimura, H. Ushiyama, A. Yamada, K. Yamashita, J. Comput. Chem. 2019, 40, 237.

[203] X. Wu, J. Zheng, Z. Gong, Y. Yang, J. Mater. Chem. 2011, 21, 18630.

[204] M. Avdeev, C. D. Ling, T. T. Tan, S. Li, G. Oyama, A. Yamada, P. Barpanda, Inorg. Chem. 2014, 53, 682.

[205] B. L. Ellis, W. R. M. Makahnouk, W. N. Rowan-Weetaluktuk, D. H. Ryan, L. F. Nazar, Chem. Mater. 2010, 22, 1059.

[206] K. Kubota, K. Yokoh, N. Yabuuchi, S. Komaba, Electrochem 2014, 82, 909.

[207] H. Zou, S. Li, X. Wu, M. J. McDonald, Y. Yang, ECS Electrochem. Lett. 2015, 4, A53.

[208] X. Lin, X. Hou, X. Wu, S. Wang, M. Gao, Y. Yang, RSC Adv. 2014, 4, 40985.

[209] H. Qin, Z. P. Song, H. Zhan, Y. H. Zhou, J. Power Sources 2014, 249, 367.

[210] L. Sharma, K. Nakamoto, R. Sakamoto, S. Okada, P. Barpanda, ChemElectroChem 2019, 6, 444.
[211] K. Nakamoto, R. Sakamoto, M. Ito, A. Kitajou, S. Okada, Electro- 1 chem 2017, 85, 179.

[212] S. Liu, L. Wang, J. Liu, M. Zhou, Q. Nian, Y. Feng, Z. Tao, L. Shao, J. Mater. Chem. A 2019, 7, 248.

[213] X. Lin, J. Huang, H. Tan, J. Huang, B. Zhang, Energy Storage Mater. 2019, 16, 97.

[214] H. Kim, D. Seo, M. Bianchini, R. J. Clément, H. Kim, J. C. Kim, Y. Tian, T. Shi, W. Yoon, G. Ceder, Adv. Energy Mater. 2018, 8, 1801591.

[215] H. Kim, J. C. Kim, S. Bo, T. Shi, D. Kwon, G. Ceder, Adv. Energy Mater. 2017, 7, 1700098.

[216] Y. Hironaka, K. Kubota, S. Komaba, Chem. Commun. 2017, 53, 3693.

[217] C. Vaalma, G. A. Giffin, D. Buchholz, S. Passerini, J. Electrochem. Soc. 2016, 163, A1295.

[218] H. Kim, D. Seo, J. C. Kim, S. Bo, L. Liu, T. Shi, G. Ceder, Adv. Mater. 2017, 29, 1702480.

[219] X. Wang, X. Xu, C. Niu, J. Meng, M. Huang, X. Liu, Z. Liu, L. Mai, Nano Lett. 2017, 17, 544.

[220] C. Liu, S. Luo, H. Huang, Z. Wang, A. Hao, Y. Zhai, Z. Wang, Electrochem. Commun. 2017, 82, 150.

[221] N. Recham, G. Rousse, M. T. Sougrati, J.-N. Chotard, C. Frayret, S. Mariyappan, B. C. Melot, J.-C. Jumas, J.-M. Tarascon, Chem. Mater. 2012, 24, 4363.

[222] S. S. Fedotov, N. R. Khasanova, A. S. Samarin, O. A. Drozhzhin, D. Batuk, O. M. Karakulina, J. Hadermann, A. M. Abakumov, E. V. Antipov, Chem. Mater. 2016, 28, 411.

[223] K. Chihara, A. Katogi, K. Kubota, S. Komaba, Chem. Commun. 2017, 53, 5208.

[224] J. W. D. Ng, M. Tang, T. F. Jaramillo, Energy Environ. Sci. 2014, 7, 2017.

[225] J. B. Goodenough, K.-S. Park, J. Am. Chem. Soc. 2013, 135, 1167.

[226] J.-M. Tarascon, Nat. Chem. 2010, 2, 510.

[227] J. Zhang, Z. Zhao, Z. Xia, L. Dai, Nat. Nanotechnol. 2015, 10, 444.

[228] K. Zeng, D. Zhang, Prog. Energy Combust. Sci. 2010, 36, 307.

[229] S. Styring, Faraday Discuss. 2012, 155, 357.

[230] R. B. Gordon, M. Bertram, T. E. Graedel, Proc. Natl. Acad. Sci. USA 2006, 103, 1209.

[231] B. Senthilkumar, Z. Khan, S. Park, I. Seo, H. Ko, Y. Kim, J. Power Sources 2016, 311, 29.

[232] H. Wan, R. Ma, X. Liu, J. Pan, H. Wang, S. Liang, G. Qiu, T. Sasaki, ACS Energy Lett. 2018, 3, 1254.

[233] C. Murugesan, S. Lochab, B. Senthilkumar, P. Barpanda, ChemCatChem 2018, 10, 1122.

[234] R. Gond, K. Sada, B. Senthilkumar, P. Barpanda, ChemElectroChem 2018, 5, 153.

[235] M. W. Kanan, D. G. Nocera, Science 2008, 321, 1072.

[236] R. Gond, D. K. Singh, M. Eswaramoorthy, P. Barpanda, Angew. Chem. 2019, 131, 8418.

[237] C.-Z. Yuan, Y.-F. Jiang, Z. Wang, X. Xie, Z.-K. Yang, A. Bin Yousaf, A.-W. Xu, J. Mater. Chem. A 2016, 4, 8155.

[238] Y. Gorlin, T. F. Jaramillo, J. Am. Chem. Soc. 2010, 132, 13612.

[239] D. Dwibedi, R. Gond, K. Sada, B. Senthilkumar, P. Barpanda, MRS Adv. 2018, 3, 1215.

[240] M. J. Lee, J. S. Kang, D. Ahn, D. Y. Chung, S. Park, Y. J. Son, J. M. Yoo, H. Shin, Y. S. Kang, N.-E. Sung, Electrochim. Acta 2017, 245, 219.

[241] L. Sharma, S. Baskar, P. Barpanda, ECS Trans. 2018, 85, 1221.

[242] T. Maiyalagan, K. A. Jarvis, S. Therese, P. J. Ferreira, A. Manthiram, Nat. Commun. 2014, 5, 3949.

[243] Z. Lu, H. Wang, D. Kong, K. Yan, P.-C. Hsu, G. Zheng, H. Yao, Z. Liang, X. Sun, Y. Cui, Nat. Commun. 2014, 5, 4345.

[244] H. Kim, J. Park, I. Park, K. Jin, S. E. Jerng, S. H. Kim, K. T. Nam, K. Kang, Nat. Commun. 2015, 6, 8253.

[245] L. Sharma, R. Gond, B. Senthilkumar, A. Roy, P. Barpanda, ACS Catal. 2020, 10, 43. 
[246] M. Abirami, S. M. Hwang, J. Yang, S. T. Senthilkumar, J. Kim, W.-S. Go, B. Senthilkumar, H.-K. Song, Y. Kim, ACS Appl. Mater. Interfaces 2016, 8, 32778.

[247] Z. Khan, B. Senthilkumar, S. O. Park, S. Park, J. Yang, J. H. Lee, H.-K. Song, Y. Kim, S. K. Kwak, H. Ko, J. Mater. Chem. A 2017, 5, 2037.

[248] S. H. Sahgong, S. T. Senthilkumar, K. Kim, S. M. Hwang, Y. Kim, Electrochem. Commun. 2015, 61, 53.
[249] M. Arbabzadeh, R. Sioshansi, J. X. Johnson, G. A. Keoleian, Nat. 1 Commun. 2019, 10, 3413.

[250] S. Sabihuddin, A. E. Kiprakis, M. Mueller, Energies 2015, 8, 172.

[251] D. M. Davies, M. G. Verde, O. Mnyshenko, Y. R. Chen, R. Rajeev, Y. S. Meng, G. Elliott, Nat. Energy 2019, 4, 42.

[252] B. Lin, W. Wu, Energy 2017, 124, 423.

[253] K. Momma, F. Izumi, J. Appl. Crystallogr. 2011, 44, 1272.

Lalit Sharma is currently a final year Integrated Ph.D. scholar at Faraday Materials Laboratory, Material Research Centre, Indian Institute of Science, Bangalore (India). Following his B.Sc. (Chemistry Hons.) degree from St. Stephens College, Delhi University (India) in 2014, he is pursuing his doctorate at the Indian Institute of Science. His research focuses on structural and electrochemical investigation of fluoro (hydroxy) phosphate-based polyanionic cathode materials for metal-ion and metal-air batteries.

Shashishekar P. Adiga obtained his Ph.D. in Materials Science and Engineering from North Carolina State University in 2003. He currently heads the Materials \& Simulations team at Samsung Advanced Institute of Technology (SAIT), India in Bangalore. Prior to joining SAIT, he worked at Argonne National Laboratory, Kodak Research Labs, Lockheed Martin Advanced Technology Laboratories and Shell Technology Center. His research interests include computational materials science, materials for energy storage and conversion, automated materials discovery, functional, and device materials.

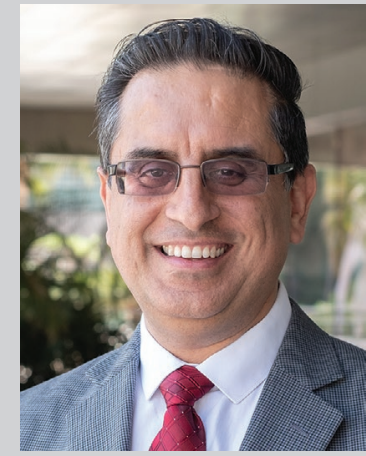

Husam Alshareef is a professor of Materials Science and Engineering at KAUST. After nearly 10 years in the semiconductor industry, he joined KAUST in 2009, where he initiated an active research group working on nanomaterial development for energy storage and electronics. He is a highly cited researcher in Materials Science, Fellow of the American Physical Society, Fellow of the Royal Society of Chemistry, and IEEE Distinguished Speaker in Nanotechnology.

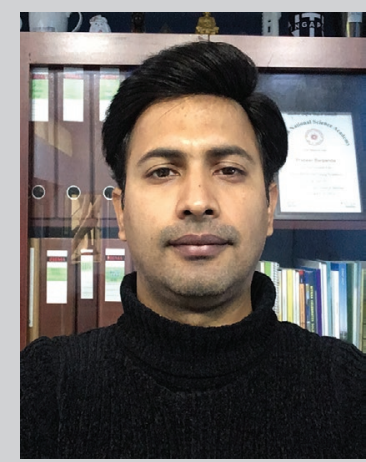

Prabeer Barpanda is currently an associate professor in the Materials Research Centre at the Indian Institute of Science (IISC) Bangalore. Following his B. Engg. (NITR, India) and M.Phil. (Cambridge, UK), he completed Ph.D. from Rutgers University (USA, 2009). Following, he pursued postdoctoral work on Li-ion and $\mathrm{Na}$-ion batteries at the Universite de Picardie Jules Verne (France, 2009-2010) and the University of Tokyo (Japan, 2010-2013). Since 2013, he is directing Faraday Materials Laboratory (IISc, India), an interdisciplinary group focusing on energy storage. 


\section{Reprint Order Form}

Charges for Reprints in Euro (excl. VAT), prices are subject to change. Minimum order 50 copies.

\begin{tabular}{|c|c|c|c|c|c|c|}
\hline No. of pages & $\begin{array}{c}\mathbf{5 0} \\
\text { copies }\end{array}$ & $\begin{array}{c}100 \\
\text { copies }\end{array}$ & $\begin{array}{c}150 \\
\text { copies }\end{array}$ & $\begin{array}{c}200 \\
\text { copies }\end{array}$ & $\begin{array}{c}300 \\
\text { copies }\end{array}$ & $\begin{array}{c}\mathbf{5 0 0} \\
\text { copies }\end{array}$ \\
\hline $1-4$ & $345,-$ & $395,-$ & $425,-$ & $445,-$ & $548,-$ & 752, \\
\hline $5-8$ & $490,-$ & $573,-$ & $608,-$ & $636,-$ & $784,-$ & 1077, \\
\hline $9-12$ & $640,-$ & $739,-$ & $786,-$ & $824,-$ & $1016,-$ & $1396,-$ \\
\hline $13-16$ & $780,-$ & $900,-$ & $958,-$ & $1004,-$ & $1237,-$ & $1701,-$ \\
\hline $17-20$ & $930,-$ & $1070,-$ & $1138,-$ & 1196,- & $1489,-$ & $2022,-$ \\
\hline $\begin{array}{l}\text { every additional } \\
4 \text { pages }\end{array}$ & $147,-$ & $169,-$ & $175,-$ & $188,-$ & $231,-$ & $315,-$ \\
\hline
\end{tabular}

Please send me send bill me for

no. of reprints

high-resolution PDF file (330 Euro excl. VAT)

E-mail address:

* Special Offer:

If you order 200 or more reprints you will get a PDF file for half price.

Please note: It is not permitted to present the PDF file on the internet or on company homepages.

Cover Posters (prices excl. VAT)

Posters of published covers are available in two sizes:

DIN A2 42 x 60 cm / 17 x 24in (one copy: 39 Euro)

DIN A1 $60 \times 84 \mathrm{~cm} / 24$ x 33in (one copy: 49 Euro)

Postage for shipping (prices excl. VAT)

overseas +25 Euro

within Europe +15 Euro
Manuscript No.:

Customer No.: (if available)

Purchase Order No.:

Author:

Information regarding VAT: The charges for publication of reprints/poster are considered to be "supply of services" and therefore subject to German VAT. However, if you are an institutional customer outside Germany, the tax can be waived if you provide us with the valid VAT number of your company. Non-EU customers may have a VAT number starting with "EU" instead of their country code, if they are registered with the EU tax authorities. If you do not have a valid EU VAT number and you are a taxable person doing business in a non-EU country, please provide a certification from your local tax authorities confirming that you are a taxable person under local tax law. Please note that the certification must confirm that you are a taxable person and are conducting an economic activity in your country. Note: certifications confirming that you are a tax-exempt legal body (non-profit organization, public body, school, political party, etc.) in your country do not exempt you from paying German VAT.

VAT number:

Mail reprints / copies of the issue to:

Send bill to:

I will pay by bank transfer

I will pay by credit card

\section{VISA, Mastercard and AMERICAN EXPRESS}

For your security please use this link (Credit Card Token Generator) to create a secure code Credit Card Token and include this number in the form instead of the credit card data. Click here:

https://www.wiley-vch.de/editorial_production/index.php

CREDIT CARD TOKEN NUMBER 